San Jose State University

SJSU ScholarWorks

Master's Theses

Master's Theses and Graduate Research

1997

\title{
Sodium chloride hideout in a simulated steam generator tube and tube support plate crevice
}

Paul M. Rogers

San Jose State University

Follow this and additional works at: https://scholarworks.sjsu.edu/etd_theses

\section{Recommended Citation}

Rogers, Paul M., "Sodium chloride hideout in a simulated steam generator tube and tube support plate crevice" (1997). Master's Theses. 1594.

DOI: https://doi.org/10.31979/etd.ard4-ytth

https://scholarworks.sjsu.edu/etd_theses/1594

This Thesis is brought to you for free and open access by the Master's Theses and Graduate Research at SJSU ScholarWorks. It has been accepted for inclusion in Master's Theses by an authorized administrator of SJSU ScholarWorks. For more information, please contact scholarworks@sjsu.edu. 


\section{INFORMATION TO USERS}

This manuscript has been reproduced from the microfilm master. UMI films the text directly from the original or copy submitted. Thus, some thesis and dissertation copies are in typewriter face, while others may be from any type of computer printer.

The quality of this reproduction is dependent upon the quality of the copy submitted. Broken or indistinct print, colored or poor quality illustrations and photographs, print bleedthrough, substandard margins, and improper alignment can adversely affect reproduction.

In the unlikely event that the author did not send UMI a complete manuscript and there are missing pages, these will be noted. Also, if unauthorized copyright material had to be removed, a note will indicate the deletion.

Oversize materials (e.g., maps, drawings, charts) are reproduced by sectioning the original, beginning at the upper left-hand comer and continuing from left to right in equal sections with small overlaps. Each original is also photographed in one exposure and is included in reduced form at the back of the book.

Photographs included in the original manuscript have been reproduced xerographically in this copy. Higher quality 6 " $\times 9$ " black and white photographic prints are available for any photographs or illustrations appearing in this copy for an additional charge. Contact UMI directly to order.

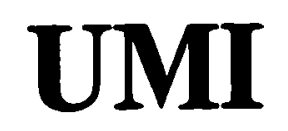

A Bell \& Howell Information Company

300 North Zeeb Road, Ann Arbor MI 48106-1346 USA

$313 / 761-4700 \quad 800 / 521-0600$ 


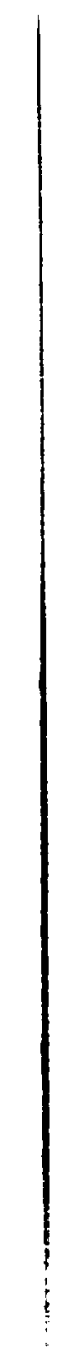




\title{
Sodium Chloride Hideout in a Simulated
}

\section{Steam Generator Tube and Tube Support Plate Crevice}

\author{
A Thesis \\ Presented to \\ The Faculty of the Department of Chemical Engineering \\ San Jose State University \\ In Partial Fulfillment \\ of the Requirements for the Degree \\ Master of Science
}

by

Paul M. Rogers

December 1997 
UMI Number: 1388212

UMI Microform 1388212

Copyright 1998, by UMI Company. All rights reserved.

This microform edition is protected against unauthorized copying under Title 17, United States Code.

\section{UMI \\ 300 North Zeeb Road \\ Ann Arbor, MI 48103}


(C) 1997

Paul Matthew Rogers

ALL RIGHTS RESERVED 
APPROVED FOR THE DEPARTMENT OF CHEMICAL ENGINEERING

$\frac{\text { Melanie, me ne }}{\text { Dr. Melanie McNeil }}$

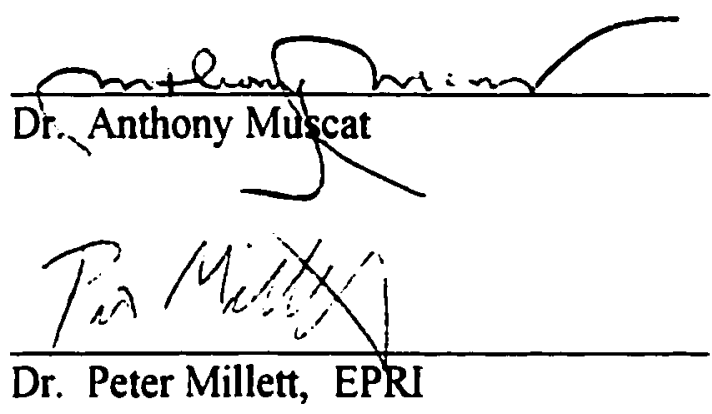

APPROVED FOR THE UNIVERSITY

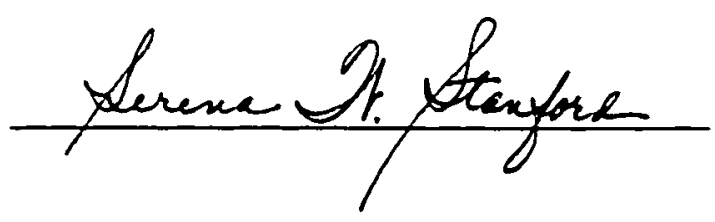




\begin{abstract}
Sodium Chloride Hideout in a Simulated Steam Generator Tube and Tube Support Plate Crevice
\end{abstract}

\author{
by Paul M. Rogers
}

A single tube and tube-support plate crevice simulator constructed by Rockwell International has been used in studies designed to increase the understanding of nuclear power steam generator crevice chemistries. The simulator resides in a 1-liter alloy 718 autoclave operating under the pressure and thermal conditions found in a steam generator. Sodium chloride solutions of 30 , 60 , and $120 \mathrm{ppm}$ with applied crevice heater powers of 85,150 and 230 watts were utilized to characterize the simulated crevice. Sodium chloride hideout was monitored using hideout return principles. When the crevice was packed with carbon fiber, hideout occurred readily. It was shown that the overall accumulation rates and equilibrium sodium chloride concentrations were a function of the heat flux placed across the crevice. Under the most corrosive conditions, a feed concentration of $120 \mathrm{ppm} \mathrm{NaCl}$ and a crevice heater power of 230 watts, the $\mathrm{NaCl}$ accumulation rate and equilibrium crevice concentration was $0.420 \mathrm{mg} / \mathrm{min}$ and $86 \mathrm{mg}$ respectively. 


\section{ACKNOWLEDGEMENTS}

This thesis is not simply a year long study but a culmination of five years of hard work and the unwavering support of the people around me. I would like to dedicate this work to everyone who stood behind me when I decided to give up everything to chase my dream of becoming a chemical engineer.

I would like to thank my wife who selflessly put her life on hold and allowed me to recognize my educational potential. Without her constant love, support and infinite patience I would not be where I am today. In addition to supporting us throughout my entire education, she was my inspiration, and my best friend.

I would like to extend my heartfelt thanks to all the members of my family. To my parents for their tireless support and confidence in me. Their love and unwavering belief that I would reach this day was strong enough to carry me through those bleak periods associated with all research. To my brother David who may never know how much he helped me by simply being "The Big Guy". To my brother Mark and his family who patiently listened to endless boring conversations regarding physics and chemistry. I would especially like to thank my sister Karen who was my on-call computer expert, who made sure all of my 
educational milestones were properly celebrated and who supported me as though we were going to school together.

I would like to thank Joanna Mincey whose significant support in the early years enabled me to reach this day. She sacrificed a great deal to make this possible and I will be eternally grateful. I would also like to thank A.J. Rosario for his confidence in me and his gentle kindness.

I would like to thank Hugh Pierce whose "Brainstorming" sessions at pool halls and golf courses across the city led to a heat exchanger that could only be described as "Brilliant".

On a professional level I would like to thank Dr. Melanie McNeil and Dr. Peter Millett for their valuable support and guidance through the course of this work. 


\section{TABLE OF CONTENTS}

1.0 INTRODUCTION 1

2.0 LITERATURE SURVEY AND REVIEW 5

3.0 RESEARCH OBJECTIVES 21

$\begin{array}{ll}3.1 \text { Justification } & 21\end{array}$

$\begin{array}{ll}3.2 \text { Objectives } & 22\end{array}$

4.0 EXPERIMENTAL DESIGN AND PROCEDURES 23

4.1 Flow Loop Design 23

4.2 Crevice Design 25

$\begin{array}{ll}4.3 \text { Crevice Packing } & 29\end{array}$

$\begin{array}{ll}4.4 \text { Hideout Return } & 30\end{array}$

4.5 Measurement Equipment and Calibration 32

4.6 Experimental Procedure $\quad 35$

5.0 RESULTS

5.1 Clean Concentric Crevice 41

5.2 Carbon Fiber Packed Crevice 42

5.3 Ion Chromatography 45 


\section{TABLE OF CONTENTS}

$\begin{array}{lll}6.0 & \text { DISCUSSION } & 49\end{array}$

$\begin{array}{ll}6.1 \text { Introduction } & 49\end{array}$

6.2 Accumulation Rates $\quad 50$

6.3 Equilibrium Concentration of $\mathrm{NaCl}$ in Crevice 53

6.4 Crevice Visual Inspection $\quad 57$

6.5 Runs for Repeatability 61

$\begin{array}{lll}7.0 & \text { CONCLUSIONS } & 64\end{array}$

NOMENCLATURE $\quad 66$

$\begin{array}{ll}\text { REFERENCES } & 67\end{array}$ 


\section{APPENDICES}

APPENDIX A: Chemicals and Equipment $\quad 69$

APPENDIX B: Equipment Calibration Curves $\quad 71$

APPENDIX C: Graphical Representations of Data 73

$\begin{array}{lr}\text { APPENDIX D: Sample Calculations } & \mathbf{8 0}\end{array}$

APPENDIX E: Raw Data Runs \#1-7 82 


\section{LIST OF FIGURES}

Figure 1. Schematic diagram of a pressurized water reactor 2

Figure 2. Diagram illustrating tube denting and secondary side 3 stress corrosion cracking

Figure 3. Diagram of a heated crevice

7

Figure 4. Typical surge in outlet concentration after switching 8 off the crevice heater

Figure 5. Weight of sodium chloride in crevice

Figure 6. Crevice pressure distribution

Figure 7. Model of solute concentration in heated crevice

Figure 8. Comparison of steady state model predictions with experimental data

Figure 9. Comparison of transient model to experimental data

Figure 10. System flow loop schematic

Figure 11. Schematic of the crevice cage assembly

Figure 12. Schematic detailing half of the clam-shell crevice ring

Figure 13. Heater power 150 watts, feed concentration $60 \mathrm{ppm}$ $\mathrm{NaCl}$ (No Packing)

Figure 14. Run I Heater power 85 watts, feed concentration $30 \mathrm{ppm} \mathrm{NaCl}$ 


\section{LIST OF FIGURES}

Figure 15. Comparison of conductivity and ion chromatograph measurements for a heater setting of 230 watts and a feed concentration of $30 \mathrm{ppm} \mathrm{NaCl}$ (Run 2)

Figure 16. Comparison of conductivity and ion chromatograph measurements for a heater setting of 85 watts and a feed concentration of $30 \mathrm{ppm} \mathrm{NaCl}$ (Run 1)

Figure 17. Results comparison, feed concentration $120 \mathrm{ppm} \mathrm{NaCl}$ comparing 85 and 230 watt heater power

Figure 18. Graphical representation of crevice accumulation rate

Figure 19. Typical Thermocouple profile for crevice heater and eutectic salt

Figure 20. Comparison of repeatability runs at $120 \mathrm{ppm} \mathrm{NaCl}$ feed and 85 watt heater power

Figure 21. Repeatability comparison, $60 \mathrm{ppm} \mathrm{NaCl}$ feed, heater power of 150 watts and run performed with no packing

Figure 22. Conductivity meter calibration curve $24-150 \mathrm{ppm}$ $\mathrm{NaCl}$ solutions

Figure 23. Conductivity meter calibration curve $60-300 \mathrm{ppm}$ $\mathrm{NaCl}$ solutions

Figure 24. Ion chromatography calibration curve for $18-96 \mathrm{ppm}$ $\mathrm{NaCl}$ solutions

Figure 25. Ion chromatography calibrations curve for $72-150 \mathrm{ppm}$ $\mathrm{NaCl}$ solutions 


\section{LIST OF FIGURES}

Figure 26. Run 2 Heater power 230 watts, feed concentration $30 \mathrm{ppm} \mathrm{NaCl}$

Figure 27. Run 3 Heater power 85 watts, feed concentration $120 \mathrm{ppm} \mathrm{NaCl}$

Figure 28. Run 4 Heater power 85 watts, feed concentration $120 \mathrm{ppm} \mathrm{NaCl}$ (repeatability)

Figure 29. Run 5 Heater power 230 watts, feed concentration $120 \mathrm{ppm} \mathrm{NaCl}$

Figure 30. Run 6 Heater power 150 watts, feed concentration $60 \mathrm{ppm} \mathrm{NaCl}$

Figure 31 . Run 7 Heater power 150 watts, feed concentration $60 \mathrm{ppm} \mathrm{NaCl}$ (repeatability)

Figure 32. Results comparison, feed concentration $30 \mathrm{ppm} \mathrm{NaCl}$ comparing 85 and 230 watt heater power

Figure 33. Sequential application of the Trapezoidal Method 


\section{LIST OF TABLES}

Table 1. Model Equations 15

Table 2. Model Boundary Conditions 15

Table 3. Experimental Matrix 38

Table 4. Data Obtained For Runs \#1-7 44 


\subsection{INTRODUCTION}

According to reports prepared by Douglas (1995), corrosion of pressurized water reactor steam generators is the greatest threat to the nuclear power industry today. Corrosion of this vital component led to an estimated worldwide yearly loss of 500 million dollars through damage, downtime and replacement power. Typical steam generators (SG) are designed to provide service for 40 years with standard maintenance. It has been found that steam generators are showing marked deterioration after 8-10 years. This results in forced shutdowns and extended refueling outages that can cost up to $I$ million dollars per day. Utility companies are now faced with the expensive decision of replacement at a cost of 100-200 million dollars, or they must reduce the amount of power the plant can produce, leading to reduced income (Douglas 1995). To fully appreciate the corrosion problem it is necessary to understand the basic operation of a nuclear power plant.

A schematic diagram of a pressurized water reactor (PWR) is illustrated in Figure 1. A tremendous amount of power is released in the reactor through nuclear fission. Energy resulting from this fission is used to heat water which is sent to a shell and tube type steam generator. Water that is heated through fission is referred to as primary water and is sent through the tubes at a pressure of 2250 
psia to avoid boiling. Secondary or cooling water is on the shell side and is kept at a pressure of $770-1050$ psia. Secondary water is converted to steam through contact with the 15-30,000 tubes containing the primary water. The resulting steam is sent to a turbine where electrical power is generated (Douglas 1995).

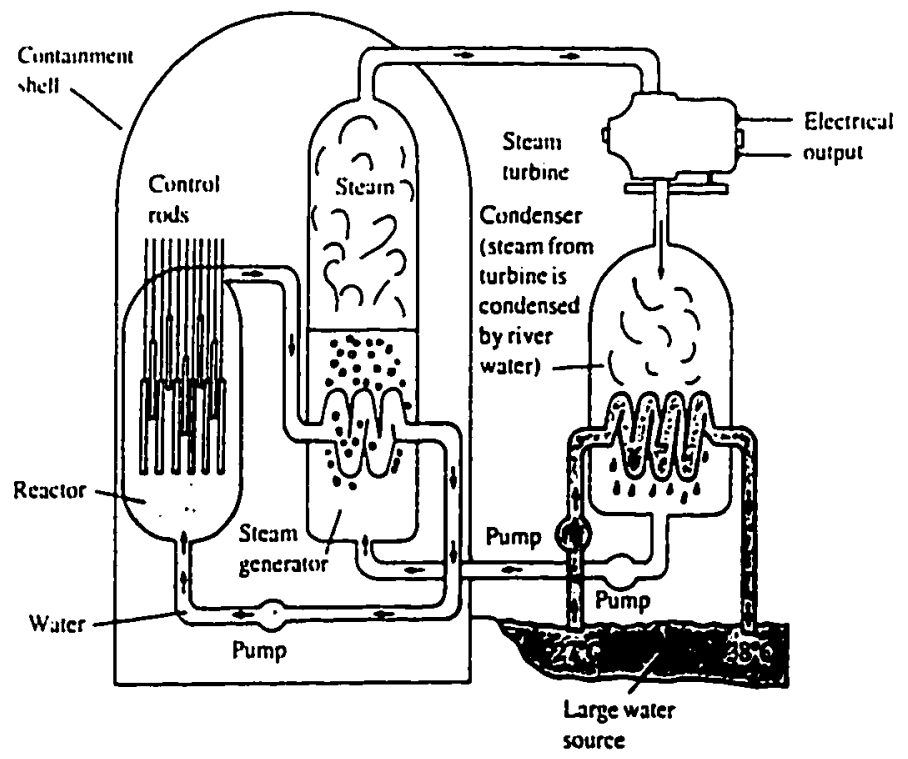

Figure 1. Schematic diagram of a pressurized water reactor (Zumdahl 1989).

Since the steam is formed on the shell side of the generator there is ample opportunity for boiling and dry-out to occur in the crevices formed between the tubes and their support structures. There are several different corrosion forms and products that are formed in the generator. In the crevices formed by the tube bundle, shown in Figure 2, corrosion products can accumulate and form porous 
deposits. This accumulation can lead to tube denting and secondary side stress corrosion cracking. The water that is fed to the shell side contains low levels (parts per billion) of impurities such as sodium, magnesium, sulfates, chlorides, nickel, calcium and iron. Through research (Hermanson 1992) it has been found that iron in the form of magnetite $\left(\mathrm{Fe}_{3} \mathrm{O}_{4}\right)$ is the predominant component in the porous deposits which result in "fouling" of the crevices.

\section{Tube denting}

Caused by conosion of carbon sleel support plates and the subsequent squeezing of tubes. Eliminated by water chemistry control measures.

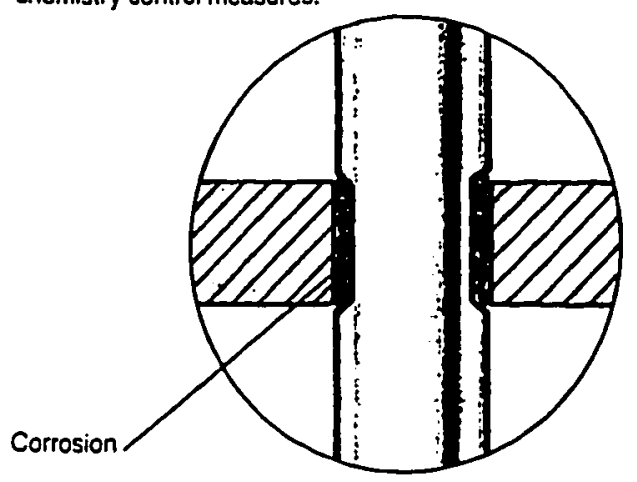

\section{Secondary.side stress corrosion cracking}

Occurs most often at or near tube support plates, where impurilies create an environment conducive to tube cracking. Not yet controlled.

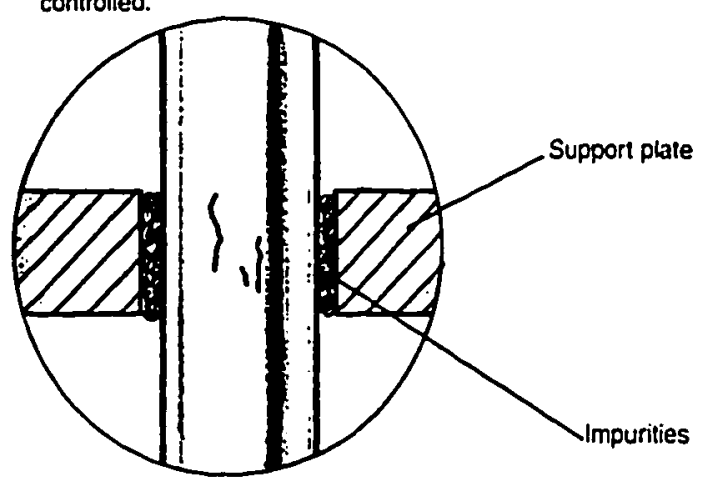

Figure 2. Diagram illustrating tube denting and secondary-side stress corrosion cracking (Douglas 1995).

A typical crevice has a poor ability to circulate fluids. This, coupled with fouling, can result in an aggressive corrosive environment. A crevice that is filled with sludge or deposits results in a simulated network of pores. Bulk water is drawn into this region by a pressure gradient. Because of the temperatures of the 
steam generator tubes and a reduction of flow in the crevice region, boiling occurs. In a packed crevice the capillary forces of the pore network allow the vapor of the solution to escape. This results in an extremely efficient concentration of the solution. Since the water contains impurities, the impurities are concentrating at a localized area. The resulting concentration is what can lead to aggressive corrosion (Millett and Fenton 1990). 


\subsection{Literature Survey and Review}

Research into the area of crevice chemistry in a steam generator has been aggressively approached due to the enormity of the problem. As a result, tube denting, anti-vibration bar wear and U-bend primary side stress corrosion cracking have now been eliminated or highly controlled through corrective measures such as water chemistry control and on site replacement or repair (Douglas 1995). Secondary side stress corrosion cracking and secondary side inter-granular attack are still a significant problem and have not been successfully controlled (Douglas 1995).

Inter-granular corrosion occurs when chemicals attack the tube along its natural grain boundaries within the metal. If the metal is not under any type of significant stress the attack will begin uniformly at the surface and slowly follow the grain boundaries. If the metal is under some type of stress, such as stresses remaining from fabrication, the grain boundaries will be attacked and cracks may propagate along these boundaries. This type of attack is most commonly found between the tubes and the tube-support plates (Douglas 1995).

Experimental research has been performed in an effort to understand and define crevice corrosion product hideout to assist in water chemistry guidelines (Mann and Castle 1983). Access to actual steam generator crevices, for sampling and monitoring purposes, has not been possible to date and is unlikely in the future 
(SGOG 1985). Thus, laboratory simulation is necessary to predict and explain the environment located within the crevice.

Several researchers have constructed small-scale simulated crevices. In experiments performed by Mann and Castle, they utilized a 1-liter autoclave to house a simulated tube and tube sheet support as illustrated in Figure 3. An electric tube heater was utilized to simulate the tube side heat flux and they loosely packed the $0.3 \mathrm{~mm}$ wide crevice with inert carbon fibers ( $56 \%$ porosity) to simulate the deposits that would be found in a crevice under normal operating conditions. The goal of the experiment was to create a crevice that mimicked actual operating conditions. This meant that the autoclave was pressurized to 64 bar and was operated at $280^{\circ} \mathrm{C}$. At these temperatures and pressures the bulk water is at saturation. This means that any heat that is applied to the crevice will result in immediate crevice boiling and can be considered superheat. Several different concentrations of sodium chloride solutions were passed through the autoclave at several different crevice heat fluxes in an effort to analyze the amount of salt that was concentrated within the "fouled" crevice. 


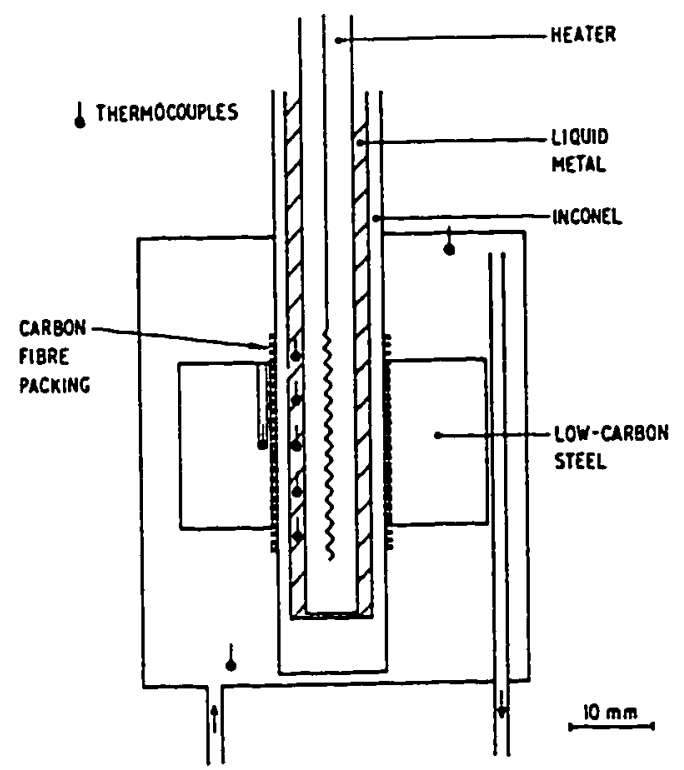

Figure 3. Diagram of heated crevice (Mann and Castle 1983).

The results of Mann and Castles work led to several key conclusions about non-volatile impurity concentrations within an actual crevice.

- Salt accumulated initially in a heated packed crevice at a constant rate determined by the bulk concentration and the rate of boiling in the crevice.

- At constant power, salt continued to accumulate at this constant rate until an equilibrium weight of salt was reached.

- The equilibrium weight of salt was dependent upon the available superheat within the crevice. 
- Salt was released slowly from the packed crevice by reducing the bulk water salt concentration to zero, but by reducing the heat flux throughout the crevice the whole mass of salt was released from the crevice within a few hours, as demonstrated in Figure 4 (Mann and Castle 1983).

- Salt hideout in support plate crevices and tube sheet crevices has led to significant levels of Inter-granular Stress Corrosion Cracking (IGSCC) and Inter-granular Attack (IGA).

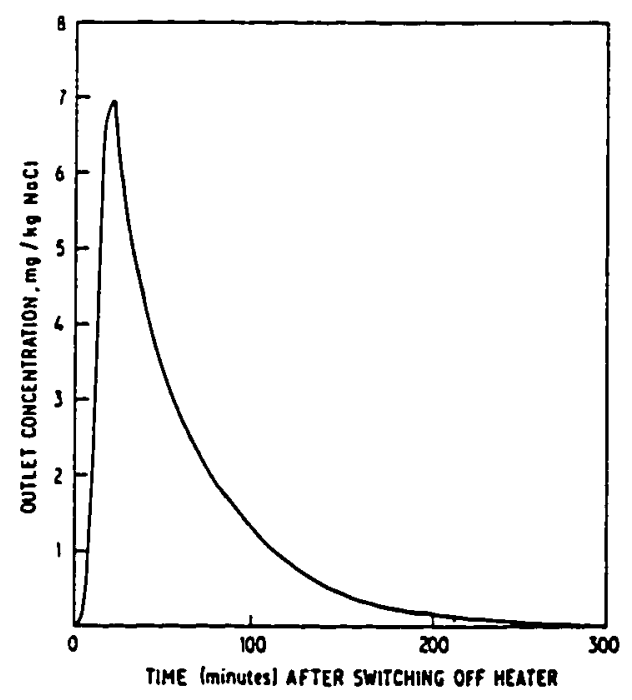

Figure 4. Typical surge in outlet concentration after switching off the crevice heater (Mann and Castle 1983).

It is important to highlight two of the more important conclusions of this research. As illustrated in Figure 5, it is clear that the mass of salt accumulated within the crevice was greater when the heat flux through the crevice was 
increased. The concentration factors for the crevice increased from 700 at 27,000 $\mathrm{Btu} / \mathrm{ft}^{2} \mathrm{hr}$ to 22,000 at $72,000 \mathrm{Btu} / \mathrm{ft}^{2} \mathrm{hr}$. This shows that the salt accumulation in the crevice was found to be related to available superheat (where superheat is defined as the difference between the excess heat flux across the crevice and the saturation point of the fluid). Once the concentrating fluid temperature has equilibrated with the tube side temperature the concentration of the crevice levels out. If the tube side temperature is again increased the concentration of the crevice increases until the boiling point again is in equilibrium with the tube side temperature. The second important conclusion is that purified water sent through the autoclave had little effect on the crevice concentration but a reduction in the heat flux through the tube led to a dramatic salt release from the crevice. 


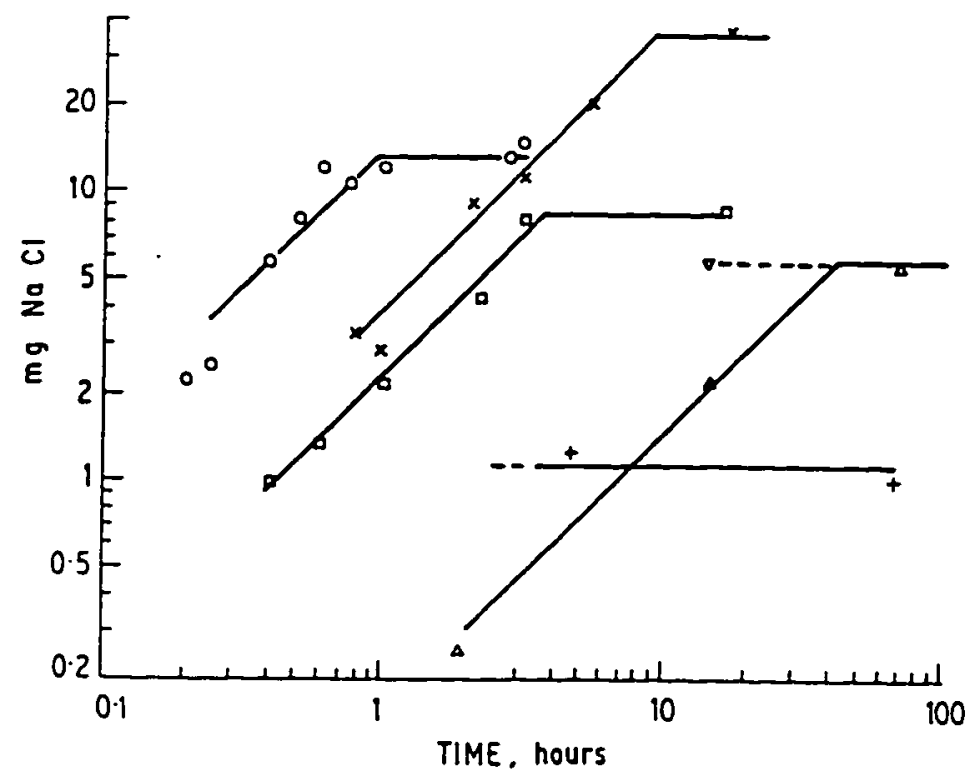

\begin{tabular}{|c|c|c|c|}
\hline & $\begin{array}{c}\text { FEED } \\
\text { CONCENTRATION }\end{array}$ & & $\begin{array}{l}\text { ATER } \\
\text { WER }\end{array}$ \\
\hline & $\mathrm{mg} / \mathrm{kg} \mathrm{NoCl}$ & Watts & $\overline{B t u} / \mathrm{ft}^{2} \mathrm{hr}$ \\
\hline 0 & 120 & 150 & 47.000 \\
\hline$x$ & 12 & 230 & 72.000 \\
\hline - & 12 & 150 & 47.000 \\
\hline+ & 12 & 85 & 27.000 \\
\hline$\Delta$ & $1 \cdot 2$ & 150 & 67.000 \\
\hline$\bullet$ & $1 \cdot 2$ & 150 & 47. 000 \\
\hline
\end{tabular}

THE POINT MARKED - WAS MEASURED AFTER PREVIOUSLY ESTABLISHING EQUILIBRIUM AT $120 \mathrm{mg} / \mathrm{kg} \mathrm{NOCl} .150$ WATTS.

Figure 5. Weight of sodium chloride in crevice (Mann and Castle 1983) Since the work performed by Mann and Castle several studies have concentrated on developing a mathematical model to describe the physical properties of a crevice. Millett and Fenton (1994) presented a detailed mathematical model of the transport processes that produce concentrated solutions in crevices. This work was a culmination of previous work performed by Millett 
(1991) and Millett and Fenton (1990). It utilized heat, mass and momentum transfer processes in heated, fouled crevices to predict concentrations of a species in the pore solutions as a function of time and at steady state. To create such a model several aspects of a fouled crevice needed to be understood. A porous deposit located within a SG crevice is highly complex and is very difficult to visualize for analytical purposes. A critical aspect of the crevice is its morphology which is characterized by three main parameters: porosity, permeability and overall pore size distribution. Permeability is defined as the flow resistance of each phase and is a function of porosity. A more permeable crevice environment will lead to deeper fluid penetration, resulting in higher overall impurity concentrations since there is a larger nucleate boiling region.

Heat flux across the porous deposit (fouling) in the crevice causes boiling to occur initially along the entire length. This phase change results in counter-current flow of liquid and vapor resulting in a pressure gradient. In a vertically orientated crevice, counter-current flow can result from the simple density difference between the two phases. In porous media, capillary forces are superimposed on the density difference, and increase the circulation rate (Millett and Fenton 1990). This is attributed to the capillary pressure that exists at the interface between the liquid and vapor as illustrated in Figure 6. 


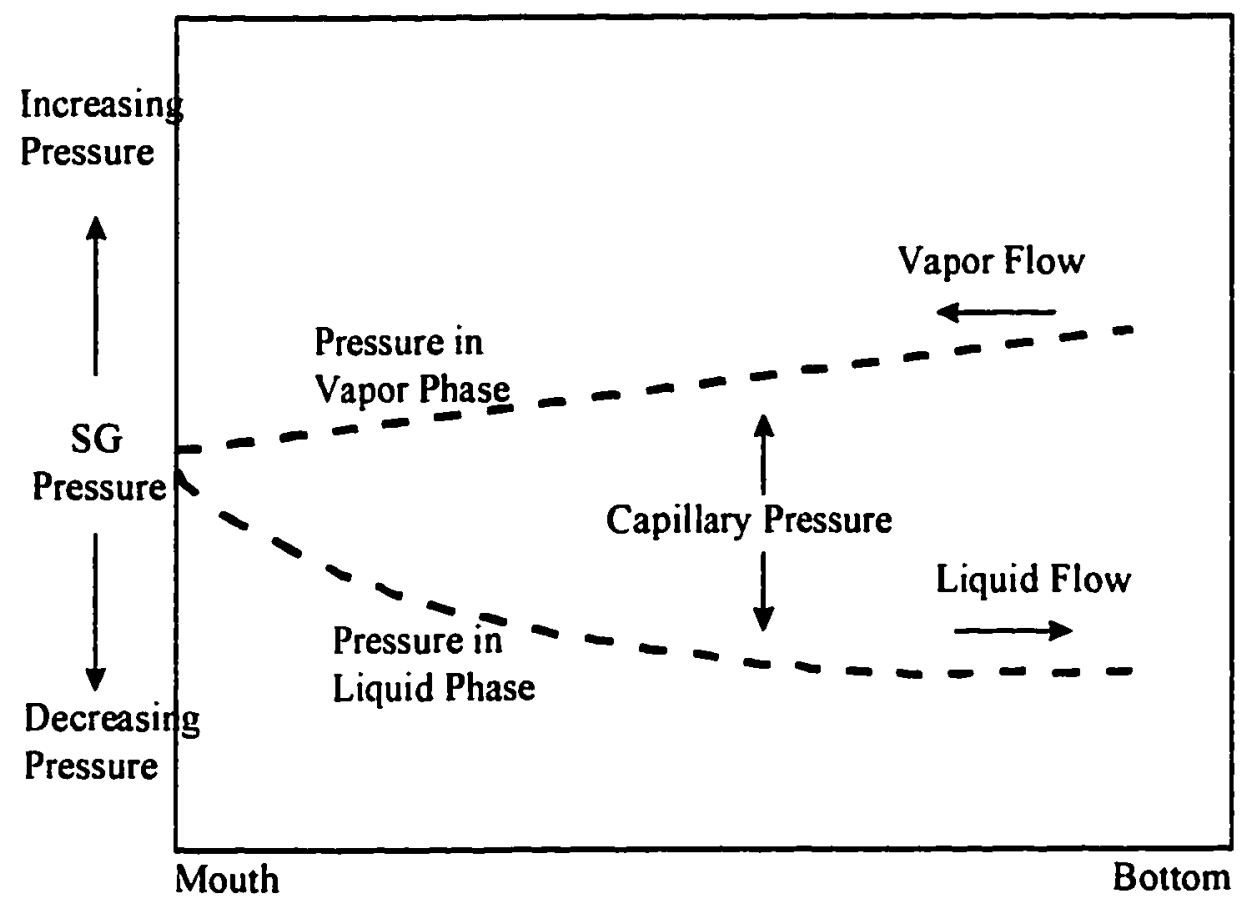

Figure 6. Crevice pressure distribution (Millett and Fenton 1990)

In very simplistic geometric terms, the vapor is located at the bottom of the pore network. The vapor pressure will be at a maximum at the bottom of the crevice and will need to flow in the low pressure direction counter-current to the liquid. The liquid phase pressure decreases in the direction of flow. Since both flow in the direction of decreasing pressure the steam escapes the pore network while the liquid phase is continually drawn into the pore network forced farther into smaller pores. The pressure difference of the liquid and vapor phase within the pore is the capillary pressure and since the liquid and vapor flow in opposite directions the capillary pressure is at a maximum at the bottom of the pore in the 
liquid direction forcing it into smaller and deeper pores. It has been found that when viscous forces are small compared to the capillary forces the liquid and vapor phases can actually flow in separate pores. In standard SG pore networks there are relatively small viscous forces resulting in the phenomenon that leads to high impurity concentrations (Millett and Fenton 1990).

In the work performed by Mann and Castle it was shown that when a heat flux was applied across their crevice, nucleate boiling occurred throughout the crevice initially. As time progressed, the regions of concentrations were at a maximum at the center of the crevice and continued to spread towards the mouth of the crevice as illustrated in Figure 7. This phenomenon was supported by temperature profiles within the crevice. When the fluids are concentrating at the center of the crevice the diffusion of non-volatile components is at a minimum. As the concentration works its way to the mouth of the crevice the diffusion coefficient increases. When the concentration reaches the mouth of the crevice an equilibrium will occur between concentrating impurities and the losses from the crevice from diffusion and turbulence. With all of this combined information, the major objective of the Millett and Fenton model was to predict the concentration profile as a function of time for a given species within the liquid phase (Millett and Fenton 1994). 

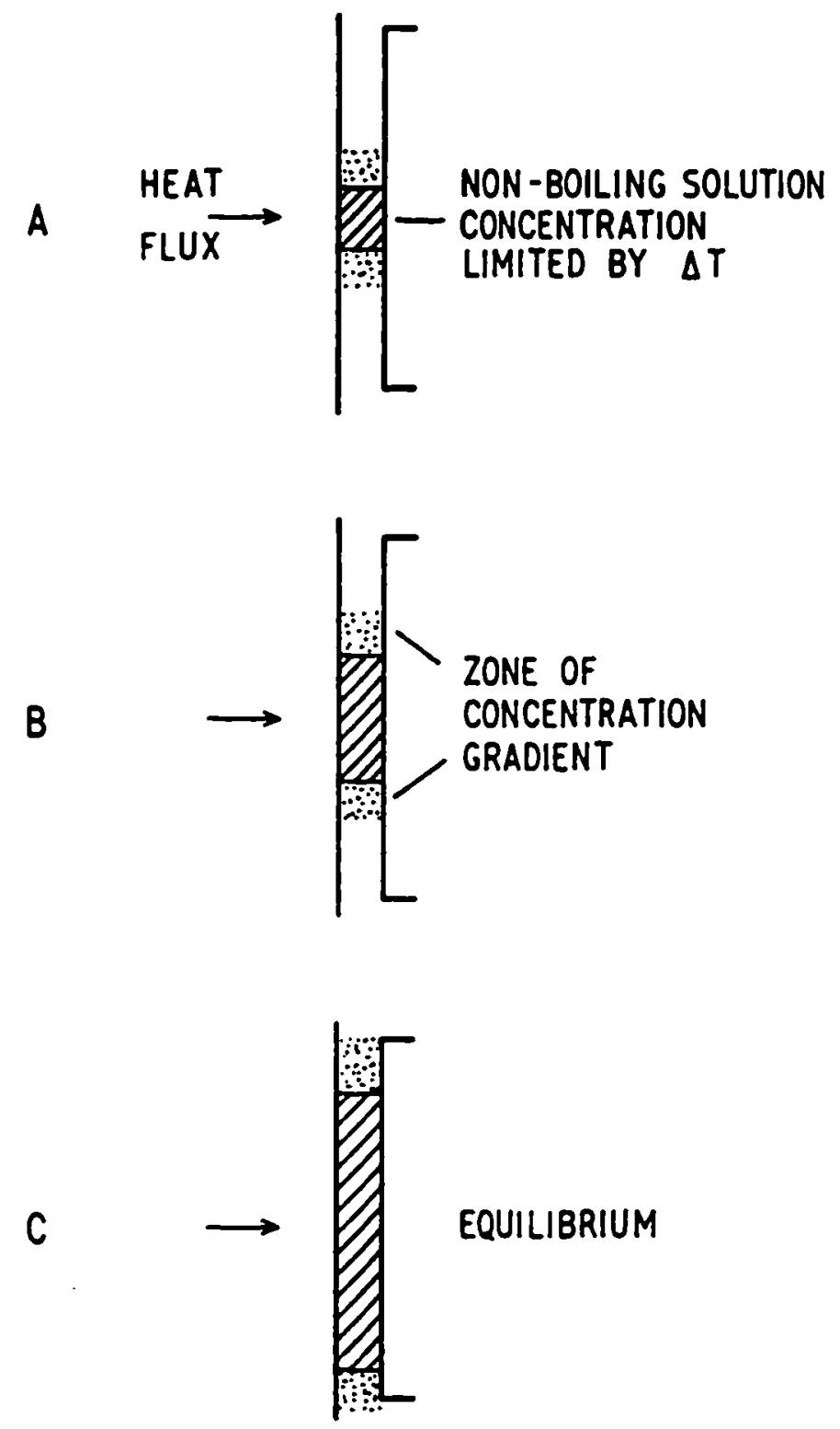

Figure 7. Model of solute concentration in heated crevice (Mann and Castle 1983) 
Table 1 and 2 contain the model equations and the boundary conditions respectively. The base case parameters of the model were specifically chosen so that they could ultimately be compared to actual experimental data. In Figure 8, the steady state model is compared to experimental data obtained by Mann and Castle (1987). The comparison is of sodium chloride in a simulated fouled tube and tube-support plate crevice. The basis of the model is linked to the key components of the earlier work performed by Mann and Castle (1983) and it is clear that the model and the experimental data are in reasonable agreement.

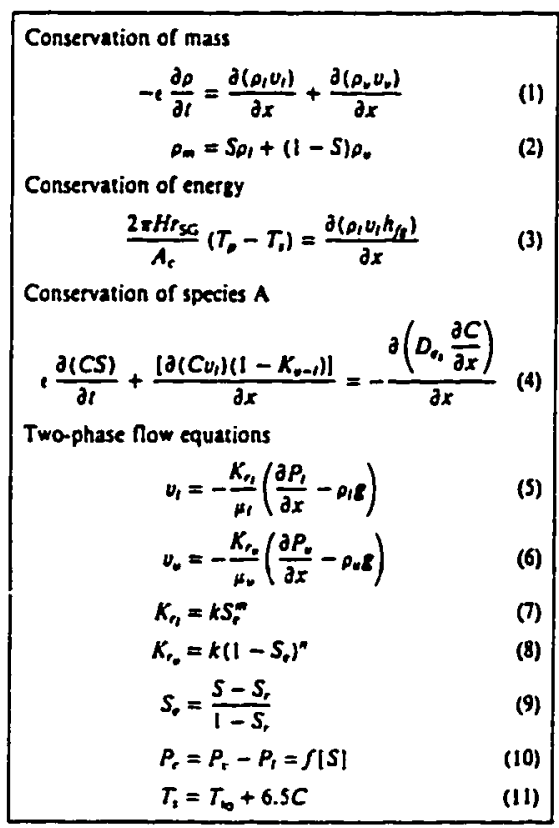

Table 1. Model Equations (Millett and Fenton 1994)

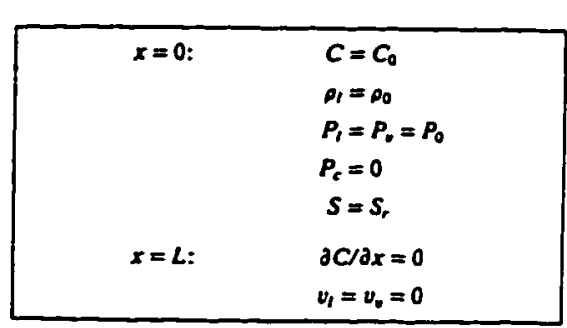

Table 2. Boundary Conditions (Millett and Fenton 1994) 
The transient behavior of the model reacted equally as well as the steadystate behavior. In Figure 9, the results of the transient model are compared to the experimental results obtained by Mann for several different concentrations of sodium chloride solutions. The model predictions and the experimental data show that the salt accumulation rate is nearly directly proportional to the bulk water concentration.

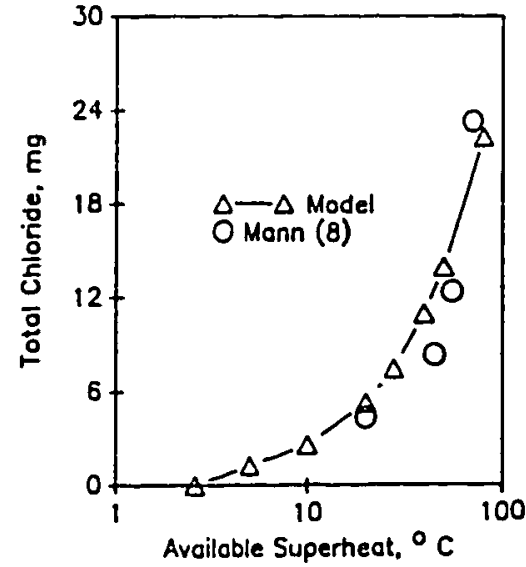

Figure 8. Comparison of Steady-State Model Predictions with Experimental Dats (Millett and Fenton 1994)

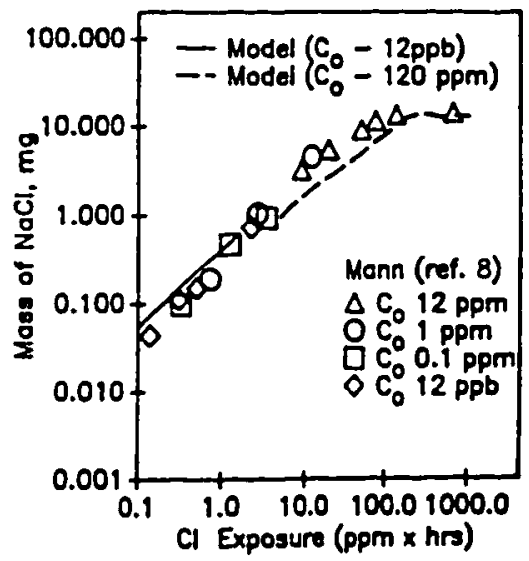

Figure 9. Comparison of Transient Model to Experimental Data (Millett and Fenton 1994)

This type of in-depth research led to several different advances within the SG industry. It is believed that the problems plaguing PWR's can be eliminated with a rigorous water chemistry treatment program. Several water chemistry programs have been initiated through the years. Several have been very successful 
in eliminating problems and several have been linked to creating worse problems. Initially PWR's adopted sodium phosphate based water chemistry for the secondary fluid side. This was based on experiences throughout the petroleum industry from which the basic design of SG's was adopted. In PWR's this led to severe tube wastage from the formation of phosphoric acid solutions and precipitates in crevices. In 1974, the All Volatile Secondary Water Treatment (AVT) was introduced (Millett 1995).

AVT originally consisted of the addition of hydrazine to scavenge for dissolved oxygen and ammonia to control $\mathrm{pH}$. This method was extremely effective in eliminating the tube wastage problem but tube denting occurred. Tube denting was improved through a new set of EPRI Secondary Water Chemistry Guidelines and improvements such as boric acid treatment. It wasn't until the 1980's that the slower developing forms of tube damage occurred such as IGA and IGSCC. It was found that this form of degradation would lead to the SG's being inoperable in $20-25$ years. To combat this new problem new initiatives were developed and implemented in 1992 that called for even more aggressive water treatment (Millett 1992).

With a number of newly developed computer tools to implement appropriate water chemistry guidelines, several new programs, such as hideout return, Molar Ratio Control (MRC), and secondary water $\mathrm{pH}$ control, were 
initiated. Nearly $50 \%$ of all U.S. PWR's utilize MRC for their older SG units. There has been a firm link established between IGSCC crack growth rate and $\mathrm{pH}$. The concept of MRC is to make sure that the concentrated solutions that occur within fouled crevices are always kept semi-neutral. Through significant amounts of experimental data it has been found that the lowest crack growth rate was achieved in crevices that had a $\mathrm{pH}$ of 5-9. It is believed that crevice $\mathrm{pH}$ can be altered to a neutral condition by the addition of chemical species to the bulk water in an effort to control the ratio of strong acid anions and strong basic cations. The key to this approach is the understanding that these anions and cations need to be kept near unity and that there needs to be a relative amount of less soluble impurities present in the crevice. It has been found that the crevice $\mathrm{pH}$ is largely controlled by the presence of low soluble impurities such as calcium, magnesium and silica. The amounts of low soluble and highly soluble species is very uncertain. This led to the new approach of Molar Ratio Index (MRI), defined as follows (Millett, 11):

$$
M R I=\frac{\mathrm{Na}+K}{\mathrm{Cl}+\text { excess } \mathrm{SO}_{4}}
$$

MRI is the key tool for MRC and the components of MRI are obtained by the analysis of hideout return (detailed later). Sodium chloride solutions have no buffering capabilities. This means that a $\mathrm{Na} / \mathrm{Cl}$ ratio slightly higher than 1.0 leads 
to a very caustic environment, whereas a ratio slightly less than 1.0 leads to a very acidic environment. Because of this it is important to have a sufficient level of impurities to act as a buffering element for the excess anions and cations. The impurities $\mathrm{Ca}, \mathrm{Mg}$ and $\mathrm{Si}$ act as buffers by their ability to form several neutral precipitates that are in equilibrium with the $\mathrm{NaCl}$ solution.

Since it has not been possible to actively monitor the crevice chemistry in a SG, the method of hideout return chemistry has been implemented. When the PWR is shut down once per year the elimination of the heat flux within the tubes allows the release of the concentrated solution within the tube and tube-support plate crevices. This is detected as an increase in impurities concentration within the bulk water during the shut down process. For the proper implementation of MRI it is critical that the analysis of the bulk water during and immediately following the shutdown be excluded from the analysis. It has been found that the impurities from flow-occluded regions occur immediately as soon as $0 \%$ power is reached (Millett, 11). The impurities from flow-occluded regions are the focus of interest since the fluids in these regions are being controlled. Disregarding information from excluded times is critical since several return processes occur at these excluded times, such as precipitate dissolution, which could result in increased sulfate desorption and a dramatic decrease in MRI. Analysis of increased bulk water species concentration leads to a very detailed view of what 
was in the crevices, but this detailed view is sullied by two drawbacks. One; since there are thousands of crevices only an average crevice chemistry can be inferred, and two; this process can only be performed once per year. Regardless of these drawbacks, several tools can be employed to the water chemistry once a running inventory has been determined from the hideout data (Millett 1995). 


\subsection{RESEARCH OBJECTIVES}

\subsection{Justification}

Through research and development performed by thousands of individuals and groups such as EPRI, average capacity factor losses for U.S. utilities has decreased from $5.5 \%$ (1980) to $3 \%$ (1987 to 1994) (Millett 1995). Along with this, SG life has been significantly increased and the forced outage rate due to tube corrosion and leakage has been reduced by a factor of 7 from 1976. It has been estimated that these improvements have saved utilities several billions of dollars (Millett 1995). However the industry's problems are not completely solved. Steam generator lives are still at best estimated to be 25 years with today's corrosion controlling factors. Research and development programs to date have led to good, but still incomplete, knowledge of the mechanisms for concentrating impurities in SG's and the underlying corrosion processes themselves (Millett 1995). In the current study, a laboratory sized steam generator simulator will be utilized to run experiments to further the understanding of steam generator crevices. 


\subsection{Objectives}

The main objective of this study is to characterize a simulated tube and tube-support plate crevice simulator by confirming concentration characteristics illustrated in previous results. This entails several different aspects of design and characterization. A simulator that has similar characteristics to that used in the work performed by Mann and Castle (1983) and constructed by Rockwell International will be used. Several tests will be run to characterize the crevice. Two major relationships will be verified for a "fouled" crevice:

- The effect of heat flux and bulk water concentration on the maximum accumulation rate within the crevice

- The relationship between heat flux across the crevice and the maximum impurity concentration within the crevice 


\subsection{Experimental Design and Procedures}

\subsection{Flow Loop Design}

An experimental tube and tube-support crevice simulator has been constructed by Rockwell International, to be suspended in a one-liter alloy 718 autoclave. The internal volume of the autoclave will simulate the secondary side of a steam generator. A flow loop was designed for the system and is illustrated in Figure 10. A metering pump (Pulsa-Feeder) with a flow range of $5-45 \mathrm{ml} / \mathrm{min}$ sends the test solution through the system at $20 \mathrm{ml} / \mathrm{min}$ from a 30 gallon Nalgene feed tank. The pump has a large pulse associated with it which requires a significant pulse dampener. A pulse dampener was created by inserting 25 feet of 1/16-inch PEEK (poly/ether/ether/ketone) tubing with a pressure rating of 3000 psia into the flow loop. It is very effective at dampening pressure pulses from the pump. A check valve with a pressure rating of 2000 psia was installed to protect the system from reverse flow in the event of pump or power failure. Plug valves are installed on each side of the autoclave to isolate it if necessary. Before the solution enters the autoclave it first enters a pre-heater. For the experiments that were performed, the pre-heater heated the solution to $522{ }^{\circ} \mathrm{F}\left(272{ }^{\circ} \mathrm{C}\right)$ before it entered the autoclave. The solution enters through a fitting located approximately 1-inch from the bottom of the autoclave and exits through a fitting located 1/2-inch 


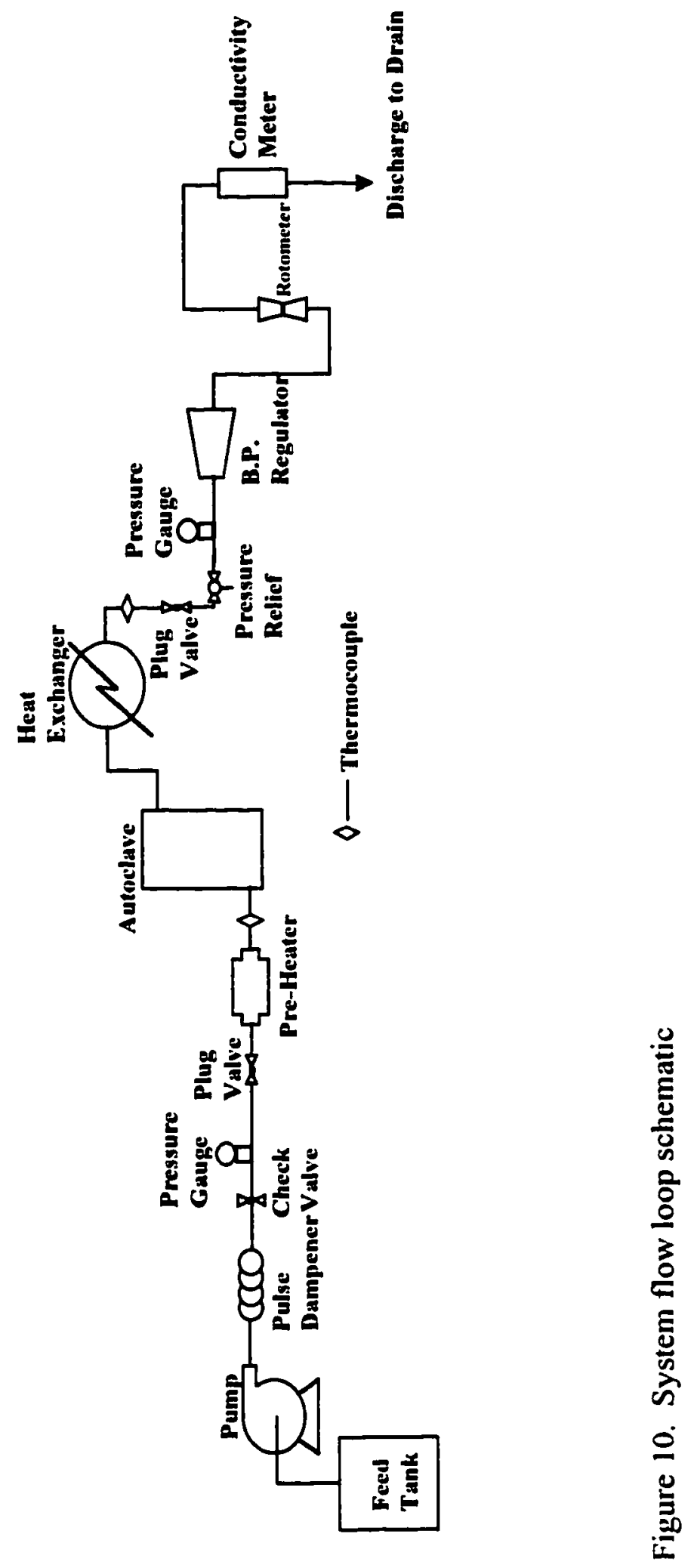


from the top. The autoclave is surrounded by three resistance band heaters that are controlled by two Fuji Electric temperature controllers. The exiting solution, which has a final temperature of approximately $525^{\circ} \mathrm{F}\left(274^{\circ} \mathrm{C}\right)$, flows through a cold water heat exchanger where it is cooled to $75^{\circ} \mathrm{F}\left(24^{\circ} \mathrm{C}\right)$. After being sufficiently cooled the fluid flows through a pressure relief valve that is designed to release pressure at 1200 psia in the event of an extreme pressure build-up. The fluid then flows through a back pressure regulator (Grove) with a maximum operating range of 1000 psia which maintains a pressure of 870 psig. After exiting the back pressure regulator the fluid flows through a standard low flow rotometer and then through a Cole-Parmer conductivity meter. The discharge fluid is then sent to a drain, or samples are collected. The entire system utilizes 1/4-inch 316 stainless steel tubing with a 0.035 inch wall thickness.

\subsection{Crevice Design}

In the work performed by Mann and Castle (1983), their crevice consisted of a ring that was placed over a tube which created a gap that was utilized as a SG crevice. The crevice that has been devised for this project is significantly different. As can be seen in Figure 11, the crevice device is a cage-like apparatus. An alloy 600 tube is located in the lid of the autoclave. This tube simulates a 


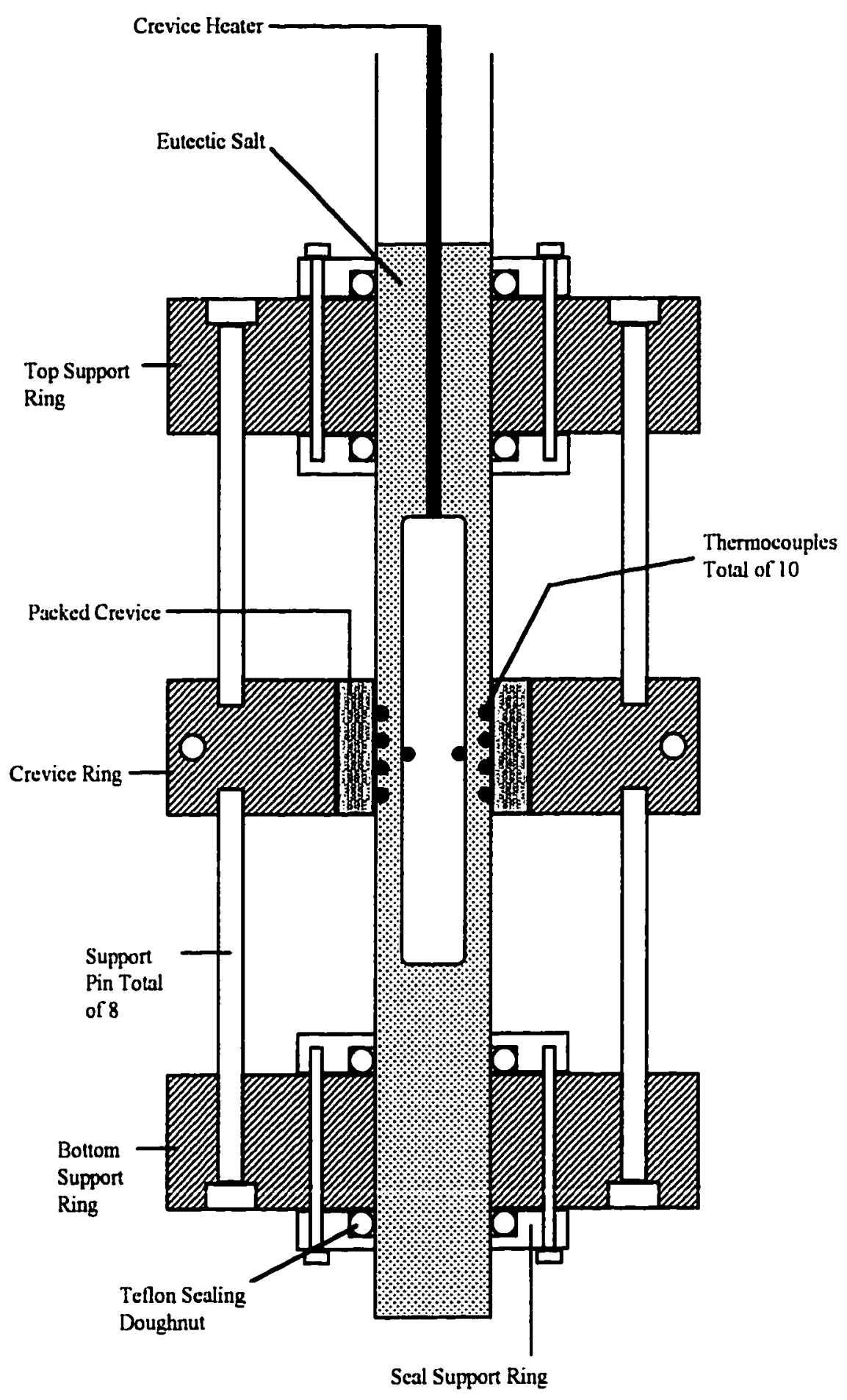

Figure 11. Schematic of the crevice cage assembly 
single tube located within an SG. Inside the tube is a 600 watt cartridge heater which is $7.62 \mathrm{~cm}$ long by $0.953 \mathrm{~cm}$ wide. This gives a heater surface area of approximately $22.8 \mathrm{~cm}^{2}$. The heater extends $2.3 \mathrm{~cm}$ above and below the crevice so that the crevice is uniformly heated. The cartridge heater is surrounded by a eutectic salt mixture consisting of $54.3 \% \mathrm{KNO}_{3}$ and $45.7 \% \mathrm{NaNO}_{3}$ to enhance heat transfer from the heater surface to the simulated crevice. Inside the tube, $8 \mathrm{~K}$ type thermocouples have been attached to the wall in the crevice region. The thermocouples are located in a helical arrangement separated by $45^{\circ}$ angles and cover the entire length of the crevice. Two separate thermocouples are located within the cartridge heater for measurement and temperature control. The crevice cage device is constructed from alloy 718 and consists of three main sections. The actual crevice is a clam-shell design which consists of two main parts as seen in Figure 12. The purpose of this design is to allow visual inspection of the crevice without disturbing the interior contents. When the clam-shell screws are removed the crevice separates into two half sections allowing relatively undisturbed crevice inspection.

The clam-shell crevice is held in place by attachment to two rings by a total of eight offset 316 stainless steel locking bolts. The upper and lower rings also have two ring assemblies attached to them. Within these rings are two offset 


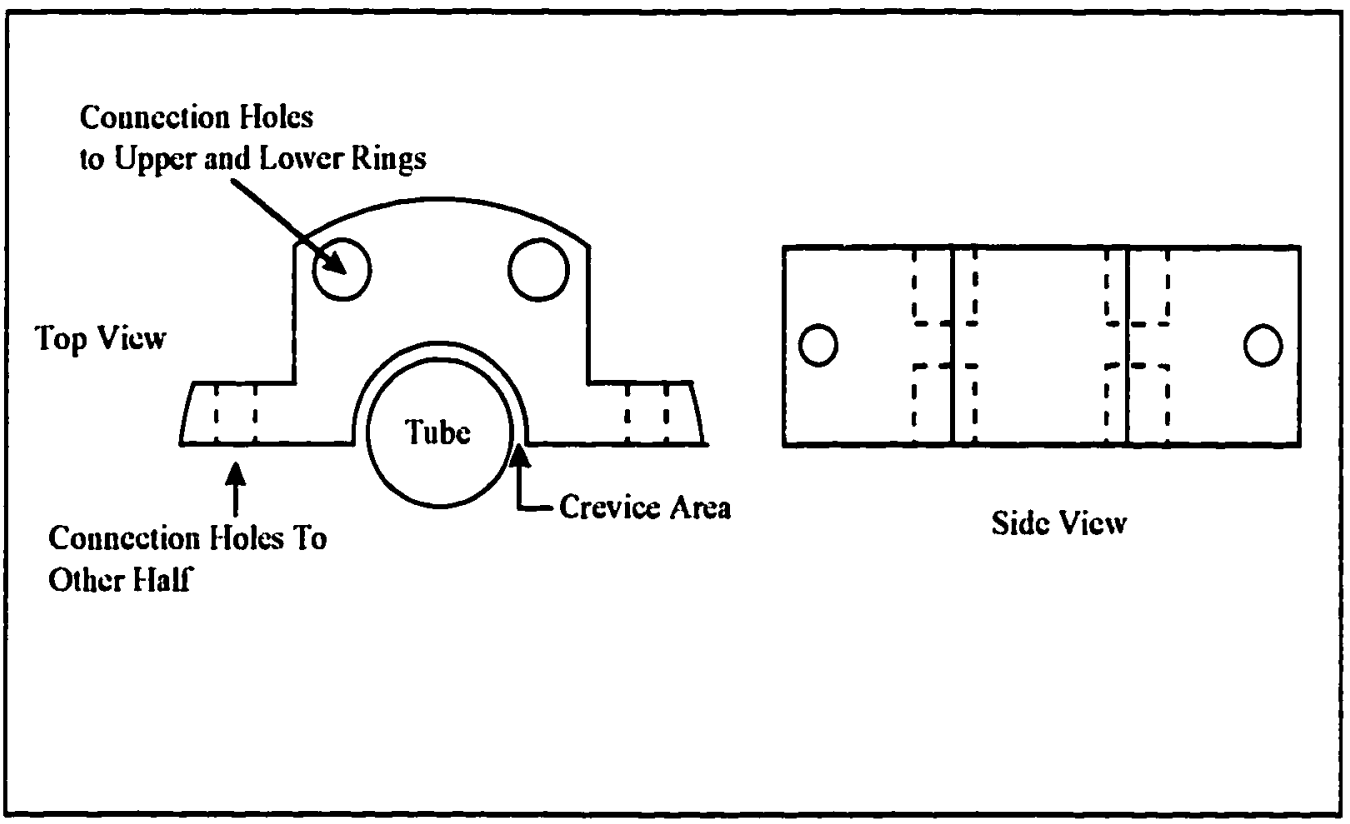

Figure 12. Schematic detailing half of the clam-shell crevice ring.

Teflon doughnuts. The Teflon doughnuts serve two critical functions. When the system is at operating conditions the Teflon rings swell, and form an effective seal keeping fluid from entering the crevices formed by the upper and lower rings. Without these seals there would be essentially three crevices of similar size within the autoclave. The other critical function served by the rings is that by swelling they straighten out the cage apparatus attached to the tube creating a uniform concentric crevice between the tube and the center clam-shell ring. It is important that the crevice is concentric because it has been found that impurities will concentrate in an eccentric crevice with concentrating efficiencies as high as $19 \%$ (Balakrishnan 1991). 
The gap that is formed between the alloy 600 tube and the alloy 718 center clam-shell ring is $0.24 \mathrm{~mm}$ in diameter. The crevice has a length of $30.5 \mathrm{~mm}$. This gives a total crevice volume of $447 \mathrm{~mm}^{3}$.

\subsection{Crevice Packing}

One of the project parameters is to study a "fouled" crevice, simulated by physically packing the crevice with inert carbon fibers. If the crevice is not packed with some type of simulated corrosion product the accumulation process will not occur. A clean concentric crevice will not accumulate a relevant amount of sodium chloride because there is no flow restriction to bulk solution. The crevice will be able to effectively flush itself.

The choice of packing for this experiment is Thornel P-75S Carbon Filament. The easiest description of this product is that it resembles a large spool of dark brown human hair. It has a density of $2.0 \mathrm{~g} / \mathrm{cm}^{3}$ and rolls off the spool in a thin uniform width of approximately $2 \mathrm{~mm}$, consisting of several thousand individual strands. An appropriate amount of fiber was weighed out and cut into several $3 \mathrm{~cm}$ lengths, which is the circular width and length of half the clam-shell crevice. The fiber was divided into two equal amounts one for each side of the clam-shell crevice. Several of these $3 \mathrm{~cm}$ cuts of carbon filament were laid 
parallel to each other until enough had been used to create $a 3 \mathrm{~cm}$ by $3 \mathrm{~cm}$ mat. These mats were then laid on top of each other perpendicular to the previous mat creating a crisscross pattern. The number of alternating mats was determined by the available amount of carbon fiber needed to be placed in each side of the crevice. The overall object was to form two similar size mats of carbon fiber with irregular porous channeling, one for each side of the crevice. Once this was completed the mats were carefully placed into each half of the clam-shell crevice. The crevice was then placed on the tube and the appropriate locking screws were attached securing the crevice and the packing. The crevice was filled with 0.3768 grams of carbon filament which translates to a volume $188 \mathrm{~mm}^{3}$. With this amount of fiber the porosity has been calculated to be $\mathbf{5 8}$ percent, which is within the experimental parameters and is very similar to the porosity of 56 percent utilized by Mann and Castle (1983).

\subsection{Hideout Return}

"Hideout Return" (HR) experiments were used to characterize the autoclave. It would be very difficult to position the proper measurement devices in the crevice to analyze sodium chloride concentrations. Because of this it makes more sense to analyze the bulk solution. The term "Hideout Return" simply refers 
to the process of monitoring the exit solution of the flow loop for any changes in sodium chloride concentrations. The procedure that is followed to initiate the HR process begins with analyzing the concentration of the feed solution to utilize it as a baseline. Without a heat flux across the crevice there is no sodium chloride accumulation and the exit conductivity of the solution equals the conductivity of the feed. When the heat flux is applied across the crevice the crevice solution begins to concentrate removing sodium chloride from the bulk solution resulting in a noticeable drop in the outlet salt concentration as measured by a decrease in conductivity. This drop in the outlet salt concentration will continue until accumulation in the crevice has reached its thermodynamic limit. After this limit has been achieved the outlet conductivity will again be equal to the feed concentration and the hideout phase of the process has been completed.

The return phase is initiated by the removal of the heat flux across the crevice. Upon removal of the heat flux the sodium chloride will immediately diffuse from the crevice resulting in a very sharp rise in outlet conductivity. According to Mann and Castle (1983), the return period will take approximately four hours for a crevice of this size as illustrated in Figure 4. When all of the sodium chloride has diffused from the crevice and has passed through the conductivity meter the return phase is complete. 
After all of the outlet conductivity data is plotted there will be two very distinct graphical areas to analyze; the area from hideout and the area from return. The integrated area of the hideout phase will give the mass of sodium chloride that accumulated within the crevice. The integrated area of the return phase will give the mass of sodium chloride that diffused from the crevice. In theory, given the permeability of carbon fiber and the relatively low pore tortuosity, the mass of sodium chloride accumulated should diffuse out of the crevice. Thus the graphical areas for the hideout and return phases should be equal.

\subsection{Measurement Equipment}

The outlet concentrations were analyzed in two ways. The exit stream salt concentration was measured by a Cole-Parmer conductivity flow cell with an accuracy of $\pm 0.3 \%$. Two calibration curves that encompass the concentrations of sodium chloride utilized in the experimental runs have been constructed and are located in Appendix B. The second method of determining exit salt concentration was analysis with an ion chromatograph. At 1-hour intervals throughout the experimental runs liquid samples were taken and analyzed with a Westec ion chromatograph utilizing a Dionex AS4 anionic membrane separator column with 
an accuracy of $\pm 1 \%$. This was to serve as a double check to the measurements of the conductivity flow cell and to check for the possibility of preferential hideout.

The column of the ion chromatograph gives sodium chloride concentrations based on calibration curves, see Appendix B. The calibration curves are determined by injecting a known concentration of sodium chloride into the column and obtaining a corresponding peak height. Although this procedure gives an accurate means of determining sodium chloride concentrations of the exit stream, the ion chromatograph is only analyzing chloride concentrations. Knowing that the ion chromatograph is only analyzing chloride makes it is possible to determine if there is preferential hideout within the crevice if irregular curves are obtained by the conductivity flow cell and ion chromatograph.

Chloride has a higher ionic conductivity than sodium with values of 76.3 and 50.1 (siemens $\mathrm{cm}^{2} / \mathrm{mol}$ ) respectively. If there is no preferential hideout the graphical data curves obtained by the conductivity flow cell and the ion chromatograph will be identical. If there is preferential hideout the curves obtained will be irregular, having similar trends but differing corresponding points. For example, if sodium hides out preferentially the bulk water will have less sodium than if sodium and chloride were hiding out relative to each other during the accumulation phase. This will result in the conductivity flow cell reading higher than it should during the accumulation phase since there is now more 
chloride in the bulk water than there would be if it was accumulating. The ion chromatograph will also see the higher amounts of chloride and both will give higher ppm sodium chloride concentrations than would be experienced if sodium and chloride were hiding out equally.

During the return phase there will be more sodium returned out of the crevice and the exit stream conductivity will go up, but not as much as it would have if it had the amount of chloride that should have accumulated if it weren't for preferential sodium hideout. The ion chromatograph will see the amount of chloride returned and give a corresponding concentration of sodium chloride. This concentration will not be as high as it would have been had the proper amount of chloride concentrated in the crevice. This will result in both units giving a smaller graphical area for the return phase. Both units will have similar trends, less than normal hideout and return, but their corresponding points will be different.

The same irregularity would be experienced if chloride had preferential hideout. The main difference being that although the accumulation and hideout trends would be similar, there would be higher than normal graphical areas for the hideout and return phase. Although the detection of preferential hideout is possible, it is not expected due to the lack of occurrence in previous studies (Mann and Castle 1983, Balakrishnan 1991). 


\subsection{Experimental Procedure}

The feed solution was prepared using de-ionized water and optical grade sodium chloride crystals (99.99\%). The amount of water and sodium chloride necessary to achieve the desired concentration was introduced into the feed tank and mixed for approximately one hour by a Cole-Parmer mixer. At that time the entire system was turned on and the fluid began pumping at $20 \mathrm{ml} / \mathrm{min}$.

The system requires an extended period of time to reach operating conditions. To ensure system stability the temperature and pressure ramping period was slow and steady. If the process was not slow and controlled the possibility existed that boiling might occur in the autoclave. If boiling occurred a steam pocket formed in the autoclave, resulting in a purging of bulk water. If bulk water was purged the system pressure fell and the exit flow discontinued until enough fluid was pumped into the system to increase the pressure back up to the back pressure regulator setting. If boiling persisted this process of purging continued, which meant that steady state could not be achieved and there was no real certainty of the fluid level in the autoclave. It is important that the autoclave be completely full of bulk solution to ensure the crevice is sufficiently submerged.

Initially the pressure of the system was elevated to approximately 400 psig and the bulk water temperature was elevated at a rate of approximately $50^{\circ} \mathrm{F}$ per 
hour. As the system temperature approached saturation at 400 psig the system pressure was elevated to its final pressure of $870 \mathrm{psig}$. The system reaches its final operating conditions of $525^{\circ} \mathrm{F}$ and 870 psig in approximately 11 hours. Ideally the system should be right on the edge of saturation, but not at boiling, to ensure that boiling readily occurs in the crevice. It is important that the crevice fluid be at saturation so that the amount of heat flux put across the crevice is utilized entirely as superheat.

The system was allowed to operate 24 hours and was monitored to ensure a stable steady state was reached. Several key points need to be noted at this time. Data was taken manually at regular intervals and did not include readings for the eight radial crevice thermocouples since they had been damaged and were not available for this set of experiments. The thermocouples located in the crevice heater were still working and a new thermocouple was placed in the tube side eutectic salt at a depth that would put it at the center of the crevice. This was accomplished by utilizing the schematics for the clam-shell crevice apparatus and the tube and tube heater dimensions to determine the exact distance to the center of the crevice. The new thermocouple was lowered into the tube at the precise distance that would place it directly at the center of the clam-shell crevice assembly. 
At the beginning of each run an exit stream liquid sample was taken and all of the system settings and parameters were logged. The crevice heater was then adjusted to supply the desired amount of power across the crevice for the given run. As would be expected, when the crevice power was applied, there was a slight outlet fluid surge indicating that a very small steam pocket had formed within the autoclave from crevice boiling. When the crevice boils the small amount of steam that is formed rises to the top of the autoclave forming a small pocket displacing a corresponding amount of fluid. During the first hour conductivity, temperature, flow and pressure data were taken every five minutes since there was a great deal of initial change. After the first hour there was little change in long term data and the data was logged every ten minutes. As stated earlier, liquid samples for the ion chromatograph were gathered every hour.

When the crevice within the system reached its thermodynamic limit the conductivity of the exit stream rose back to its original feed value. At this time a liquid sample was taken and the crevice heater was turned off to initiate hideout return. Upon removal of the heat flux across the crevice the system pressure dropped slightly along with the exit flow indicating that the small steam pocket was being displaced by fluid now that boiling had ceased. In a short period the pressure was again $870 \mathrm{psig}$ with a flow of $20 \mathrm{ml} / \mathrm{min}$. At this time the conductivity would dramatically rise indicating solute release. Because of the 
rapid change in salt concentration data was taken every minute. After the first hour data taking was again resumed in ten minute intervals until all of the sodium chloride had been released from the crevice.

The bulk water concentrations were chosen to ensure that the system would complete its run within a day since the data was taken manually. After the run was completed the system was allowed to run through the evening to ensure that it was again stabilized and the next morning a new run could proceed. When the bulk water solutions needed to be changed the new solutions would be created and at the end of the day the new solution would be allowed to pump through the system. By allowing the new solution concentration to pump through the system during the evening it was assured that the system was flushed. This means that all runs were performed in one long series where the data was obtained during the day and the system was allowed to equilibrate during the night.

Table 3 illustrates the runs that were performed for the characterization of the autoclave. Two runs were performed twice to illustrate repeatability. The

Table 3. Experimental Matrix

\begin{tabular}{|c|c|c|c|}
\hline $\begin{array}{c}\text { Crevice Heater } \\
\text { Power (Watts) }\end{array}$ & \multicolumn{3}{|c|}{$\begin{array}{c}\text { Feed Concentration } \\
\text { (ppm.) }\end{array}$} \\
\hline 85 & $120^{*}$ & & 30 \\
\hline 150 & & $60^{*}$ & \\
\hline 230 & 120 & & 30 \\
\hline
\end{tabular}

* indicates that this run was performed twice to illustrate repeatability 
experimental matrix illustrates that there was a total of seven runs performed. There were, in fact, a total of nine. The first run that was performed consisted of a clean concentric crevice to show that there would be no appreciable accumulation in a crevice that was not fouled. This run was performed with a feed solution of $60 \mathrm{ppm}$ and a heater power of 150 watts. The run followed the same procedure outlined previously.

A final run, intended for crevice visual inspection, was performed at the completion of all experimental runs. The run was performed with a feed solution of $120 \mathrm{ppm}$ sodium chloride solution and a heater power of 230 watts. When the hideout in the crevice was completed a different procedure was followed. Since the crevice had a clam-shell design and the eight main radial thermocouples had failed it was determined that it would be critical to visually examine the accumulation pattern of the sodium chloride in the packed crevice .

When the hideout was complete, the heat flux across the crevice was not reduced, to ensure that the sodium chloride would not diffuse into the bulk water. At this time the pump was turned off and the plug valve on the feed side was closed isolating half the system. When isolation was achieved, the back pressure regulator was opened, allowing a slow constant reduction in pressure across the system. With the reduction in pressure the 1-liter of bulk solution in the autoclave 
began to vaporize and flow through the heat exchanger where it became liquid and flowed out the exit line. The autoclave was successfully evacuated, the system was allowed to cool, and analysis of all nine runs began. 


\subsection{RESULTS}

\subsection{Clean Concentric Crevice}

In the first test that was performed the crevice was not packed with fiber and was a clean concentric crevice. A solution of $60 \mathrm{ppm}$ sodium chloride was introduced to the system and a heater power of 150 watts was utilized. As seen in Figure 13, the heater power was applied for a total of five hours. When the heater power was eliminated there was a $4 \mathrm{mg}$ surge of sodium chloride in the return peak.

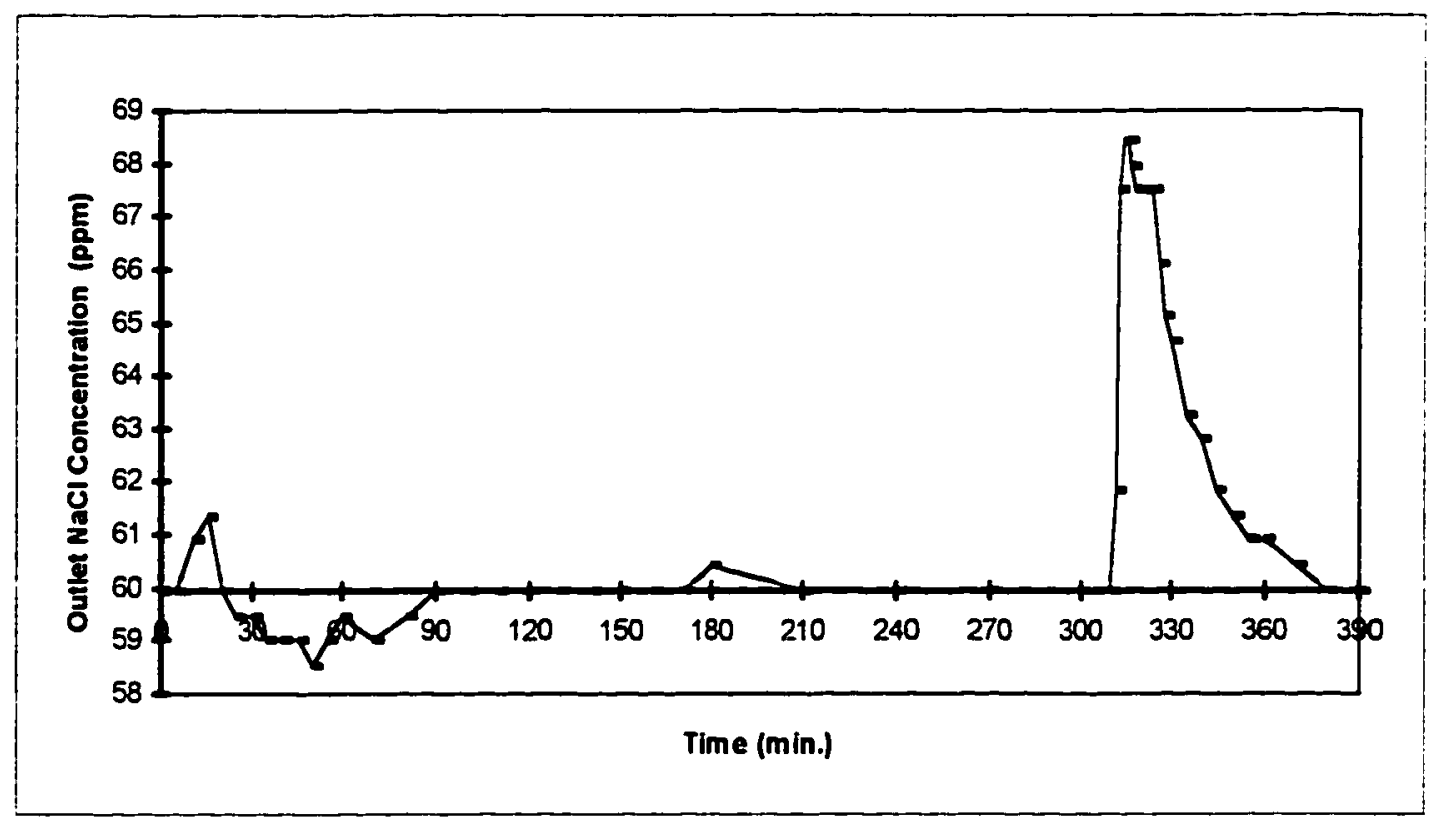

Figure 13. Heater power 150 watts, feed concentration $60 \mathrm{ppm} \mathrm{NaCl}$ (no packing) 


\subsection{Carbon Fiber Packed Crevice}

Two tests were performed using a feed solution of $30 \mathrm{ppm}$ sodium chloride. As was stated earlier, all tests utilized a flow rate of $20 \mathrm{ml} / \mathrm{min}$. A typical $H R$ graph is shown in Figure 14. The first test was performed at a heater power of 85 watts. The HR graphs for runs 2-7 are shown in Appendix C.

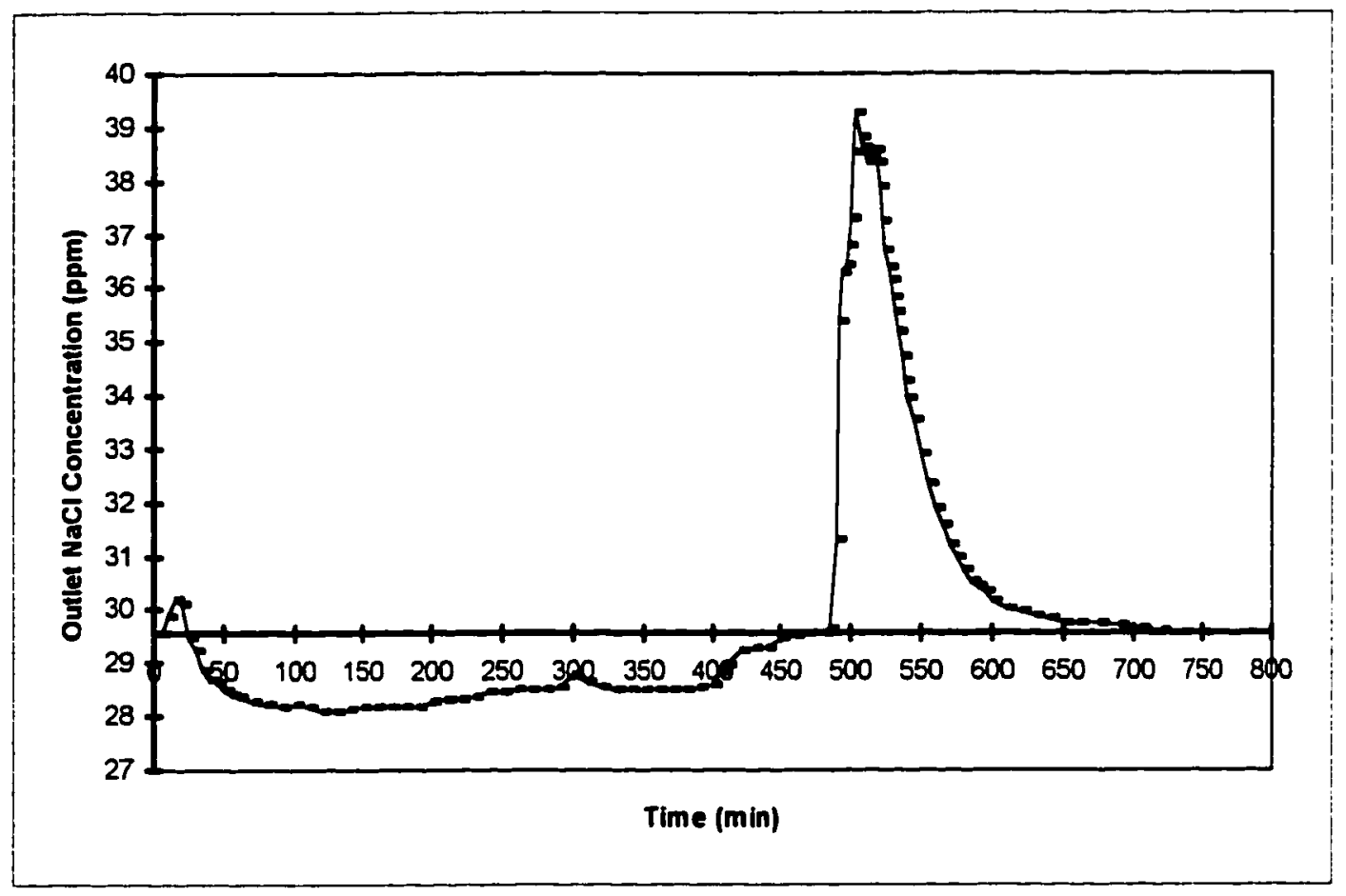

Figure 14. Run 1, heater power 85 watts, feed concentration $30 \mathrm{ppm} \mathrm{NaCl}$

The hideout phase lasted 470 minutes and when the heater power was eliminated there was a significant return of sodium chloride. The second test, run 2 , utilized a heater power of 230 watts. The hideout phase lasted for 750 minutes and there 
was the same significant return of sodium chloride when the heater power was eliminated.

Three tests were performed using a feed solution of $120 \mathrm{ppm}$ sodium chloride. Run 3 was performed utilizing a heater power of 85 watts and had a hideout phase that lasted 245 minutes. Run 4 also had a heater power of 85 watts and was performed as one of the repeatability runs, it had a hideout phase of $\mathbf{2 8 0}$ minutes. Run 5 was performed at 230 watts and it had a hideout phase that lasted 370 minutes.

Two tests were performed using a feed solution of $60 \mathrm{ppm}$ sodium chloride. Run 6 was performed utilizing a heater power of 150 watts and had a hideout phase that lasted 635 minutes. Run 7 was performed to show repeatability and also had a heater power of 150 watts. Its hideout phase lasted a total of 480 minutes.

Table 4 contains all of the accumulation data for the runs performed. Also located in the table are accumulation rates, theoretical accumulation rates and concentrating efficiency. It was found that the maximum amount of sodium chloride held in the crevice was $87 \mathrm{mg}$. This amount was obtained using a feed concentration of $120 \mathrm{ppm}$ and a heater power of 230 watts. The amounts of solute in the crevice and the amount of hideout return were obtained by integrating 


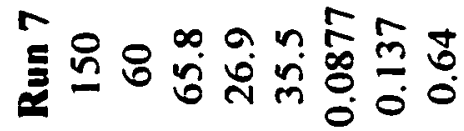

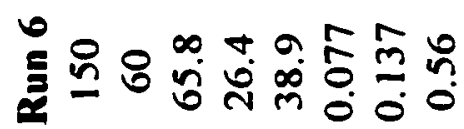

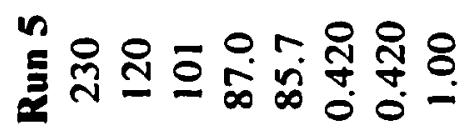

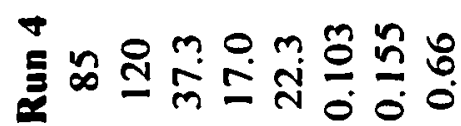

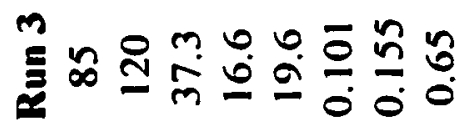

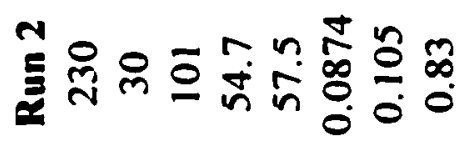

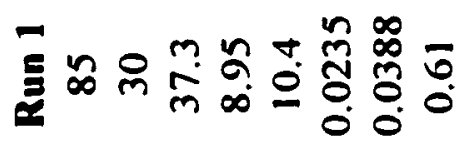

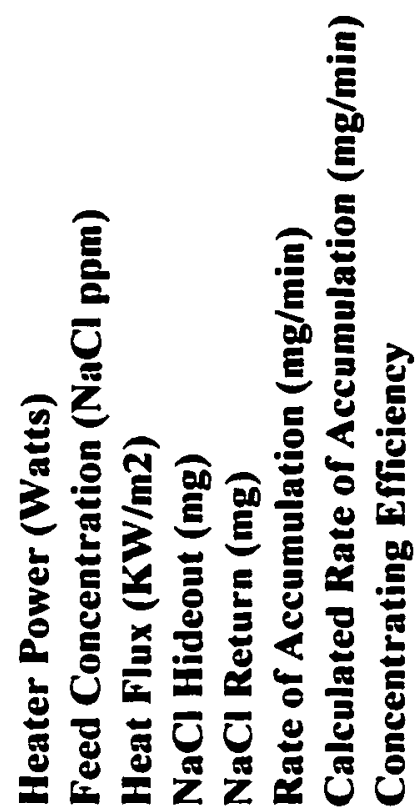


the areas under the curves of a (mass/time) vs. time graph. The term (mass/time) was calculated by the following:

$$
\left(\text { conc } \frac{m g}{L}\right)\left(\frac{1 L}{1000 m l}\right)\left(\frac{20 m l}{m i n}\right)
$$

The integration of these areas was performed using the trapezoidal method. Sample calculations are contained in Appendix D.

\subsection{Ion Chromatography}

The ion chromatograph is a sensitive analyzer capable of parts per billion analysis. This type of sensitivity led to severe problems utilizing it for the current experiments. When injecting a sample that was in the 30 to $120 \mathrm{ppm}$ sodium chloride concentration range the sensitivity of the analyzer was greatly reduced. The settings for sensitivity had to be adjusted to a factor that made the unit incapable of accurately discerning the difference between a sample with a concentration of $29.5 \mathrm{ppm} \mathrm{NaCl}$ and one with $30 \mathrm{ppm} \mathrm{NaCl}$. At its reduced sensitivity the ion chromatograph was capable of determining the difference between 30 and $25 \mathrm{ppm}$ sodium chloride solutions, but this was not typical for the

majority of the runs. At low heater power settings ( 85 watts) the accumulation 
rates are small and this type of accuracy is critical since the bulk water exit stream may only have a 0.25 to $1.0 \mathrm{ppm}$ drop in sodium chloride concentrations.

The relative fluid concentrations are determined by the relative peak heights. With the low power settings, the difference in peak heights to discern between 30 and $29 \mathrm{ppm}$ could be as small as $1 \mathrm{~mm}$. This type of difference leads to obvious human errors and puts a strain on the accuracy of the calibration curves. To illustrate the discrepancies, Figure 15 is a comparison of the data obtained by the conductivity meter and the liquid ion chromatograph samples. It is apparent

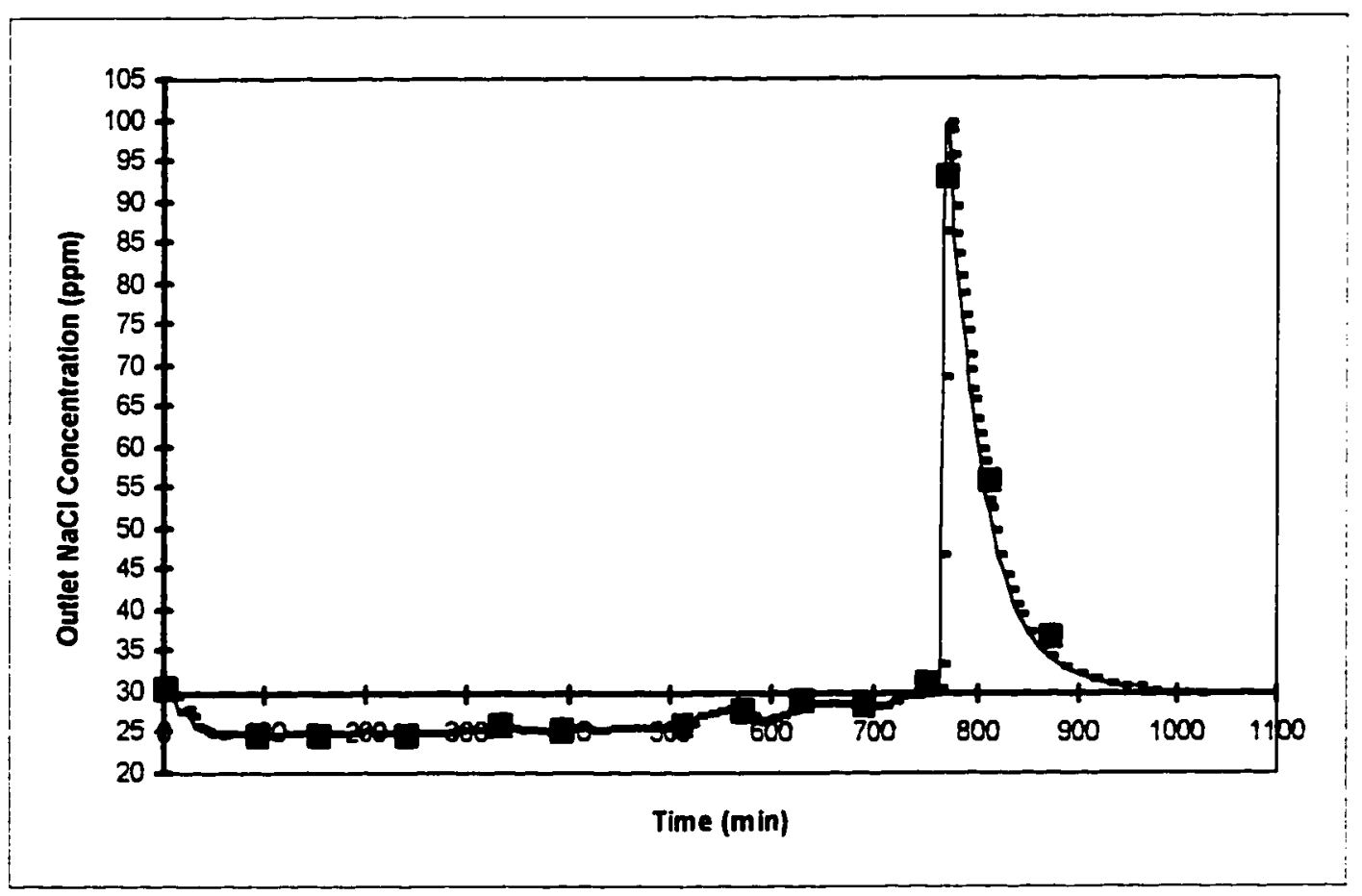

Figure 15. Comparison of Conductivity and Ion Chromatograph Measurements for a heater setting of 230 watts and a feed concentration of $30 \mathrm{ppm} \mathrm{NaCl}$ (Run 2) 
from Figure 15 that the ion chromatograph measurements coincide with the measurements of the conductivity meter. This is at a high power setting of 230 watts, meaning that the drop in outlet concentration is as high as $5 \mathrm{ppm}$ in the accumulation phase. As seen in Figure 16, there is a significant discrepancy when the power setting is lower and the drop in outlet concentration is on the order of 1 ppm for the accumulation phase. These types of results were consistent for all the runs.

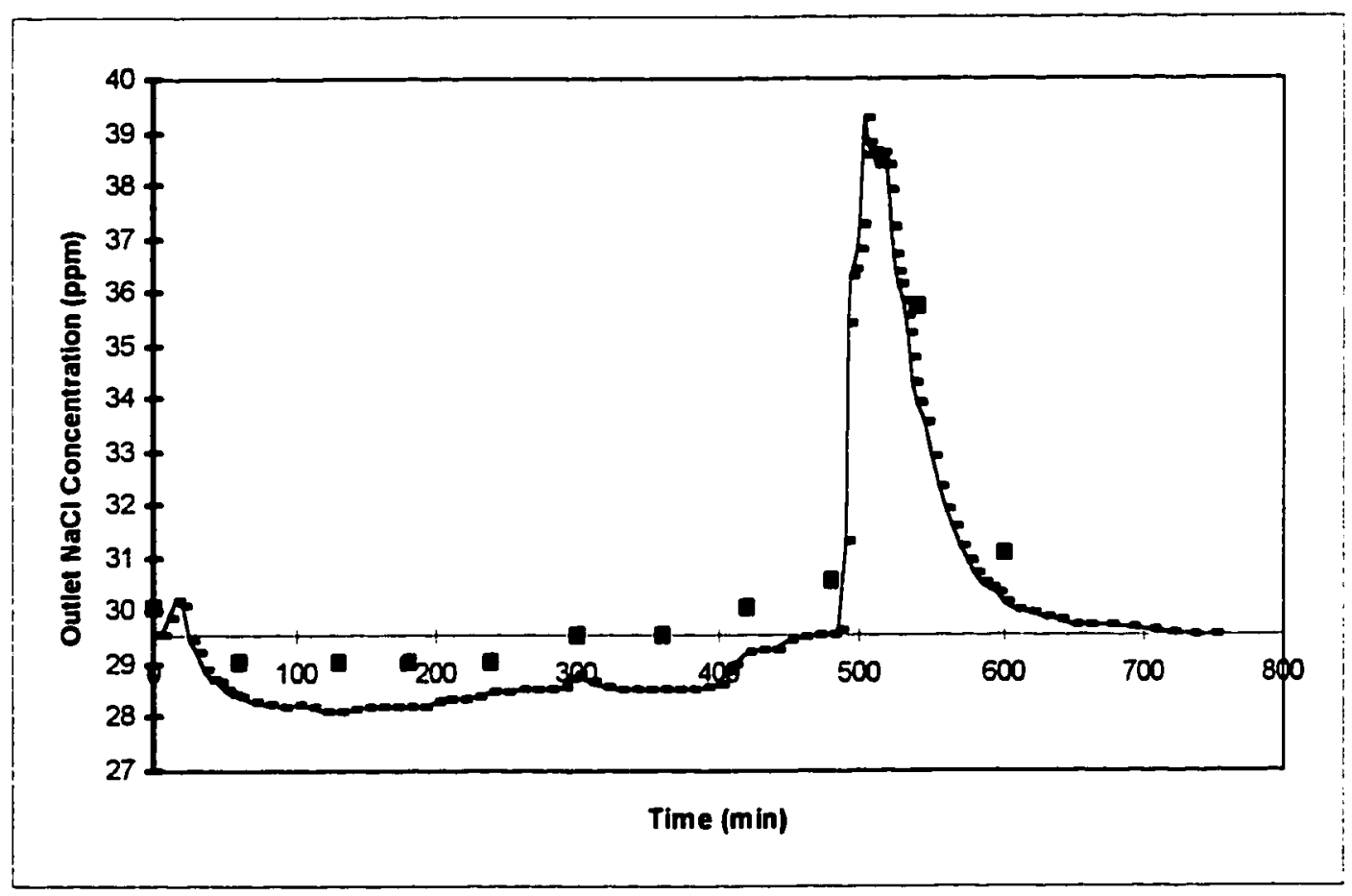

Figure 16. Comparison of Conductivity and Ion Chromatograph Measurements for a heater setting of 85 watts and a feed concentration of $30 \mathrm{ppm} \mathrm{NaCl}$ (Run l) 
It should be noted that although the ion chromatograph data in Figure 15 appears to be very accurate and Figure 16 appears to be very inaccurate, this is due to the dramatic difference in y-axis scaling. Inaccuracies of $0.25-0.50 \mathrm{ppm} \mathrm{NaCl}$ appear to be insignificant in the $5 \mathrm{ppm}$ y-axis scaling increment of Figure 15. Because of the high bulk fluid concentrations used and the corresponding reduced sensitivity settings the ion chromatograph is inappropriate as a check for this system. 


\subsection{DISCUSSION}

\subsection{Introduction}

The results that were obtained indicate that sodium chloride accumulated within the crevice when there was an applied heat source and the crevice was sufficiently fouled to create restrictive flow. When the crevice is clean and concentric there is a minimal amount of accumulation. As shown in Figure 13, there was an accumulation of $\mathbf{4} \mathrm{mg}$ of sodium chloride. In previous studies (Balakrishnan 1991) there was an accumulation of approximately 6-8 $\mathrm{mg}$ of impurities and it was felt that in overall terms this was insignificant. The concentration process for the experimental runs performed was driven by the crevice heat flux. When the heat flux was applied the carbon fiber behaved like a pore network which utilized capillary action to draw in bulk solution and discharge the gas phase. The overall characterization of the crevice closely followed the trends of previous researchers (Mann and Castle 1983, Balakrishnan 1991) and the data obtained is being compared to the predictions of the model developed by Millett and Fenton (1994) as a parallel study. 


\subsection{Accumulation Rates}

Based on the data obtained there is a direct relationship between accumulation rates and the amount of heat flux across the crevice. As the heat flux is increased the rate of accumulation increases. As seen in Figure 17,

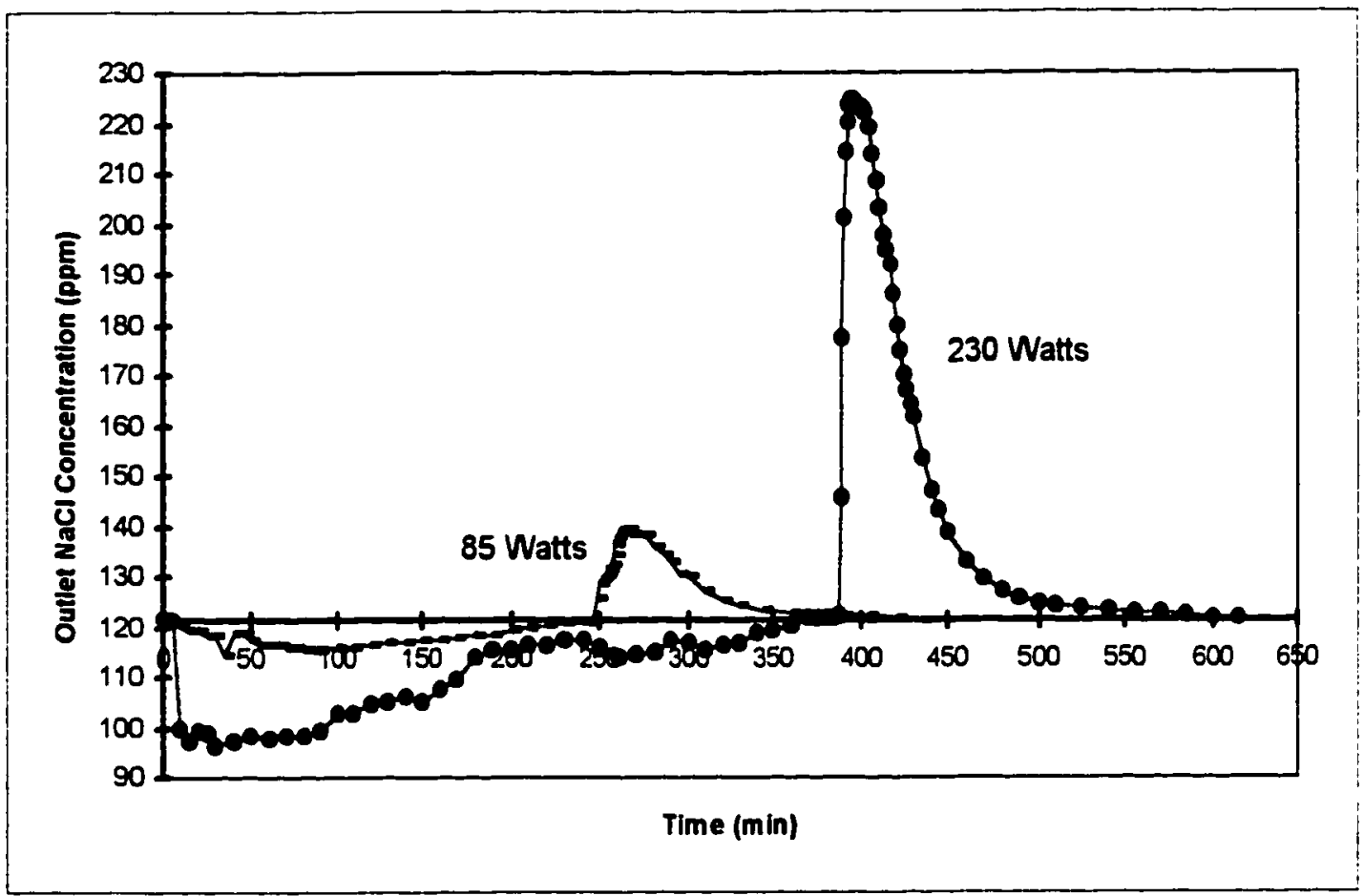

Figure 17. Results comparison, feed concentration $120 \mathrm{ppm} \mathrm{NaCl}$, comparing 85 and 230 watt heater power settings

the accumulation area of the 230 watt run is significantly larger than the accumulation area of the 85 watt run. The larger graphical area of the 230 watt run indicates a larger rate of accumulation. 
As seen in Figure 18, at a constant heater power the salt accumulates at a linear constant rate and then declines as equilibrium is achieved. This can be interpreted as the rate of accumulation being directly proportional to the rate of evaporation within the crevice (Mann and Castle 1983).

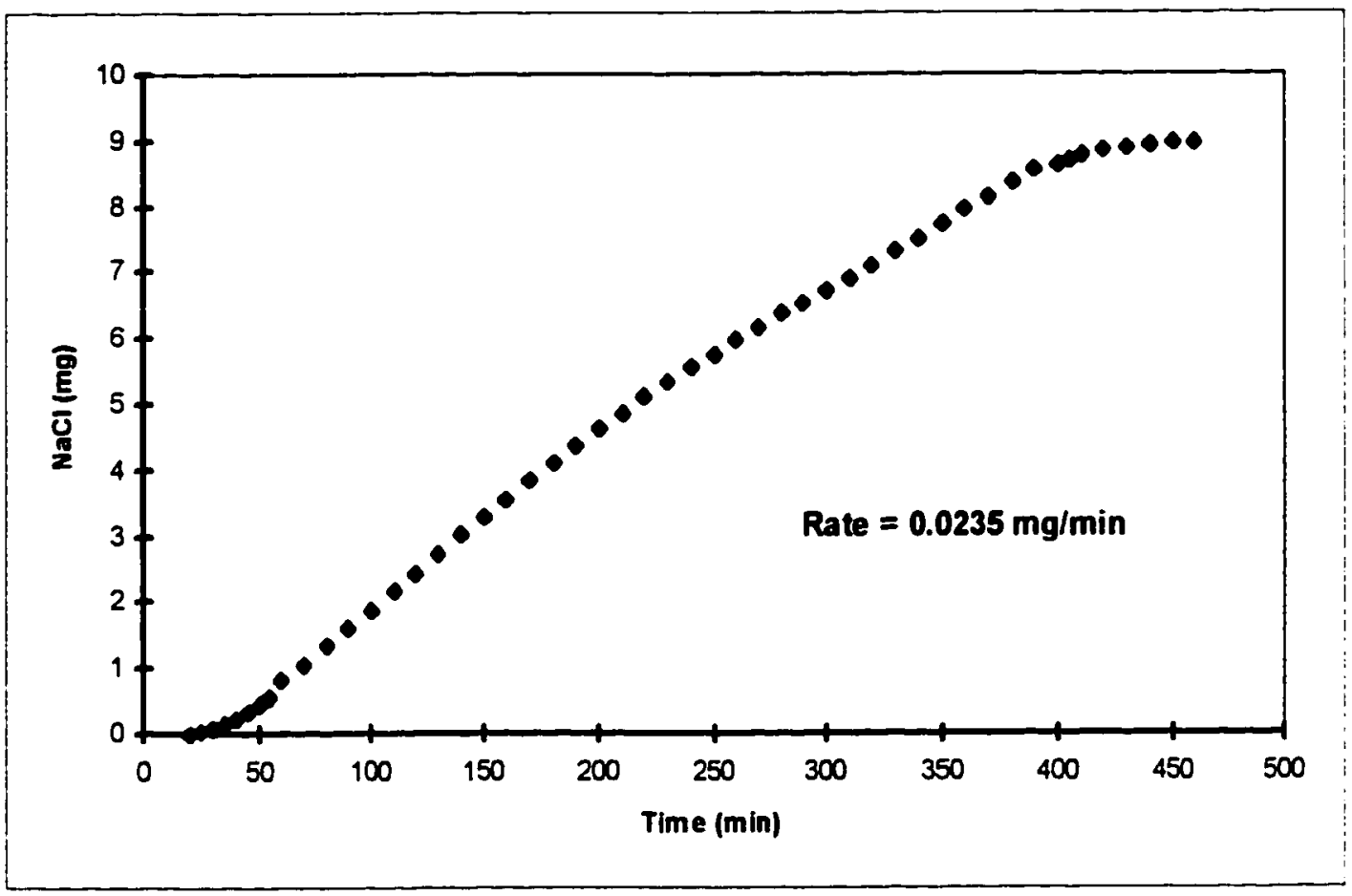

Figure 18. Graphical representation of crevice accumulation rate

The maximum possible rate of accumulation can be calculated with the crevice rate of evaporation, heater power and bulk concentration. This assumes that there is no entrainment and all of the salt remains in the crevice during evaporation. For the conditions of the system, the latent heat of evaporation is 
$1578 \mathrm{KJ} / \mathrm{kg}$. The tube cartridge heater is $76.2 \mathrm{~mm}$ and the crevice length is 30.5 $\mathrm{mm}$. This means that the crevice is only capable of seeing $40 \%$ of the heater power. The theoretical rate of salt accumulation can be calculated with the following equation:

$$
\text { Rate of Accumulation }=\frac{(0.40)(\text { Heater Power })(\text { Feed Concentration })}{(\text { Latent Heat of Evaporation })}
$$

This information is contained in Table 4. In a real steam generator the tubes are heated along their entire length with the primary water. In the experimental set-up the cartridge heater within the tube extends above and below the crevice to simulate the entire tube length heating characteristics of a real steam generator. Even with the oversized cartridge heater some of the heat will travel to other areas of the tube, being lost in areas such as the eutectic salt mixture. The crevice will see $40 \%$ of the heater, but because of the above mentioned losses, $40 \%$ may be a generous figure.

With the data obtained, there is a proven relationship between the bulk water concentration and the rate of sodium chloride crevice concentration. The data indicates that as the bulk water concentration increases the rate of accumulation increases. With a heater power of 85 watts and a feed solution of 30 
ppm sodium chloride solution the rate of accumulation is $0.0235 \mathrm{mg} / \mathrm{min}$. With the same heater power and a feed solution of $120 \mathrm{ppm}$ sodium chloride solution the rate of accumulation is $0.101 \mathrm{mg} / \mathrm{min}$. This type of behavior is consistent with all of the runs and was experienced by several researchers (Mann and Castle 1983, Balakrishnan 1991).

\subsection{Equilibrium Concentration of $\mathrm{NaCl}$ in Crevice}

In the experiments performed the data obtained shows that the equilibrium concentration of sodium chloride in the crevice is a function of the applied crevice heat flux. As the heat flux is increased the amount of sodium chloride hideout increases. This was expected since the amount of available superheat increases, which in turn determines the equilibrium concentration. With a feed concentration of $30 \mathrm{ppm}$ sodium chloride solution $8.9 \mathrm{mg}$ of sodium chloride accumulated in the crevice with an applied heater power of 85 watts. With the same feed concentration of $30 \mathrm{ppm}$ and an applied heater power of 230 watts the amount of sodium chloride accumulated in the crevice increases to $54.7 \mathrm{mg}$. This type of behavior was experienced at all feed concentrations. By increasing the available superheat the equilibrium point between the boiling solution and the tube heater 
increases. It has been shown that if the superheat is great enough precipitation can occur (Balakrishnan 1991).

The bulk water concentration had a slight effect on the crevice equilibrium concentration. As can be seen in Table 4, a quadrupling of the bulk water concentration typically led to a doubling of the equilibrium mass of sodium chloride accumulating in the crevice. This indicates that the bulk water concentration had an effect, but as described by previous researchers (Mann and Castle 1983, Balakrishnan 1991), a "weak effect when compared to the crevice heat flux".

The release of sodium chloride from the crevice followed the same trend as the work performed by Mann and Castle (1983). Return typically took 4 hours to complete and began immediately after the heat flux to the crevice was removed. After eliminating the crevice heat flux, the length of time that passed before the increase in exit bulk water conductivity measurements occurred was approximately 10 minutes. Based on the length of tubing between the autoclave and the conductivity flow cell, it has been calculated that it should take a minimum of 7 minutes for the fluid from the autoclave to reach the conductivity flow meter. As was stated earlier, when the heat flux is removed from the crevice the small steam pocket that formed in the autoclave from crevice boiling collapses, resulting in a loss of exit flow. This results in a short lag of a few minutes while enough 
fluid is pumped in to increase pressure back up to operating conditions to allow flow. This time lag information indicates that the release of solute is immediate when the applied heat flux is removed. The release curve was always similar to an immediate spike and a decay with the bulk of the salt being released in the first 2 hours.

It was expected that the amount of sodium chloride hideout should equal the amount of sodium chloride in the return phase. In that case the accumulation and return graphical areas should be equal. In almost all of the runs more sodium chloride was returned than accumulated. The difference in graphical areas varied from $1.5 \%$ to as high as $32 \%$ with an average overall variance of approximately 16\%. In previous studies (Balakrishnan 1991), these differences ran as high as $50 \%$ with a slightly erratic pattern of retum and accumulation amounts. In the current study, the graphical differences are slight but noteworthy since it could be expected that a very small amount of sodium chloride would not be returned due to packing permeability and imperfect diffusion. This should have resulted in the graphical area of the return phase being slightly less than the graphical area of the accumulation phase, but the opposite was true.

The expectation of the current study was that the amount of salt pumped into the system would equal the amount pumped out. During the course of experiments there were two factors that slightly altered this expectation; internal 
corrosion and autoclave bulk water concentrating. By using a standard conductivity flow cell the exit stream was treated as an ionic soup as opposed to previous experiments (Balakrishnan 1991) where ion specific electrodes were utilized. With the conductivity flow cell it would be impossible to differentiate between sodium chloride, dissolved gases or small amounts of corrosion products.

During the course of the runs there was a slight amount of corrosion within the system. This corrosion typically occurred with the 316 stainless steel pins located within the crevice cage apparatus. Depending on when these corrosion products were released they would have an obvious, but slight, effect on the outlet conductivity. The second factor is more consistent and predictable. When the heater power is applied across the crevice there is a severe concentrating effect within the crevice and a slight concentrating effect on the autoclave bulk water. The heater across the crevice extends above and below the crevice a total of $5 \mathrm{~cm}$. This results in a small amount of concentration in the violent boiling region in these areas. There is also a small reduction in the autoclave volume from the formation of a small steam pocket experienced when crevice boiling occurs. This slight concentration occurred in the work performed at the Rockwell Science Center (Lumsden et al. 1997). They analyzed their feed stream and their autoclave bulk water concentration and ended up with a 2 to $7 \mathrm{ppm}$ feed and bulk water 
concentration differential. These types of experimental discrepancies explain why the graphical areas are for all intensive purposes equal but not exact.

\subsection{Crevice Visual Inspection}

The last run performed was to obtain a visual impression of how the sodium chloride accumulated in the crevice. In this run the sodium chloride was allowed to accumulate in the crevice and the cylinder was evacuated leaving the sodium chloride to crystallize where it was located. As it turned out this became a crucial piece of information due to the failure of the radial crevice thermocouples.

The thermocouples that were located in the eutectic salt and the cartridge heater indicated the possibility of steam blanketing within the center of the crevice. During all of the runs there was no significant increase in temperature associated with the cartridge heater thermocouple or the thermocouple located in the tube eutectic salt mixture. As described earlier, as the crevice solution increases in concentration its boiling point increases resulting in an increase in heat transfer resistance. With this increase in resistance the temperature associated with the heaters and eutectic salt increase. Figure 19 illustrates the temperature profile of these thermocouples for the run performed with a feed concentration of $30 \mathrm{ppm}$ and crevice heater power of 230 watts. 


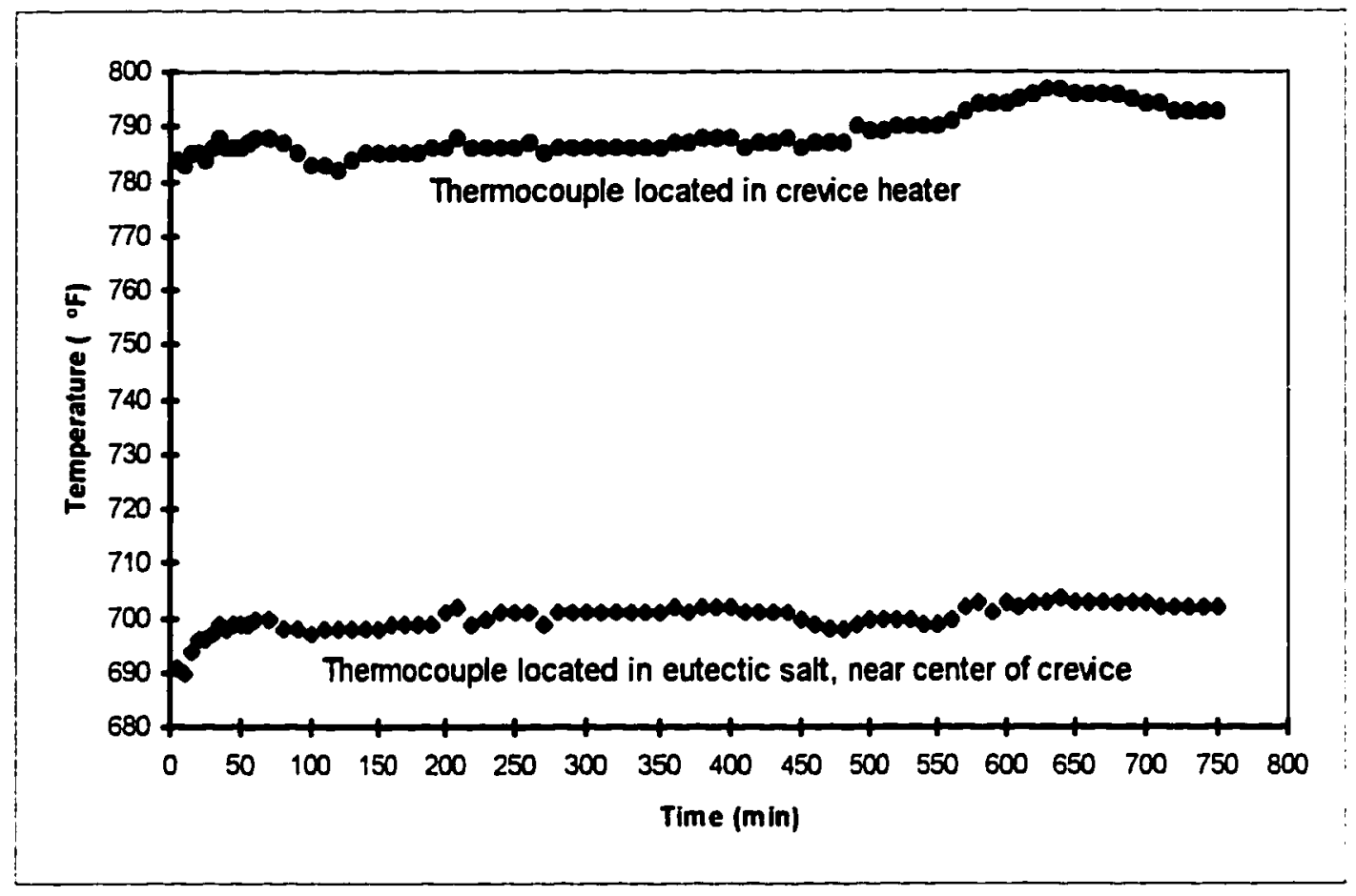

Figure 19. Typical thermocouple profile for crevice heater and eutectic salt.

Larger temperature gradients have been experienced by most researchers (Mann and Castle 1983, Balakrishnan 1991) in the range of $25^{\circ} \mathrm{C}$. The typical temperature rise experienced in the current runs varied from $5-10^{\circ} \mathrm{F}$. The lack of temperature rise within the center of the crevice would indicate steam blanketing. Based on a visual inspection this was confirmed.

When the clamshell crevice was opened there was a relatively clear picture of how the sodium chloride accumulated. The sodium chloride appeared to be a slightly rust colored white powder. In the very center of the crevice there was no evidence of a sodium chloride buildup. The packing was relatively clean. Where 
the packing was clean, a dime sized region in the very center of the crevice, there was green scale which, based on descriptions, was assumed to be nickel monoxide. The feed was not deoxygenated which would allow this type of scale to occur. The scale did not form in any of the regions containing the crystallized salt concentrations.

The regions that contained the most salt were the areas near the mouth of the crevice and along the seam inside the crevice where the two halves of the clamshell came together and were connected using bolts. It was evident that there had been some sodium chloride build-up in the seam itself. This would make sense since the seam, no matter how well it was machined, would in fact form a very small crevice. This may answer the question as to where some of the $4 \mathrm{mg}$ of salt accumulated during the clean concentric crevice test.

Based on the clamshell configuration the region along the seam would have the most porous environment. Each half of the clamshell crevice was packed with a fashioned carbon fiber mat created from crisscrossing $3 \mathrm{~cm}$ long lengths. The nature of packing a clamshell crevice and putting the halves together would give regions at the seams that consisted solely of an interface between the two carbon mats. There is really no way to tell if these two mats were even fully in contact. It would resemble the interface formed by pushing the tips of two paint brushes into each other. 
The results of the visual inspection and the temperature trends in the center of the crevice indicate that up to one-third of the crevice was effectively steam blanketed. This has no real effect on the accumulation rates or how the accumulation occurs, but it will have a large effect on the equilibrium concentration. This means that the maximum amount of sodium chloride that accumulated could have been larger in all cases had there been no central steam blanketing.

Several researchers (Mann and Castle 1983, Balakrishnan 1991, Lumsden et al. 1997) have been plagued with steam blanketing but it usually occurred with carbon or diamond powder packing. In those cases, steam blanketing occurred at the center of the crevice or in a pocket. The bulk solution would then concentrate at the upper and lower regions of the crevice. In previous experiments the steam blanketed region would slowly fill with solution. This type of behavior did not occur with the runs performed. The apparent steam filled regions remained blanketed throughout the experiment. The choice of carbon fiber was made to reduce or eliminate this problem but with the results obtained it is clear that it still has a relatively large effect on this system. 


\subsection{Runs for Repeatability}

Two sets of runs were performed to illustrate repeatability. Two runs were performed with a heater power of 85 watts and a feed concentration of $120 \mathrm{ppm}$ sodium chloride solution, as illustrated in Figure 20.

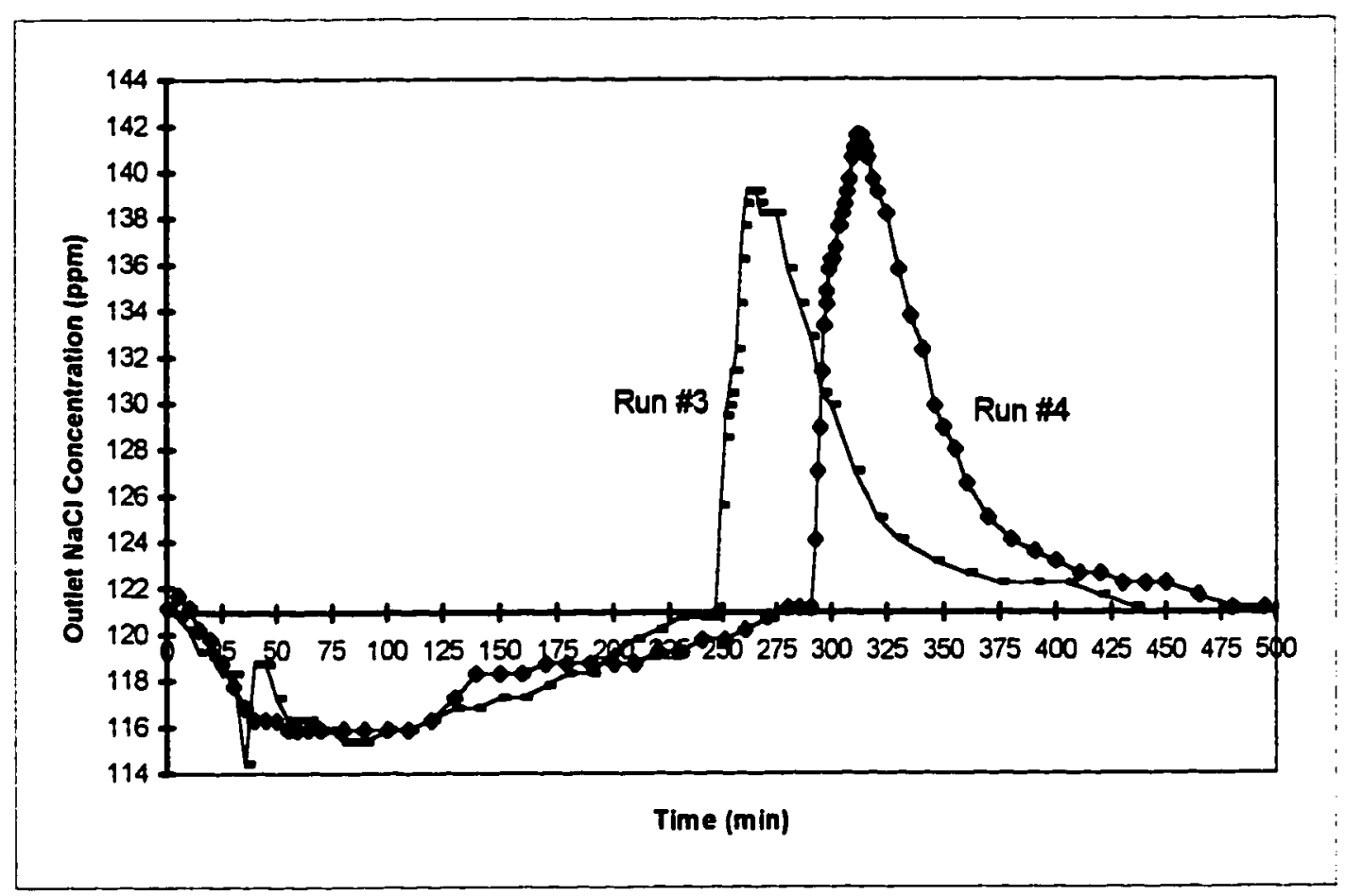

Figure 20. Comparison of repeatability runs at $120 \mathrm{ppm} \mathrm{NaCl}$ feed and 85 watt heater power

As can be seen in Figure 20, the runs are very similar in appearance. In run 3 the amount of accumulation was $16.6 \mathrm{mg}$ sodium chloride compared to $17.0 \mathrm{mg}$ for run 4, with a 30 minute shift in accumulation times. For the return phase run 3 
returned $19.6 \mathrm{mg}$ and run 4 returned $22.3 \mathrm{mg}$. This would give a $2.4 \%$ differential in accumulation and $12 \%$ differential in return for the two runs.

The second set of runs was performed with a heater power of 150 watts and a feed solution of $60 \mathrm{ppm}$ sodium chloride, as illustrated in Figure 21 . The clean concentric run has also been included in Figure 21 to illustrate its relative magnitude. Out of all the runs performed the runs at these settings were the

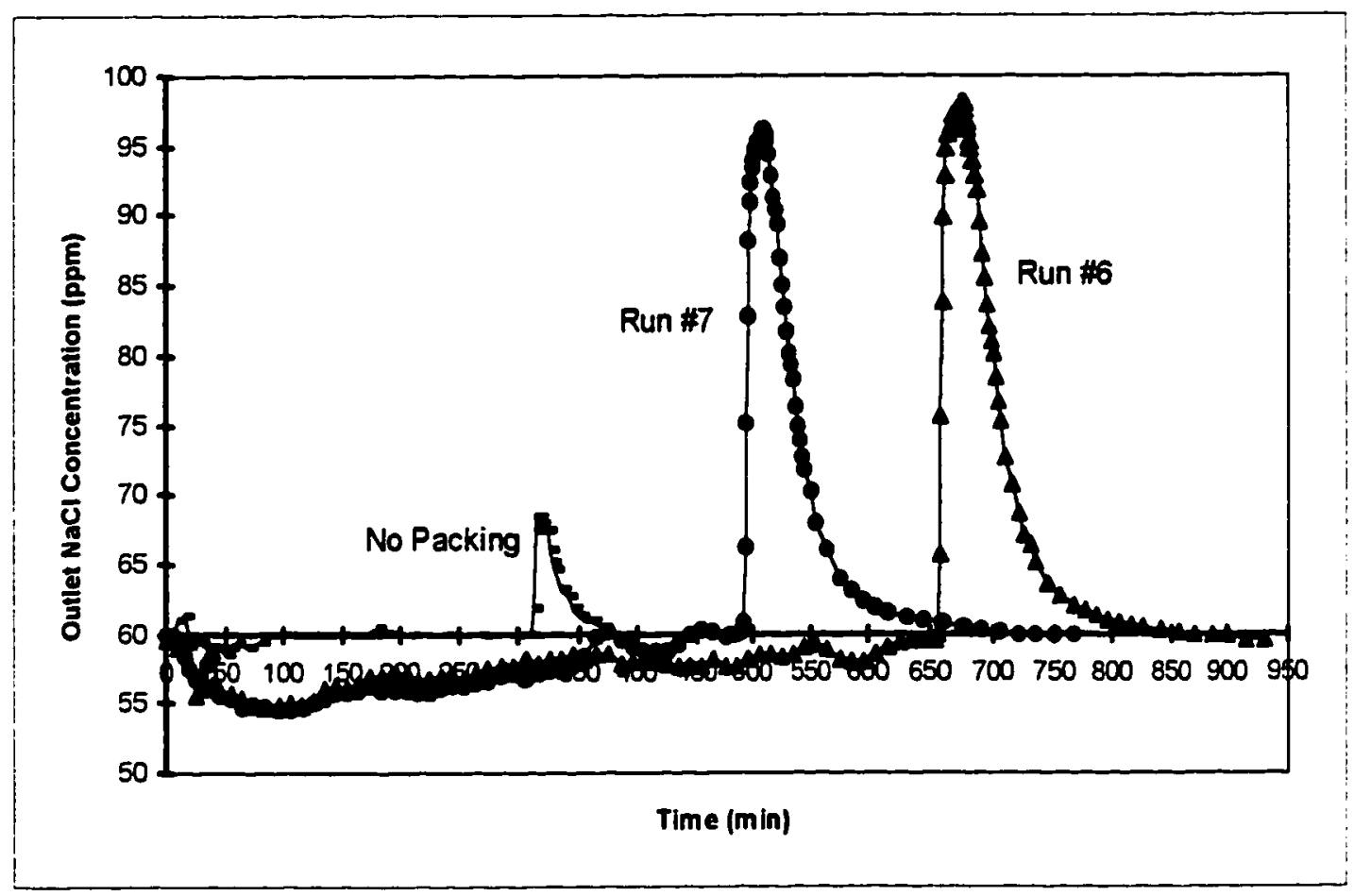

Figure 21. Repeatability comparison, $60 \mathrm{ppm} \mathrm{NaCl}$ feed, heater power of 150 watts, and run performed with no packing

most erratic. Run 6 had a differential between its accumulation and return amounts of sodium chloride on the order of $30 \%$. Run 7 also had a differential on the order of $30 \%$. What is interesting is that their behavior is erratic but 
repeatable. The accumulation amount of sodium chloride for run 6 was $26.4 \mathrm{mg}$ and for run 7, $26.9 \mathrm{mg}$. This is a difference of only $1.9 \%$, with a difference in accumulation times of approximately 100 minutes. The return amount of sodium chloride was $38.9 \mathrm{mg}$ for run 6 , and $35.5 \mathrm{mg}$ for run 7 , resulting in a differential of $8.7 \%$. 


\subsection{CONCLUSIONS}

An experimental system has been constructed to simulate the crevice that is formed between a tube and tube-support plate found in a pressurized water reactor steam generator. Using feed solutions of 30,60 and $120 \mathrm{ppm}$ sodium chloride and crevice heater powers of 85,150 and 230 watts the characterization of the experimental crevice has been completed. It was shown that with a clean concentric crevice there is little tendency for sodium chloride to hideout. When the crevice is packed with carbon filament and a heat flux is applied there is an immediate concentrating effect across the crevice. When the heat flux is removed there is an immediate return of the accumulated impurities through diffusion.

The relationship between heat flux across the crevice and the maximum impurity concentration was shown. As the heat flux across the crevice was increased, the available superheat was increased resulting in a higher crevice concentration. It was shown that the rate of impurity concentration was related to the bulk water concentration and heat flux across the crevice. As these were increased the relative rate of accumulation increased.

Through visual observation and temperature measurements it was shown that the crevice volume had been reduced by approximately one-third through 
steam blanketing. This steam blanketing was persistent through all of the runs performed and did not diminish through the course of each run. 


\section{NOMENCLATURE}

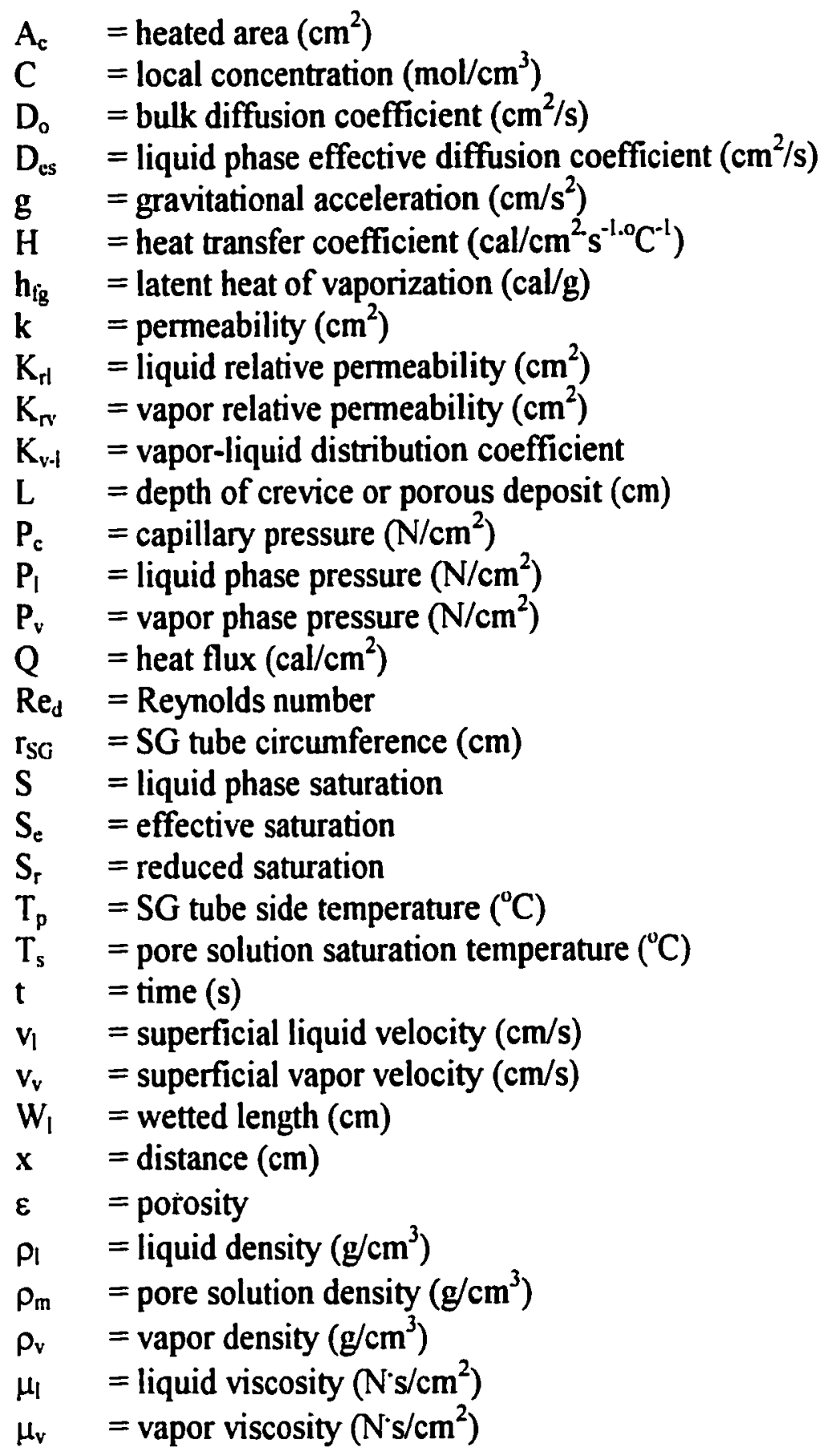




\section{REFERENCES}

1) Douglas, J., Solutions for Steam Generators, EPRI Joumal May/June 1995, pg. 29-34.

2) Zumdahl, S., Chemistry, D.C. Heath and Company, Toronto, 1989.

3) Millett, P.; Fenton, J., Review of PWR Steam Generator Crevice Impurity Concentration Mechanisms, Proceedings of a Conference on Steam Generators and Heat Exchangers, 1990.

4) Mann, G.W.; Castle R., Salt Concentration in Heated Crevices and Simulated Scale, EPRI NP-3050, October 1983.

5) Electric Power Research Institute, Steam Generator Reference Book, Steam Generators Owners Group, 1985.

6) Millett, P.; Fenton, J., A Modeling Study of Parameters Controlling Local Concentration Processes in Pressurized Water Reactor Steam Generators, Nuclear Technology, vol. 108, November 1994, pg. 256-265.

7) Millett, P., PhD Dissertation University of Connecticut, June 1991.

8) Millett, P., Steam Generator Degradation: Current Mitigation Strategies for Controlling Corrosion, CNRA/CSNI Workshop, 1995.

9) Mann, G.W.; Castle, R., Hideout and Return of Chloride Salts in Heated Crevices Prototypic of Support Plates in Steam Generators, EPRI NP-5015, January 1987.

10) Hermanson, H.; Persson, G.; Reinvall, A., Corrosion Particles in Boiling Water Reactor Condensates, Nuclear Technology, vol. 103, July 1993, pg. 101-113.

11) Millett, P.; Brobst, G.; Riddle, J.; A Probabilistic Approach to Controlling Crevice Chemistry, Unpublished, 1997. 
12) Millett, P.; Fenton, J., A Detailed Model of Localized Concentration Processes in Porous Deposits of SG's, Proceedings of the Fifth International Symposium on Environmental Degradation of Materials in Nuclear Power Systems Water Reactors, August 1991, pg. 745-751.

13) Lumsden, J.; Pollock G.; Stocker, P., Hideout in Prototypic Tube/Tube Support Plate Heated Crevices, EPRI Project No. RPS 520-08, 1997

14) Balakrishnan P., Hideout and Return of Complex Mixtures in Crevices, EPRI Project No. S407-13, September 1991.

15) Riggs, J., An Introduction to Numerical Methods for Chemical Engineers, Texas Tech University Press, Texas, 1994. 


\section{APPENDIX A}

\section{CHEMICALS}
1) Inert Gas
2) Eutectic Salt Mixture (54.3\% $\left.\mathrm{KNO}_{3}, 45.7 \% \mathrm{NaNO}_{3}\right)$
3) Sulfuric Acid 18M
4) Conductivity Standards $\mathrm{NaCl}$
5) De-ionized Water (ultra-pure)
6) De-ionized Water (nano-pure)
7) Sodium Hydrogen Carbonate $99.7+\%$
8) Sodium Chloride $99.99 \%$
9) Sodium Carbonate $99.995 \%$
10) Inert Carbon Fibers

\section{EQUIPMENT}

1) 1-Liter High Pressure Autoclave alloy 718

2) 15 Thermocouples (K Type)

3) $1 / 4 " 316$ S.S. Tubing (approx. $40 \mathrm{ft}$ )

4) Conductivity Flow Cell

5) Pump (30 ml/min, 1000 psia)

6) Conductivity Dip Cell

7) 2 Plug Valves

8) Conductivity Meter

9) l Check Valve 


\section{EQUIPMENT (cont'd)}

10) Ion Chromatograph

11) 1 Pressure Relief Valve

12) Data Acquisition System

13) 1 Pressure Transducer

14) 600 Watt Cartridge Heater

15) 3-Temperature Controllers

16) Pre-Heater $\left(280^{\circ} \mathrm{C}\right)$

17) Tube Fittings, Elbows, T's

18) Mixer and Motor

19) Back Pressure Regulator (1000 psia)

20) 4 Ring Heaters

21) Roto-meter (up to $40 \mathrm{ml} / \mathrm{min}$ )

22) Heat Exchanger

23) Feed, Exit Containers

24) Thermocouple Wire (200 ft)

25) Rubber Tubing (10 ft)

26) DC Power Supply

27) Insulation

28) Variac Voltage Controllers (3)

29) Volt, Amp, Temperature Meter

30) Pulse Dampener

31) Plexi-glass $\left(20 \mathrm{ft}^{2}\right)$

32) Pressure Gauges (2)

33) Crevice Assembly

34) Pressure Fittings 


\section{APPENDIX B}

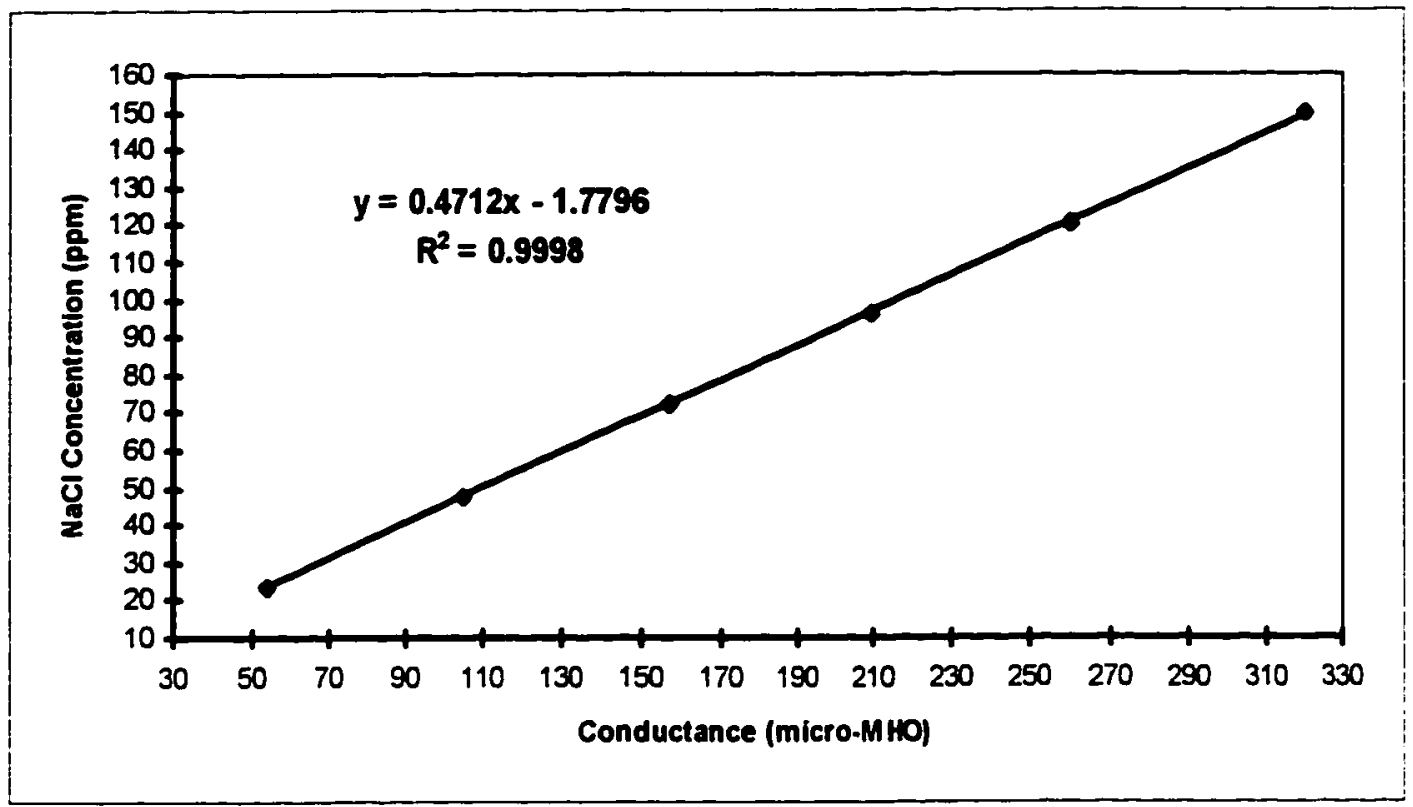

Figure 22 . Conductivity meter calibration curve $24-150 \mathrm{ppm} \mathrm{NaCl}$ solutions

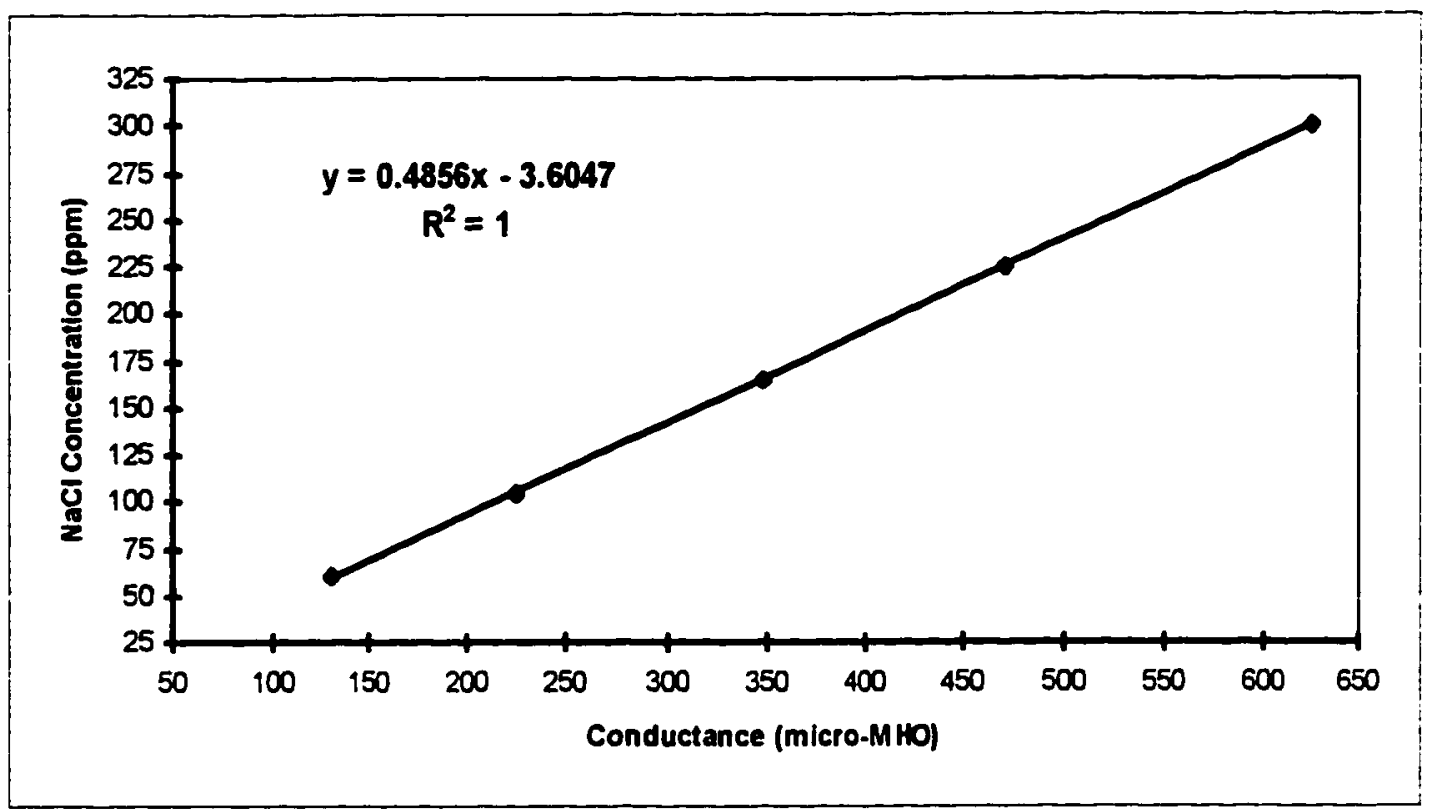

Figure 23 . Conductivity meter calibration curve $60-300 \mathrm{ppm} \mathrm{NaCl}$ solutions 


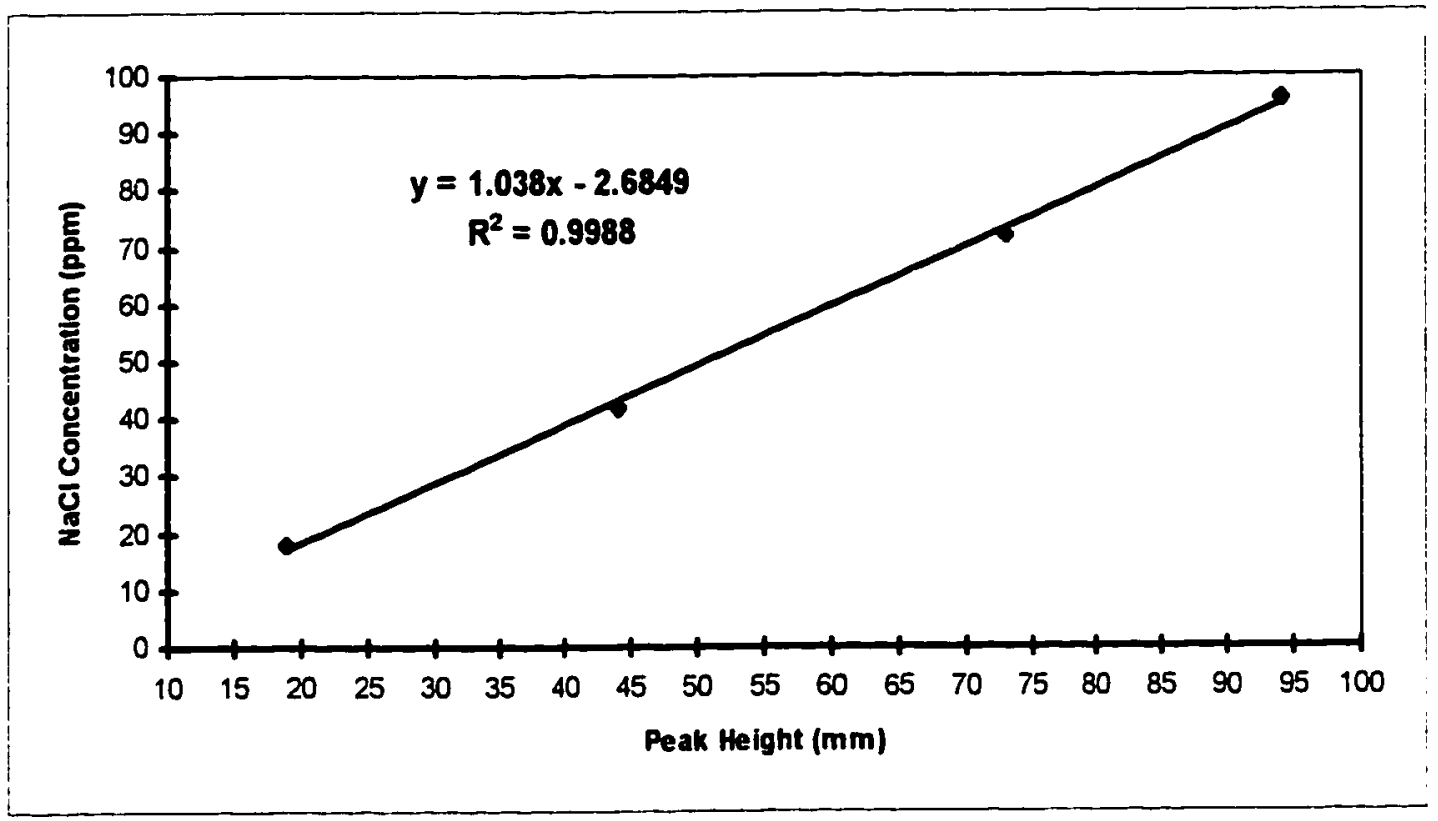

Figure 24. Ion chromatograph calibration curve for $18-96 \mathrm{ppm} \mathrm{NaCl}$ solutions

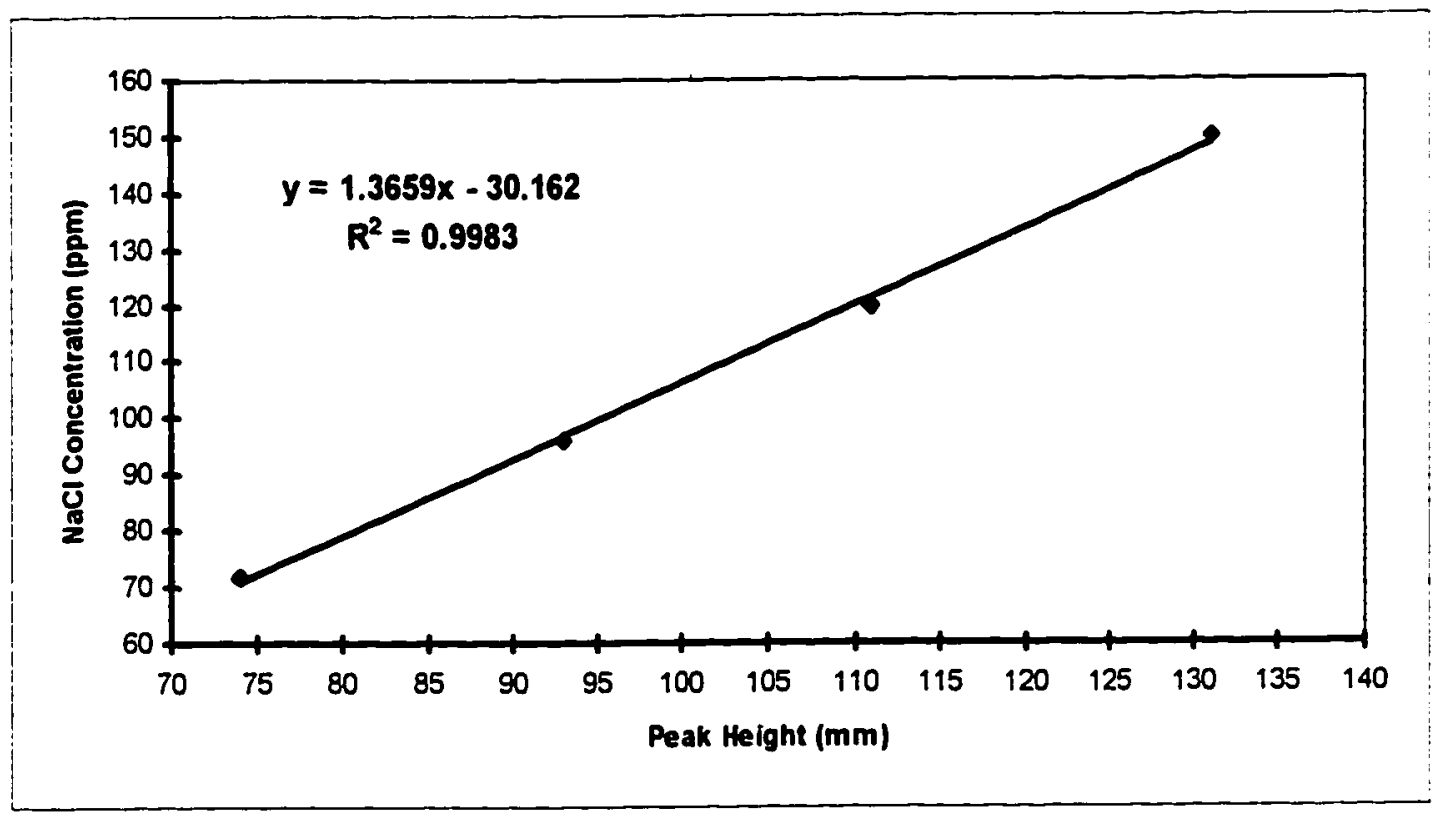

Figure 25. Ion chromatograph calibration curve for $72-150 \mathrm{ppm} \mathrm{NaCl}$ solutions 


\section{APPENDIX C}

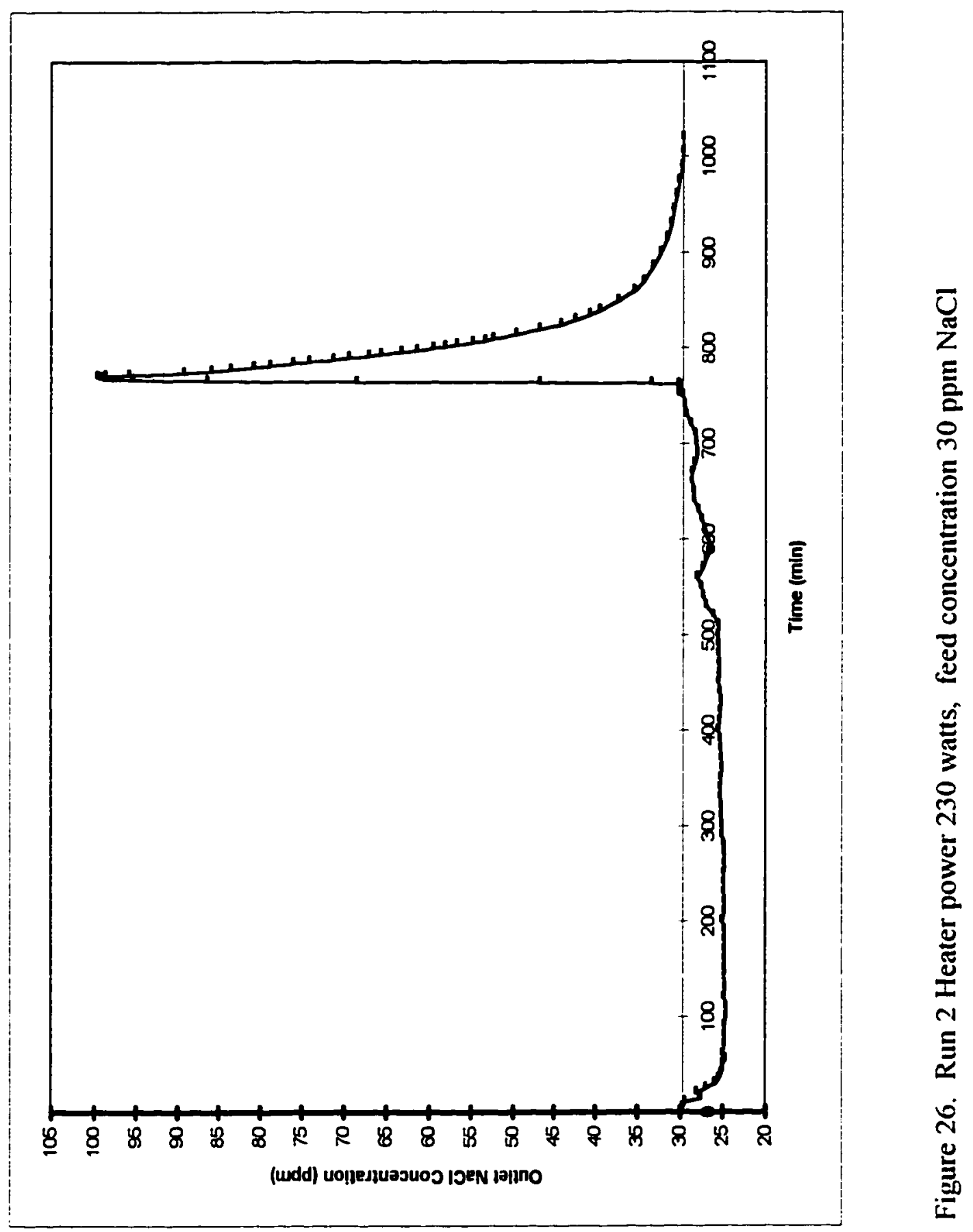




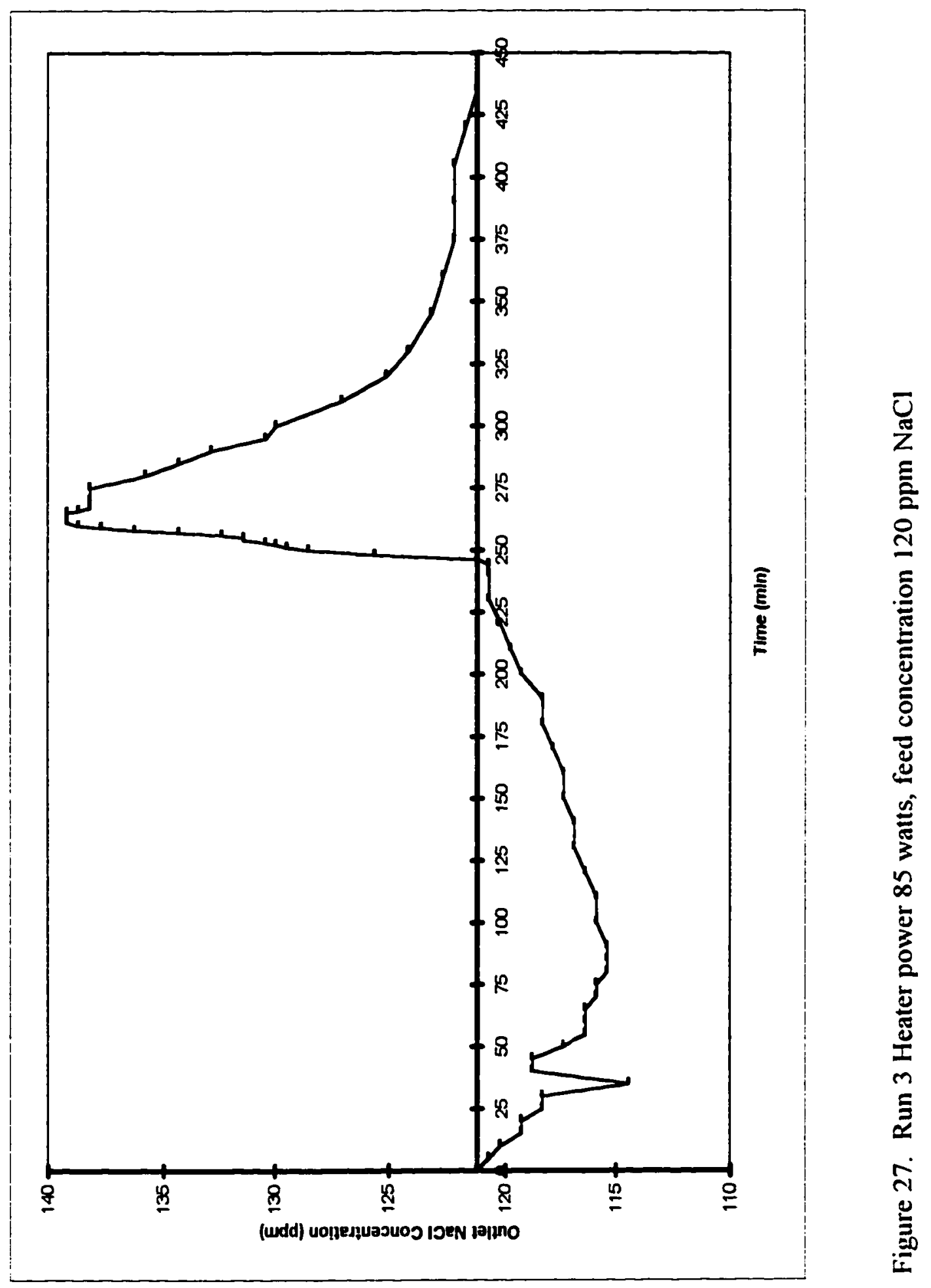




$$
\text { II }
$$




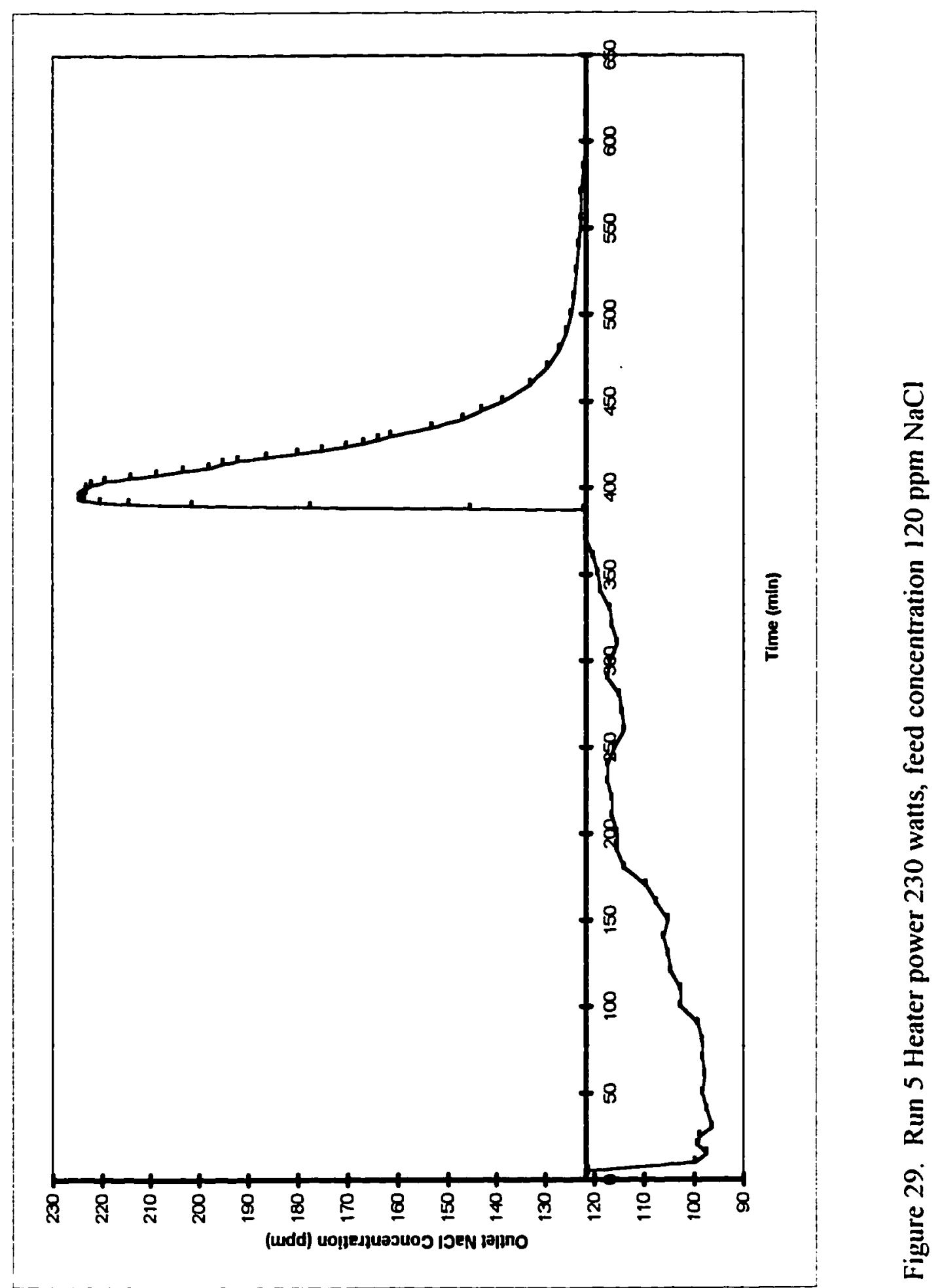




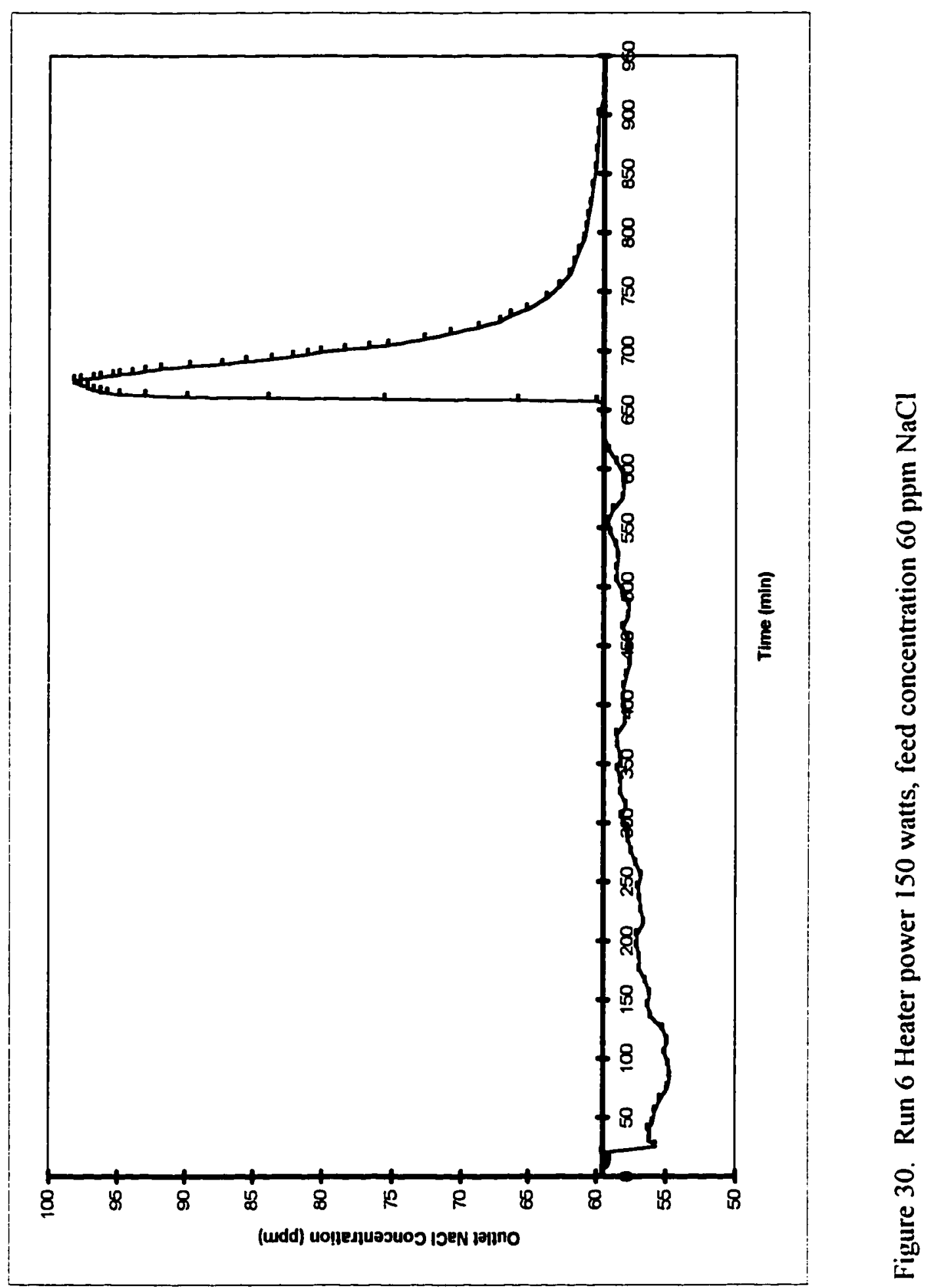




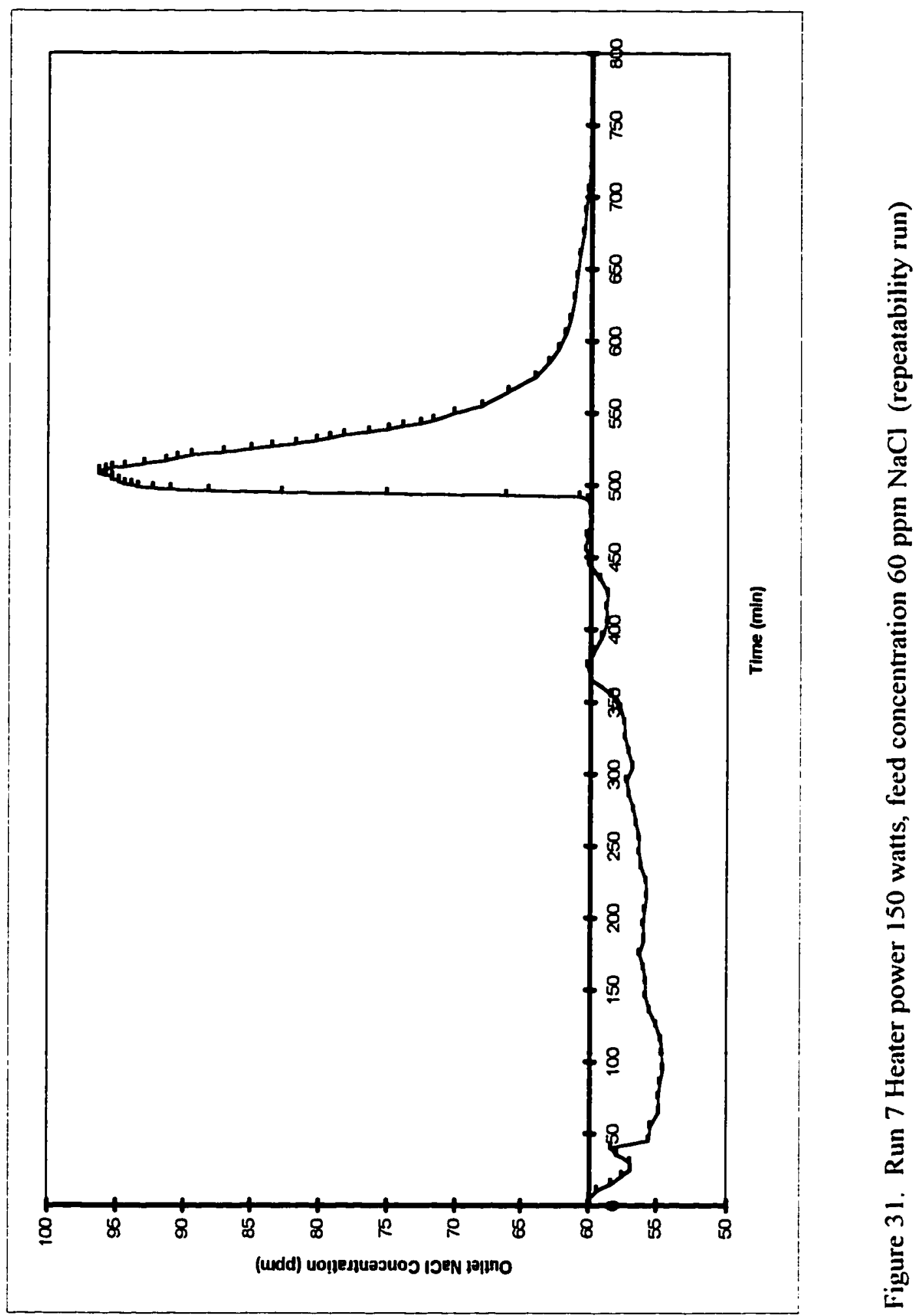




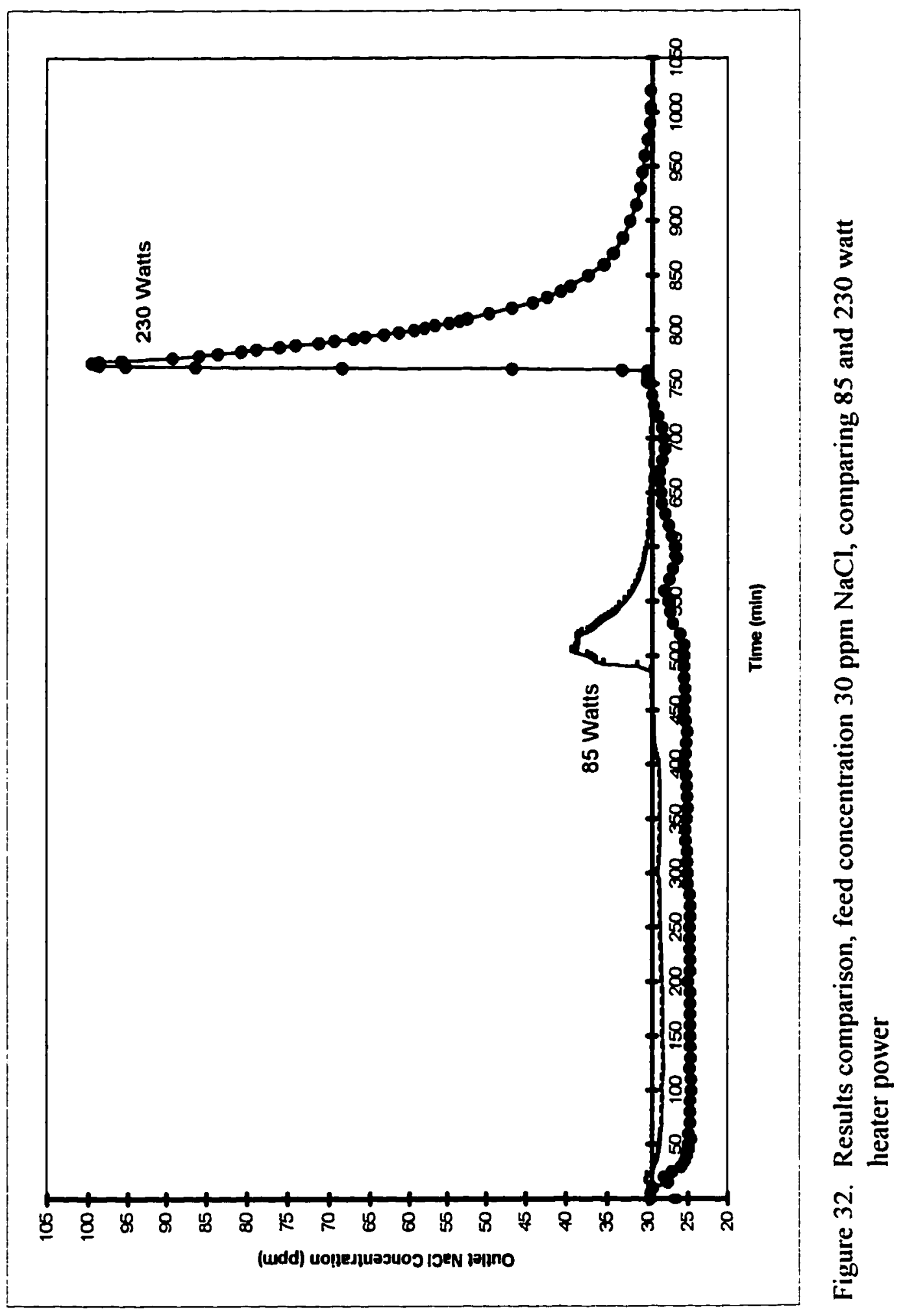




\section{APPENDIX D}

\section{Sample Calculations:}

Theoretical rate of accumulation run 1:

$$
\text { Rate }=\frac{(0.40)(\text { Heater Power })(\text { Feed Concentration })}{(\text { Latent Heat of Evaporation })}=\frac{(0.40)\left(85 \frac{\mathrm{J}}{\mathrm{s}}\right)\left(30 \frac{\mathrm{mg}}{\mathrm{s}}\right)\left(60 \frac{\mathrm{s}}{\mathrm{min}}\right)}{\left(1578 \frac{\mathrm{KJ}}{\mathrm{KG}}\right)\left(\frac{1000 \mathrm{~J}}{\mathrm{KJ}}\right)\left(\frac{\mathrm{KG}}{\mathrm{L}}\right)}=0.0388 \frac{\mathrm{mg}}{\mathrm{min}}
$$

Utilization of the Trapezoidal Method for integration of HR data:

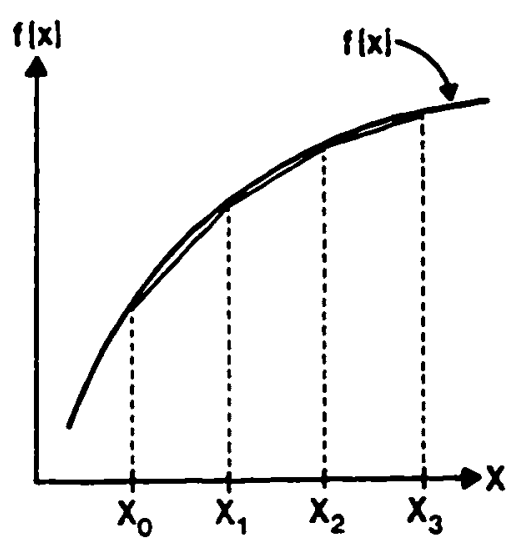

Figure 33. Sequential application of the Trapezoidal Method

$$
\text { Example: Run } 1 ; t=25 \mathrm{~min} \quad t=30 \mathrm{~min}
$$

Outlet conc. $\mathrm{NaCl} \quad \mathrm{C}=29.5 \mathrm{ppm} \quad \mathrm{C}=29.2 \mathrm{ppm}$

Baseline outlet conc. $\mathrm{NaCl}=29.6 \mathrm{ppm}$

Convert all points to mass/time

Baseline $=\left(\right.$ conc. $\left.\frac{m g}{L}\right)\left(\frac{1 L}{1000 m l}\right)\left(\frac{20 m l}{\min }\right)=\left(29.6 \frac{\mathrm{mg}}{L}\right)\left(\frac{\mathrm{IL}}{1000 \mathrm{ml}}\right)\left(\frac{20 \mathrm{ml}}{\mathrm{min}}\right)=0592 \frac{\mathrm{mg}}{\mathrm{min}}$ 


$$
\begin{aligned}
& \mathrm{t}=25 \mathrm{~min}, \quad\left(29.5 \cdot \frac{\mathrm{mg}}{L}\right)\left(\frac{\mathrm{l} L}{1000 \mathrm{ml}}\right)\left(\frac{20 \mathrm{ml}}{\mathrm{min}}\right)=0.590 \frac{\mathrm{mg}}{\mathrm{min}} \\
& \mathrm{t}=30 \mathrm{~min}, \quad\left(29.2 \cdot \frac{\mathrm{mg}}{L}\right)\left(\frac{\mathrm{l} L}{1000 \mathrm{ml}}\right)\left(\frac{20 \mathrm{ml}}{\mathrm{min}}\right)=0.584 \frac{\mathrm{mg}}{\mathrm{min}}
\end{aligned}
$$

\section{Calculation of deviation from baseline:}

$$
\begin{aligned}
& \mathrm{t}=25 \mathrm{~min}, \quad 0.592-0.590=0.002 \mathrm{mg} / \mathrm{min} \\
& \mathrm{t}=30 \mathrm{~min}, \quad 0.592-0.584=0.008 \mathrm{mg} / \mathrm{min} \\
& \text { Area under curve }=\sum_{i=1}^{n} \frac{f\left(x_{i}\right)+f\left(x_{i-1}\right)}{2}\left(x_{i}-x_{i-1}\right) \\
& \text { Area }=\frac{\left(0.008 \frac{m g}{\min }+0.002 \frac{\mathrm{mg}}{\mathrm{min}}\right)}{2}(30 \mathrm{~min}-25 \mathrm{~min})=0.025 \mathrm{mg} \mathrm{NaCl}
\end{aligned}
$$

The entire area under the curve is the summation of sequentially applying the above formula. 


\section{APPENDIX E}

\section{Run \#1 30 ppm, heater power 85 Watts}

$\begin{array}{ccc}\text { Time (min) } & \text { Outlet Conductivity (micro-MHO) } & \text { Outlet Concentration (ppm) } \\ 0 & 66.5 & 29.6 \\ 5 & 66.5 & 29.6 \\ 10 & 67.2 & 29.9 \\ 15 & 67.9 & 30.2 \\ 20 & 67.7 & 30.1 \\ 25 & 66.3 & 29.5 \\ 30 & 65.8 & 29.2 \\ 35 & 65.1 & 28.9 \\ 40 & 64.7 & 28.7 \\ 45 & 64.6 & 28.7 \\ 50 & 64.3 & 28.5 \\ 55 & 64.1 & 28.4 \\ 60 & 64 & 28.4 \\ 70 & 63.8 & 28.3 \\ 80 & 63.7 & 28.2 \\ 90 & 63.6 & 28.2 \\ 100 & 63.7 & 28.2 \\ 110 & 63.6 & 28.2 \\ 120 & 63.4 & 28.1 \\ 130 & 63.4 & 28.1 \\ 140 & 63.5 & 28.1 \\ 150 & 63.6 & 28.2 \\ 160 & 63.6 & 28.2 \\ 170 & 63.6 & 28.2 \\ 180 & 63.6 & 28.2 \\ 190 & 63.6 & 28.2 \\ 200 & 63.8 & 28.3 \\ 210 & 63.9 & 28.3 \\ 220 & 63.9 & 28.3 \\ 230 & 64 & 28.4 \\ 240 & 64.2 & 28.5 \\ 250 & 64.2 & 28.5 \\ 260 & 64.3 & 28.5 \\ 270 & 64.3 & 28.5 \\ 280 & 64.3 & 28.5 \\ 290 & 64.4 & 28.6 \\ 300 & 64.9 & 28.8 \\ 310 & 64.6 & 28.7 \\ 320 & 64.4 & 28.6 \\ 330 & 64.3 & 28.5 \\ 340 & 64.3 & 28.5 \\ & & \end{array}$




\begin{tabular}{|c|c|c|}
\hline Time (min) & Outlet Conductivity (micro-MHO) & Outlet Concentration (ppm) \\
\hline 350 & $64.3^{\circ}$ & 28.5 \\
\hline 360 & 64.3 & 28.5 \\
\hline 370 & 64.3 & 28.5 \\
\hline 380 & 64.3 & 28.5 \\
\hline 390 & 64.4 & 28.6 \\
\hline 400 & 64.5 & 28.6 \\
\hline 405 & 65 & 28.8 \\
\hline 410 & 65.3 & 29.0 \\
\hline 420 & 65.8 & 29.2 \\
\hline 430 & 65.9 & 29.3 \\
\hline 440 & 65.9 & 29.3 \\
\hline 450 & 66.3 & 29.5 \\
\hline 460 & 66.4 & 29.5 \\
\hline 470 & 66.5 & 29.6 \\
\hline 480 & 66.5 & 29.6 \\
\hline 485 & 66.7 & 29.6 \\
\hline 490 & 70.2 & 31.3 \\
\hline 492 & 78.9 & 35.4 \\
\hline 494 & 80.8 & 36.3 \\
\hline 496 & 81.1 & 36.4 \\
\hline 498 & 81.9 & 36.8 \\
\hline 500 & 82.9 & 37.3 \\
\hline 502 & 85.6 & 38.6 \\
\hline 504 & 87.1 & 39.3 \\
\hline 506 & 86.1 & 38.8 \\
\hline 508 & 85.8 & 38.6 \\
\hline 510 & 85.5 & 38.5 \\
\hline 512 & 85.2 & 38.4 \\
\hline 514 & 85.4 & 38.5 \\
\hline 516 & 85.7 & 38.6 \\
\hline 518 & 85.2 & 38.4 \\
\hline 520 & 84.2 & 37.9 \\
\hline 522 & 82.8 & 37.2 \\
\hline 524 & 81.7 & 36.7 \\
\hline 526 & 81 & 36.4 \\
\hline 528 & 80.5 & 36.2 \\
\hline 530 & 79.8 & 35.8 \\
\hline 532 & 79.2 & 35.5 \\
\hline 534 & 78.5 & 35.2 \\
\hline 536 & 77.5 & 34.7 \\
\hline 538 & 76.5 & 34.3 \\
\hline 540 & 75.8 & 33.9 \\
\hline 545 & 75 & 33.6 \\
\hline 550 & 73.6 & 32.9 \\
\hline 555 & 72.4 & 32.3 \\
\hline 560 & 71.5 & 31.9 \\
\hline 565 & 70.8 & 31.6 \\
\hline
\end{tabular}




$$
\| \Pi
$$




\section{Run \#2 30 ppm, heater power 230 Watts}

\begin{tabular}{|c|c|c|}
\hline Time (min) & Outlet Conductivity (micro-MHO) & Outlet Concentration (ppm) \\
\hline 0 & 66.8 & 29.7 \\
\hline 5 & 66.8 & 29.7 \\
\hline 10 & 66.2 & 29.4 \\
\hline 15 & 62.1 & 27.5 \\
\hline 20 & 63.2 & 28.0 \\
\hline 25 & 61 & 27.0 \\
\hline 30 & 58.6 & 25.8 \\
\hline 35 & 57.7 & 25.4 \\
\hline 40 & 57.1 & 25.1 \\
\hline 45 & 56.8 & 25.0 \\
\hline 50 & 56.8 & 25.0 \\
\hline 55 & 56.1 & 24.7 \\
\hline 60 & 56.7 & 24.9 \\
\hline 70 & 56.4 & 24.8 \\
\hline 80 & 56.4 & 24.8 \\
\hline 90 & 56.3 & 24.7 \\
\hline 100 & 56 & 24.6 \\
\hline 110 & 56 & 24.6 \\
\hline 120 & 56.5 & 24.8 \\
\hline 130 & 56.2 & 24.7 \\
\hline 140 & 56.3 & 24.7 \\
\hline 150 & 56.3 & 24.7 \\
\hline 160 & 56.3 & 24.7 \\
\hline 170 & 56.3 & 24.7 \\
\hline 180 & 56.4 & 24.8 \\
\hline 190 & 56.3 & 24.7 \\
\hline 200 & 56.9 & 25.0 \\
\hline 210 & 56.3 & 24.7 \\
\hline 220 & 56.3 & 24.7 \\
\hline 230 & 56.5 & 24.8 \\
\hline 240 & 56.5 & 24.8 \\
\hline 250 & 56.5 & 24.8 \\
\hline 260 & 56.4 & 24.8 \\
\hline 270 & 56.4 & 24.8 \\
\hline 280 & 56.5 & 24.8 \\
\hline 290 & 57 & 25.1 \\
\hline 300 & 57 & 25.1 \\
\hline 310 & 57.1 & 25.1 \\
\hline 320 & 57.1 & 25.1 \\
\hline 330 & 57.5 & 25.3 \\
\hline 340 & 57.5 & 25.3 \\
\hline 350 & 57.3 & 25.2 \\
\hline 360 & 57 & 25.1 \\
\hline 370 & 57.2 & 25.2 \\
\hline 380 & 57.3 & 25.2 \\
\hline
\end{tabular}




\begin{tabular}{|c|c|c|}
\hline Time (min) & Outlet Conductivity (micro-MHO) & Outlet Concentration $\mathrm{NaCl}$ (ppm) \\
\hline 390 & 57.4 & 25.3 \\
\hline 400 & 58 & 25.6 \\
\hline 410 & 57.6 & 25.4 \\
\hline 420 & 57.4 & 25.3 \\
\hline 430 & 57.2 & 25.2 \\
\hline 440 & 57.6 & 25.4 \\
\hline 450 & 57.9 & 25.5 \\
\hline 460 & 57.7 & 25.4 \\
\hline 470 & 57.7 & 25.4 \\
\hline 480 & 57.9 & 25.5 \\
\hline 490 & 57.9 & 25.5 \\
\hline 500 & 58 & 25.6 \\
\hline 510 & 57.9 & 25.5 \\
\hline 520 & 59 & 26.0 \\
\hline 530 & 60.9 & 26.9 \\
\hline 540 & 61.6 & 27.2 \\
\hline 550 & 62.1 & 27.5 \\
\hline 560 & 63.2 & 28.0 \\
\hline 570 & 61.8 & 27.3 \\
\hline 580 & 60.9 & 26.9 \\
\hline 590 & 59.8 & 26.4 \\
\hline 600 & 60.4 & 26.7 \\
\hline 610 & 61.2 & 27.1 \\
\hline 620 & 62 & 27.4 \\
\hline 630 & 62.9 & 27.9 \\
\hline 640 & 63.9 & 28.3 \\
\hline 650 & 64 & 28.4 \\
\hline 660 & 64.4 & 28.6 \\
\hline 670 & 64.4 & 28.6 \\
\hline 680 & 63.8 & 28.3 \\
\hline 690 & 63.1 & 28.0 \\
\hline 700 & 63.4 & 28.1 \\
\hline 710 & 63.7 & 28.2 \\
\hline 720 & 64.8 & 28.8 \\
\hline 730 & 66 & 29.3 \\
\hline 740 & 66.4 & 29.5 \\
\hline 750 & 66.8 & 29.7 \\
\hline 752 & 67.8 & 30.2 \\
\hline 754 & 67.8 & 30.2 \\
\hline 756 & 67.6 & 30.1 \\
\hline 758 & 67.4 & 30.0 \\
\hline 760 & 67.4 & 30.0 \\
\hline 762 & 67.8 & 30.2 \\
\hline 763 & 74.4 & 33.3 \\
\hline 764 & 103 & 46.8 \\
\hline 765 & 149 & 68.4 \\
\hline 766 & 187 & 86.3 \\
\hline
\end{tabular}




\begin{tabular}{|c|c|c|}
\hline Time (min) & Outlet Conductivity (micro-MHO) & Outlet Concentration $\mathrm{NaCl}$ (ppm) \\
\hline 767 & $206^{\circ}$ & 95.3 \\
\hline 768 & 213 & 98.6 \\
\hline 769 & 214 & 99.1 \\
\hline 770 & 215 & 99.5 \\
\hline 771 & 213 & 98.6 \\
\hline 772 & 207 & 95.8 \\
\hline 774 & 193 & 89.2 \\
\hline 776 & 186 & 85.9 \\
\hline 778 & 181 & 83.5 \\
\hline 780 & 175 & 80.7 \\
\hline 782 & 171 & 78.8 \\
\hline 784 & 165 & 76.0 \\
\hline 786 & 161 & 74.1 \\
\hline 788 & 155 & 71.3 \\
\hline 790 & 151 & 69.4 \\
\hline 792 & 146 & 67.0 \\
\hline 794 & 143 & 65.6 \\
\hline 796 & 138 & 63.2 \\
\hline 798 & 134 & 61.4 \\
\hline 800 & 130 & 59.5 \\
\hline 802 & 127 & 58.1 \\
\hline 804 & 124 & 56.6 \\
\hline 806 & 120 & 54.8 \\
\hline 808 & 117 & 53.4 \\
\hline 810 & 115 & 52.4 \\
\hline 815 & 109 & 49.6 \\
\hline 820 & 103 & 46.8 \\
\hline 825 & 97.4 & 44.1 \\
\hline 830 & 93.7 & 42.4 \\
\hline 835 & 90 & 40.6 \\
\hline 840 & 87.5 & 39.5 \\
\hline 850 & 82.7 & 37.2 \\
\hline 860 & 78.8 & 35.4 \\
\hline 870 & 76.5 & 34.3 \\
\hline 885 & 74.1 & 33.1 \\
\hline 900 & 72.2 & 32.2 \\
\hline 915 & 70.6 & 31.5 \\
\hline 930 & 69.6 & 31.0 \\
\hline 945 & 69 & 30.7 \\
\hline 960 & 68.4 & 30.5 \\
\hline 975 & 67.7 & 30.1 \\
\hline 990 & 67 & 29.8 \\
\hline 1005 & 66.8 & 29.7 \\
\hline 1020 & 66.8 & 29.7 \\
\hline
\end{tabular}




\section{Run \#3 120 ppm, heater power 85 Watts}

\begin{tabular}{|c|c|c|}
\hline Time (min) & Outlet Conductivity (micro-MHO) & Outlet Concentration (ppm) \\
\hline 0 & 257 & 121.2 \\
\hline 5 & 256 & 120.7 \\
\hline 10 & 255 & 120.2 \\
\hline 15 & 253 & 119.3 \\
\hline 20 & 253 & 119.3 \\
\hline 25 & 251 & 118.3 \\
\hline 30 & 251 & 118.3 \\
\hline 35 & 243 & 114.4 \\
\hline 40 & 252 & 118.8 \\
\hline 45 & 252 & 118.8 \\
\hline 50 & 249 & 117.3 \\
\hline 55 & 247 & 116.3 \\
\hline 60 & 247 & 116.3 \\
\hline 65 & 247 & 116.3 \\
\hline 70 & 246 & 115.9 \\
\hline 75 & 246 & 115.9 \\
\hline 80 & 245 & 115.4 \\
\hline 85 & 245 & 115.4 \\
\hline 90 & 245 & 115.4 \\
\hline 100 & 246 & 115.9 \\
\hline 110 & 246 & 115.9 \\
\hline 120 & 247 & 116.3 \\
\hline 130 & 248 & 116.8 \\
\hline 140 & 248 & 116.8 \\
\hline 150 & 249 & 117.3 \\
\hline 160 & 249 & 117.3 \\
\hline 170 & 250 & 117.8 \\
\hline 180 & 251 & 118.3 \\
\hline 190 & 251 & 118.3 \\
\hline 200 & 253 & 119.3 \\
\hline 210 & 254 & 119.7 \\
\hline 220 & 255 & 120.2 \\
\hline 230 & 256 & 120.7 \\
\hline 240 & 256 & 120.7 \\
\hline 242 & 256 & 120.7 \\
\hline 244 & 256 & 120.7 \\
\hline 246 & 257 & 121.2 \\
\hline 248 & 266 & 125.6 \\
\hline 250 & 272 & 128.5 \\
\hline 251 & 274 & 129.4 \\
\hline 252 & 275 & 129.9 \\
\hline 253 & 276 & 130.4 \\
\hline 254 & 278 & 131.4 \\
\hline 255 & 278 & 131.4 \\
\hline 256 & 280 & 132.4 \\
\hline
\end{tabular}




$\begin{array}{ccc}\text { Time (min) } & \text { Outlet Conductivity (micro-MHO) } & \text { Outlet Concentration (ppm) } \\ 257 & 284 & 134.3 \\ 258 & 288 & 136.2 \\ 259 & 291 & 137.7 \\ 260 & 293 & 138.7 \\ 261 & 294 & 139.2 \\ 262 & 294 & 139.2 \\ 263 & 294 & 139.2 \\ 264 & 294 & 139.2 \\ 265 & 294 & 139.2 \\ 266 & 293 & 138.7 \\ 267 & 292 & 138.2 \\ 268 & 292 & 138.2 \\ 269 & 292 & 138.2 \\ 270 & 292 & 138.2 \\ 275 & 292 & 138.2 \\ 280 & 287 & 135.8 \\ 285 & 284 & 134.3 \\ 290 & 281 & 132.8 \\ 295 & 276 & 130.4 \\ 300 & 275 & 129.9 \\ 310 & 269 & 127.0 \\ 320 & 265 & 125.1 \\ 330 & 263 & 124.1 \\ 345 & 261 & 123.1 \\ 360 & 260 & 122.7 \\ 375 & 259 & 122.2 \\ 390 & 259 & 122.2 \\ 405 & 259 & 122.2 \\ 420 & 258 & 121.7 \\ 435 & 257 & 121.2 \\ & & \end{array}$


Run \#4 120 ppm, heater power 85 Watts

\begin{tabular}{|c|c|c|}
\hline Time (min) & Outlet Conductivity (micro-MHO) & Outlet Concentration (ppm) \\
\hline 0 & 257 & 121.2 \\
\hline 5 & 258 & 121.7 \\
\hline 10 & 257 & 121.2 \\
\hline 15 & 255 & 120.2 \\
\hline 20 & 254 & 119.7 \\
\hline 25 & 252 & 118.8 \\
\hline 30 & 250 & 117.8 \\
\hline 35 & 248 & 116.8 \\
\hline 40 & 247 & 116.3 \\
\hline 45 & 247 & 116.3 \\
\hline 50 & 247 & 116.3 \\
\hline 55 & 246 & 115.9 \\
\hline 60 & 246 & 115.9 \\
\hline 65 & 246 & 115.9 \\
\hline 70 & 246 & 115.9 \\
\hline 80 & 246 & 115.9 \\
\hline 90 & 246 & 115.9 \\
\hline 100 & 246 & 115.9 \\
\hline 110 & 246 & 115.9 \\
\hline 120 & 247 & 116.3 \\
\hline 130 & 249 & 117.3 \\
\hline 140 & 251 & 118.3 \\
\hline 150 & 251 & 118.3 \\
\hline 160 & 251 & 118.3 \\
\hline 170 & 252 & 118.8 \\
\hline 180 & 252 & 118.8 \\
\hline 190 & 252 & 118.8 \\
\hline 200 & 252 & 118.8 \\
\hline 210 & 252 & 118.8 \\
\hline 220 & 253 & 119.3 \\
\hline 230 & 253 & 119.3 \\
\hline 240 & 254 & 119.7 \\
\hline 250 & 254 & 119.7 \\
\hline 260 & 255 & 120.2 \\
\hline 270 & 256 & 120.7 \\
\hline 280 & 257 & 121.2 \\
\hline 285 & 257 & 121.2 \\
\hline 290 & 257 & 121.2 \\
\hline 292 & 263 & 124.1 \\
\hline 293 & 269 & 127.0 \\
\hline 294 & 273 & 129.0 \\
\hline 295 & 278 & 131.4 \\
\hline 296 & 282 & 133.3 \\
\hline 297 & 284 & 134.3 \\
\hline 298 & 285 & 134.8 \\
\hline
\end{tabular}




\begin{tabular}{|c|c|c|}
\hline Time (min) & Outlet Conductivity (micro-MHO) & Outlet Concentration (ppm) \\
\hline 299 & 287 & 135.8 \\
\hline 300 & 288 & 136.2 \\
\hline 301 & 288 & 136.2 \\
\hline 302 & 289 & 136.7 \\
\hline 303 & 291 & 137.7 \\
\hline 304 & 291 & 137.7 \\
\hline 305 & 292 & 138.2 \\
\hline 306 & 293 & 138.7 \\
\hline 307 & 294 & 139.2 \\
\hline 308 & 295 & 139.6 \\
\hline 309 & 297 & 140.6 \\
\hline 310 & 298 & 141.1 \\
\hline 311 & 299 & 141.6 \\
\hline 312 & 299 & 141.6 \\
\hline 313 & 299 & 141.6 \\
\hline 314 & 298 & 141.1 \\
\hline 315 & 298 & 141.1 \\
\hline 316 & 297 & 140.6 \\
\hline 318 & 295 & 139.6 \\
\hline 320 & 294 & 139.2 \\
\hline 325 & 292 & 138.2 \\
\hline 330 & 287 & 135.8 \\
\hline 335 & 283 & 133.8 \\
\hline 340 & 280 & 132.4 \\
\hline 345 & 275 & 129.9 \\
\hline 350 & 273 & 129.0 \\
\hline 355 & 271 & 128.0 \\
\hline 360 & 268 & 126.5 \\
\hline 370 & 265 & 125.1 \\
\hline 380 & 263 & 124.1 \\
\hline 390 & 262 & 123.6 \\
\hline 400 & 261 & 123.1 \\
\hline 410 & 260 & 122.7 \\
\hline 420 & 260 & 122.7 \\
\hline 430 & 259 & 122.2 \\
\hline 440 & 259 & 122.2 \\
\hline 450 & 259 & 122.2 \\
\hline 465 & 258 & 121.7 \\
\hline 480 & 257 & 121.2 \\
\hline 495 & 257 & 121.2 \\
\hline
\end{tabular}


Run \#5 120 ppm, heater power 230 Watts

\begin{tabular}{|c|c|c|}
\hline Time (min) & Outlet Conductivity (micro-MHO) & Outlet Concentratrion (ppm) \\
\hline 0 & 258 & 121.7 \\
\hline 5 & 257 & 121.2 \\
\hline 10 & 213 & 99.8 \\
\hline 15 & 208 & 97.4 \\
\hline 20 & 212 & 99.3 \\
\hline 25 & 211 & 98.9 \\
\hline 30 & 206 & 96.4 \\
\hline 40 & 208 & 97.4 \\
\hline 50 & 210 & 98.4 \\
\hline 60 & 209 & 97.9 \\
\hline 70 & 210 & 98.4 \\
\hline 80 & 210 & 98.4 \\
\hline 90 & 212 & 99.3 \\
\hline 100 & 219 & 102.7 \\
\hline 110 & 219 & 102.7 \\
\hline 120 & 223 & 104.7 \\
\hline 130 & 224 & 105.2 \\
\hline 140 & 226 & 106.1 \\
\hline 150 & 224 & 105.2 \\
\hline 160 & 229 & 107.6 \\
\hline 170 & 233 & 109.5 \\
\hline 180 & 242 & 113.9 \\
\hline 190 & 245 & 115.4 \\
\hline 200 & 245 & 115.4 \\
\hline 210 & 247 & 116.3 \\
\hline 220 & 247 & 116.3 \\
\hline 230 & 249 & 117.3 \\
\hline 240 & 249 & 117.3 \\
\hline 250 & 246 & 115.9 \\
\hline 260 & 242 & 113.9 \\
\hline 270 & 243 & 114.4 \\
\hline 280 & 244 & 114.9 \\
\hline 290 & 249 & 117.3 \\
\hline 300 & 248 & 116.8 \\
\hline 310 & 245 & 115.4 \\
\hline 320 & 247 & 116.3 \\
\hline 330 & 248 & 116.8 \\
\hline 340 & 252 & 118.8 \\
\hline 350 & 253 & 119.3 \\
\hline 360 & 255 & 120.2 \\
\hline 370 & 258 & 121.7 \\
\hline 375 & 258 & 121.7 \\
\hline 380 & 258 & 121.7 \\
\hline 385 & 258 & 121.7 \\
\hline 387 & 259 & 122.2 \\
\hline
\end{tabular}




\begin{tabular}{|c|c|c|}
\hline Time (min) & Outlet Conductivity (micro-MHO) & Outlet Concentratrion (ppm) \\
\hline 388 & 307 & 145.5 \\
\hline 389 & 373 & 177.5 \\
\hline 390 & 422 & 201.3 \\
\hline 391 & 449 & 214.4 \\
\hline 392 & 461 & 220.3 \\
\hline 393 & 468 & 223.7 \\
\hline 394 & 470 & 224.6 \\
\hline 395 & 470 & 224.6 \\
\hline 396 & 469 & 224.1 \\
\hline 397 & 468 & 223.7 \\
\hline 398 & 467 & 223.2 \\
\hline 400 & 467 & 223.2 \\
\hline 402 & 465 & 222.2 \\
\hline 404 & 459 & 219.3 \\
\hline 406 & 448 & 213.9 \\
\hline 408 & 437 & 208.6 \\
\hline 410 & 426 & 203.3 \\
\hline 412 & 415 & 197.9 \\
\hline 414 & 409 & 195.0 \\
\hline 416 & 403 & 192.1 \\
\hline 418 & 391 & 186.3 \\
\hline 420 & 378 & 180.0 \\
\hline 422 & 368 & 175.1 \\
\hline 424 & 358 & 170.2 \\
\hline 426 & 351 & 166.8 \\
\hline 428 & 345 & 163.9 \\
\hline 430 & 340 & 161.5 \\
\hline 435 & 323 & 153.2 \\
\hline 440 & 310 & 146.9 \\
\hline 445 & 302 & 143.0 \\
\hline 450 & 293 & 138.7 \\
\hline 460 & 281 & 132.8 \\
\hline 470 & 274 & 129.4 \\
\hline 480 & 269 & 127.0 \\
\hline 490 & 266 & 125.6 \\
\hline 500 & 264 & 124.6 \\
\hline 510 & 263 & 124.1 \\
\hline 525 & 262 & 123.6 \\
\hline 540 & 261 & 123.1 \\
\hline 555 & 260 & 122.7 \\
\hline 570 & 260 & 122.7 \\
\hline 585 & 259 & 122.2 \\
\hline 600 & 258 & 121.7 \\
\hline 615 & 258 & 121.7 \\
\hline
\end{tabular}


Run \#6 60 ppm, heater power 150 Watts

\begin{tabular}{|c|c|c|}
\hline $\begin{array}{c}\text { Time (min) } \\
0\end{array}$ & Outlet Conductivity (micro-MHO) & Outlet Concentration (ppm) \\
\hline $\begin{array}{l}0 \\
5\end{array}$ & 130.1 & 59.5 \\
\hline $\begin{array}{c}5 \\
10\end{array}$ & 130.1 & 59.5 \\
\hline $\begin{array}{l}10 \\
15\end{array}$ & 129.2 & 59.1 \\
\hline 20 & 129 & 59.0 \\
\hline 25 & 130.2 & 59.6 \\
\hline $\begin{array}{l}25 \\
30\end{array}$ & 121.9 & 55.7 \\
\hline $\begin{array}{l}30 \\
35\end{array}$ & 122.9 & 56.1 \\
\hline $\begin{array}{l}35 \\
40\end{array}$ & 122.8 & 56.1 \\
\hline $\begin{array}{l}40 \\
45\end{array}$ & 123.1 & 56.2 \\
\hline $\begin{array}{l}45 \\
55\end{array}$ & 122.4 & 55.9 \\
\hline $\begin{array}{l}55 \\
65\end{array}$ & 122.1 & 55.8 \\
\hline $\begin{array}{l}65 \\
75\end{array}$ & 121.3 & 55.4 \\
\hline $\begin{array}{l}75 \\
85\end{array}$ & 120.2 & 54.9 \\
\hline $\begin{array}{l}85 \\
95\end{array}$ & 119.9 & 54.7 \\
\hline 95 & 120.1 & 54.8 \\
\hline 105 & 120.7 & 55.1 \\
\hline 115 & 120.3 & 54.9 \\
\hline 125 & 120.9 & 55.2 \\
\hline 135 & 122.7 & 56.0 \\
\hline 145 & 123.2 & 56.3 \\
\hline 155 & 122.9 & 56.1 \\
\hline 165 & 123.5 & 56.4 \\
\hline 175 & 124.5 & 56.9 \\
\hline 185 & 124.5 & 56.9 \\
\hline 195 & 124.9 & 57.1 \\
\hline 205 & 124.9 & 57.1 \\
\hline 215 & 123.8 & 56.6 \\
\hline 225 & 124.2 & 56.7 \\
\hline 235 & 124.5 & 56.9 \\
\hline 245 & 124.7 & 57.0 \\
\hline 255 & 124.2 & 56.7 \\
\hline 265 & 125 & 57.1 \\
\hline 275 & 125.7 & 57.5 \\
\hline 285 & 126.2 & 57.7 \\
\hline 295 & 126.2 & 57.7 \\
\hline 305 & 127.3 & 58.2 \\
\hline 315 & 126.5 & 57.8 \\
\hline 325 & 127.4 & 58.3 \\
\hline 335 & 127.4 & 58.3 \\
\hline 345 & 127.9 & 58.5 \\
\hline 355 & 127.4 & 58.3 \\
\hline 365 & 127.9 & 58.5 \\
\hline 375 & 128 & 58.5 \\
\hline 385 & 126.7 & 57.9 \\
\hline 395 & 126.8 & 58.0 \\
\hline
\end{tabular}




\begin{tabular}{|c|c|c|}
\hline Time (min) & Outlet Conductivity (micro-MHO) & Outlet Concentration (ppm) \\
\hline 405 & 127 & 58.1 \\
\hline 415 & 126.9 & 58.0 \\
\hline 425 & 126.5 & 57.8 \\
\hline 435 & 126 & 57.6 \\
\hline 445 & 126 & 57.6 \\
\hline 455 & 126.3 & 57.7 \\
\hline 465 & 127.1 & 58.1 \\
\hline 475 & 126.2 & 57.7 \\
\hline 485 & 126.1 & 57.6 \\
\hline 495 & 127.1 & 58.1 \\
\hline 505 & 128 & 58.5 \\
\hline 515 & 128 & 58.5 \\
\hline 525 & 127.8 & 58.4 \\
\hline 535 & 128.1 & 58.6 \\
\hline 545 & 129 & 59.0 \\
\hline 555 & 129.5 & 59.2 \\
\hline 565 & 128.6 & 58.8 \\
\hline 575 & 127.1 & 58.1 \\
\hline 585 & 126.9 & 58.0 \\
\hline 595 & 127 & 58.1 \\
\hline 605 & 128 & 58.5 \\
\hline 615 & 129.2 & 59.1 \\
\hline 625 & 130 & 59.5 \\
\hline 635 & 130.1 & 59.5 \\
\hline 645 & 130.1 & 59.5 \\
\hline 650 & 130.1 & 59.5 \\
\hline 655 & 130.1 & 59.5 \\
\hline 657 & 131.1 & 60.0 \\
\hline 658 & 143.3 & 65.7 \\
\hline 659 & 164.2 & 75.6 \\
\hline 660 & 181.7 & 83.8 \\
\hline 661 & 194.4 & 89.8 \\
\hline 662 & 201 & 92.9 \\
\hline 663 & 205 & 94.8 \\
\hline 664 & 207 & 95.8 \\
\hline 665 & 208 & 96.2 \\
\hline 666 & 208 & 96.2 \\
\hline 667 & 209 & 96.7 \\
\hline 668 & 210 & 97.2 \\
\hline 669 & 210 & 97.2 \\
\hline 670 & 210 & 97.2 \\
\hline 671 & 211 & 97.6 \\
\hline 672 & 211 & 97.6 \\
\hline 673 & 212 & 98.1 \\
\hline 674 & 212 & 98.1 \\
\hline 675 & 212 & 98.1 \\
\hline 676 & 211 & 97.6 \\
\hline
\end{tabular}




\begin{tabular}{|c|c|c|}
\hline Time (min) & Outlet Conductivity (micro-MHO) & Outlet Concentration (ppm) \\
\hline 677 & 209 & 96.7 \\
\hline 678 & 208 & 96.2 \\
\hline 679 & 206 & 95.3 \\
\hline 680 & 205 & 94.8 \\
\hline 681 & 203 & 93.9 \\
\hline 683 & 201 & 92.9 \\
\hline 685 & 198.6 & 91.8 \\
\hline 687 & 194 & 89.6 \\
\hline 689 & 188.9 & 87.2 \\
\hline 691 & 185.2 & 85.5 \\
\hline 693 & 181.2 & 83.6 \\
\hline 695 & 178 & 82.1 \\
\hline 697 & 175.7 & 81.0 \\
\hline 699 & 173.7 & 80.1 \\
\hline 701 & 170.1 & 78.4 \\
\hline 703 & 166.5 & 76.7 \\
\hline 705 & 163.6 & 75.3 \\
\hline 710 & 158.1 & 72.7 \\
\hline 715 & 154 & 70.8 \\
\hline 720 & 149.6 & 68.7 \\
\hline 725 & 146.2 & 67.1 \\
\hline 730 & 144.5 & 66.3 \\
\hline 735 & 142 & 65.1 \\
\hline 745 & 138.9 & 63.7 \\
\hline 755 & 136.9 & 62.7 \\
\hline 765 & 135.3 & 62.0 \\
\hline 775 & 134.6 & 61.6 \\
\hline 785 & 133.9 & 61.3 \\
\hline 795 & 133.1 & 60.9 \\
\hline 805 & 132.7 & 60.7 \\
\hline 815 & 132.5 & 60.7 \\
\hline 825 & 132.1 & 60.5 \\
\hline 840 & 131.8 & 60.3 \\
\hline 855 & 131.3 & 60.1 \\
\hline 870 & 131.1 & 60.0 \\
\hline 885 & 130.9 & 59.9 \\
\hline 900 & 130.9 & 59.9 \\
\hline 915 & 130.1 & 59.5 \\
\hline 930 & 130.1 & 59.5 \\
\hline
\end{tabular}


Run \#7 60 ppm, heater power 150 Watts

\begin{tabular}{|c|c|c|}
\hline Time (min) & Outlet Conductivity (micro-MHO) & Outlet Concentration (ppm) \\
\hline 0 & 130.9 & 59.9 \\
\hline 5 & 130.9 & 59.9 \\
\hline 10 & 129.7 & 59.3 \\
\hline 15 & 127.5 & 58.3 \\
\hline 20 & 125.7 & 57.5 \\
\hline 25 & 124.4 & 56.8 \\
\hline 30 & 124.5 & 56.9 \\
\hline 35 & 126.5 & 57.8 \\
\hline 40 & 127.5 & 58.3 \\
\hline 45 & 121.6 & 55.5 \\
\hline 55 & 121.4 & 55.4 \\
\hline 65 & 120 & 54.8 \\
\hline 75 & 120.1 & 54.8 \\
\hline 85 & 119.9 & 54.7 \\
\hline 95 & 119.5 & 54.5 \\
\hline 105 & 119.6 & 54.6 \\
\hline 115 & 119.8 & 54.7 \\
\hline 125 & 120.5 & 55.0 \\
\hline 135 & 121.5 & 55.5 \\
\hline 145 & 122.2 & 55.8 \\
\hline 155 & 122.2 & 55.8 \\
\hline 165 & 122.5 & 55.9 \\
\hline 175 & 123.1 & 56.2 \\
\hline 185 & 122.4 & 55.9 \\
\hline 195 & 122.6 & 56.0 \\
\hline 205 & 122.3 & 55.8 \\
\hline 215 & 122 & 55.7 \\
\hline 225 & 122.1 & 55.8 \\
\hline 235 & 122.9 & 56.1 \\
\hline 245 & 123.2 & 56.3 \\
\hline 255 & 123.2 & 56.3 \\
\hline 265 & 123.7 & 56.5 \\
\hline 275 & 124.1 & 56.7 \\
\hline 285 & 124.8 & 57.0 \\
\hline 295 & 125.2 & 57.2 \\
\hline 305 & 124.2 & 56.7 \\
\hline 315 & 124.9 & 57.1 \\
\hline 325 & 125.4 & 57.3 \\
\hline 335 & 125.5 & 57.4 \\
\hline 345 & 126.1 & 57.6 \\
\hline 355 & 127.6 & 58.3 \\
\hline 365 & 130.7 & 59.8 \\
\hline 375 & 131.4 & 60.1 \\
\hline 385 & 130.3 & 59.6 \\
\hline 395 & 129.1 & 59.1 \\
\hline
\end{tabular}




\begin{tabular}{|c|c|c|}
\hline Time (min) & Outlet Conductivity (micro-MHO) & Outlet Concentration (ppm) \\
\hline 405 & 128.3 & 58.7 \\
\hline 415 & 128.4 & 58.7 \\
\hline 425 & 128.2 & 58.6 \\
\hline 435 & 129.4 & 59.2 \\
\hline 445 & 131.1 & 60.0 \\
\hline 455 & 131.6 & 60.2 \\
\hline 465 & 131.5 & 60.2 \\
\hline 475 & 130.7 & 59.8 \\
\hline 480 & 130.9 & 59.9 \\
\hline 485 & 130.9 & 59.9 \\
\hline 490 & 131.4 & 60.1 \\
\hline 492 & 132.7 & 60.7 \\
\hline 493 & 144.1 & 66.1 \\
\hline 494 & 163.1 & 75.1 \\
\hline 495 & 179.3 & 82.7 \\
\hline 496 & 190.8 & 88.1 \\
\hline 497 & 196.9 & 91.0 \\
\hline 498 & 199.7 & 92.3 \\
\hline 499 & 202 & 93.4 \\
\hline 500 & 203 & 93.9 \\
\hline 501 & 204 & 94.3 \\
\hline 502 & 205 & 94.8 \\
\hline 503 & 205 & 94.8 \\
\hline 504 & 206 & 95.3 \\
\hline 505 & 206 & 95.3 \\
\hline 506 & 206 & 95.3 \\
\hline 507 & 207 & 95.8 \\
\hline 508 & 208 & 96.2 \\
\hline 509 & 208 & 96.2 \\
\hline 510 & 208 & 96.2 \\
\hline 511 & 207 & 95.8 \\
\hline 512 & 206 & 95.3 \\
\hline 513 & 204 & 94.3 \\
\hline 515 & 201 & 92.9 \\
\hline 517 & 197.6 & 91.3 \\
\hline 519 & 195.8 & 90.5 \\
\hline 521 & 193.5 & 89.4 \\
\hline 523 & 188.4 & 87.0 \\
\hline 525 & 184.1 & 85.0 \\
\hline 527 & 180.8 & 83.4 \\
\hline 529 & 177.2 & 81.7 \\
\hline 531 & 173.9 & 80.2 \\
\hline 533 & 171.9 & 79.2 \\
\hline 535 & 169.8 & 78.2 \\
\hline 537 & 165.9 & 76.4 \\
\hline 539 & 162.8 & 74.9 \\
\hline 541 & 160.6 & 73.9 \\
\hline
\end{tabular}




$\begin{array}{ccc}\text { Time }(\mathbf{m i n}) & \text { Outlet Conductivity (micro-MHO) } & \text { Outlet Concentration (ppm) } \\ 543 & 157.8 & 72.6 \\ 545 & 156 & 71.7 \\ 550 & 152.6 & 70.1 \\ 555 & 148 & 68.0 \\ 565 & 143.8 & 66.0 \\ 575 & 139.6 & 64.0 \\ 585 & 137.5 & 63.0 \\ 595 & 136 & 62.3 \\ 605 & 134.9 & 61.8 \\ 615 & 134.2 & 61.5 \\ 630 & 133.6 & 61.2 \\ 645 & 133.2 & 61.0 \\ 660 & 132.7 & 60.7 \\ 675 & 132.1 & 60.5 \\ 690 & 131.8 & 60.3 \\ 705 & 131.4 & 60.1 \\ 720 & 131 & 59.9 \\ 735 & 130.9 & 59.9 \\ 750 & 130.9 & 59.9 \\ 765 & 130.9 & 59.9\end{array}$

